Portland State University

PDXScholar

Spring 6-5-2018

\title{
Building Climate Empire: Power, Authority, and Knowledge within Pacific Islands Climate Change Diplomacy and Governance Networks
}

Ashlie Denée Denton

Portland State University

Follow this and additional works at: https://pdxscholar.library.pdx.edu/open_access_etds

Part of the International Relations Commons, Public Affairs Commons, and the Public Policy

Commons

Let us know how access to this document benefits you.

\section{Recommended Citation}

Denton, Ashlie Denée, "Building Climate Empire: Power, Authority, and Knowledge within Pacific Islands Climate Change Diplomacy and Governance Networks" (2018). Dissertations and Theses. Paper 4401. https://doi.org/10.15760/etd.6285

This Dissertation is brought to you for free and open access. It has been accepted for inclusion in Dissertations and Theses by an authorized administrator of PDXScholar. Please contact us if we can make this document more accessible: pdxscholar@pdx.edu. 
Building Climate Empire: Power, Authority, and Knowledge within Pacific Islands Climate Change Diplomacy and Governance Networks

\title{
by
}

Ashlie Denée Denton

A dissertation submitted in partial fulfillment of the requirements for the degree of

\author{
Doctor of Philosophy \\ in \\ Public Affairs and Policy
Dissertation Committee:
David Kinsella, Chair
Jennifer Allen, Co-Chair
Billie Sandberg
Veronica Dujon

Portland State University

2018 
(C) 2018 Ashlie Denée Denton 


\begin{abstract}
Transnational networks are growing in prevalence and importance as states, nongovernmental, and intergovernmental organizations seek to meet climate change goals; yet, the organizations in these networks struggle between the global, technical and local, contextual sources of power, authority, and knowledge used to influence decision-making and governance. This dissertation analyzes these contestations in Pacific Islands climate change diplomacy and governance efforts by asking: i) What do power relations look like among the Pacific Islands' networked organizations? ii) To what authority do organizations appeal to access sources of power? iii) What sources of knowledge are produced and reproduced by these organizations? and iv) How do these patterns fit within the broader history of the Pacific Islands and climate change? I draw from interviews, document analysis, event participation, and social network analysis of Pacific Island climate change diplomacy and governance. This examination leads me to propose the concept of "Climate Empire," which can be understood as the network of knowledge and communicative services that imagine, build, and administer the globe through a decentralized and deterritorialized apparatus of rule.
\end{abstract}

In the Pacific Islands, Climate Empire upholds technical bureaucratic and scientific approaches to overcoming climate challenges; however, the global spaces in which these approaches are produced are reconnected with the spaces of local resistance through data collection networks and efforts to 
relocalize knowledge. Thus, the local/global divisions found in diplomacy and governance in the Pacific Islands collectively produce and reform Climate Empire as organizations interact in the network. Further research is necessary to understand the extensiveness of Climate Empire, as well as to ensure the inclusion and empowerment of Pacific Island voices in climate governance for both justice and efficacy. 


\section{Acknowledgements}

I am indebted to the hard-working and dedicated people in the Pacific Islands and domestically that are working toward a better climate future and took a bit (or a lot!) of time out of their days to share their stories with me. Thank you for your kind investment into this dissertation and my life. I will forever be grateful. Vinaka vaka levu, faafetai, meitaki ma'ata, and thank you.

I am grateful to my committee who have been incredible guides throughout this process. I am thankful to my dissertation chair, David Kinsella, for being willing to go on this wild intellectual ride with me and provide such a useful roadmap; to Jennifer Allen for being a true confidant and advisor when I needed some clarity and encouragement; to Billie Sandberg for her astute guidance and intellectual provocations; and to Veronica Dujon for her invaluable insight. Their collective input and support has brought me through some of the more challenging times in this process, and I can only hope I did all of their hard work justice.

I could not have come this far without the extraordinary teams of which I was a part during this doctoral journey. The Ecosystem Services supporting Urbanizing Regions (ESUR) IGERT program gave me an opportunity to explore ideas I never would have on my own, while also providing me with the most incredible support group I could have hoped for. A particular thank you to the Restoration/Infrastructure/PFESTS/Wherever-Our-Quandaries-Lead group for constantly pushing the envelope (until it was time to get the paper finished! 
Ok... and maybe then some...) To my PAP team, thank you for assuring me that I was not alone in all this mess. Dissertating is a hard and isolating journey, and I could never have done it without a few complaining sessions along the way.

A huge thank you to my family for your love and support. Mom and dad, you've been there for me through 24 years of schooling - not a small featreminding me that I can accomplish all I set out to do. It wouldn't have been possible without you. Finally, to Jon-Michael who has lived through all the ups and downs, the doubts and the excitement, the days where I couldn't stop talking and the days when I needed utter silence: you deserve a medal, but please accept this thank you as a solid second best. 
Table of Contents

Abstract.

Acknowledgements

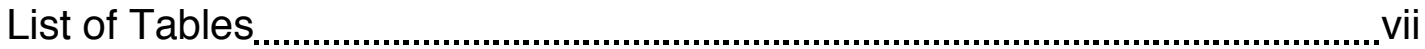

List of Figures

List of Abbreviations

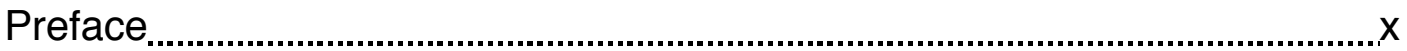

Chapter 1: Introduction: Transnational Climate Change Governance....1

Governing the Climate ..........................................................................2

Case Study: Pacific Islands ........................................................................ 4

Who Are the Pacific Islands? ........................................................... 5

Pacific Island Environmental Struggles.............................................. 7

Regional Governance Efforts in the Pacific Islands.............................. 9

Pacific Island Climate Change Governance Networks .......................... 12

Research Strategy Overview.........................................................................

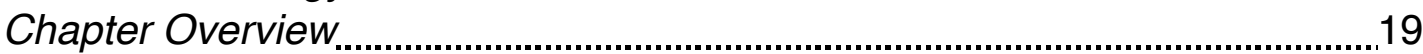

Chapter 2: Power, Authority, and Knowledge in Networked

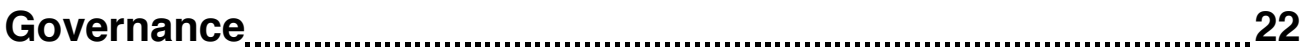

Transnational Governance

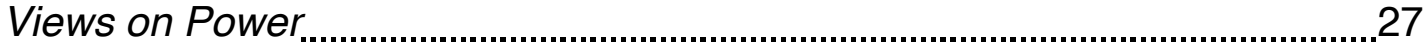

Productive, Relational, and Societal Power ........................................30

Discursive Power .........................................................................................3

Discourse in Environmental Governance ..............................................36

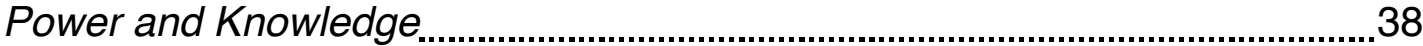

Global and Local Knowledge ................................................................4 41

Network Approaches ..................................................................................4

Power, Authority, and Knowledge in Transnational Networks..........................47

Typology of Power, Authority, and Knowledge Relations......................50

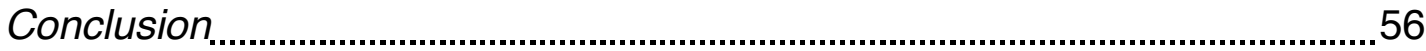

Chapter 3: Narrative-Networks in Diplomatic Spaces ................................58

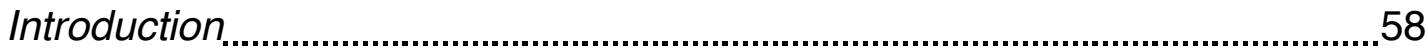

Scientific Authority in Multi-Scalar Space

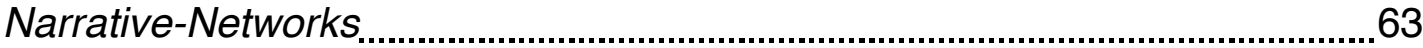

Narrative-Networks in the Pacific Islands .........................................6. 65

Pacific Islands Climate Change Diplomacy ......................................................6. 67

Materials and Methods .................................................................................6 68

Thematic and Narrative Analysis of Interviews ....................................68

Network Visualization ........................................................................... 70

Pacific Island Forum Summit Narrative................................................... 75

Pacific Islands Development Forum Summit Narrative ..........................81

Narrative Comparisons of PIF and PIDF Summit Declarations .........................86

Implications for Climate Governance................................................................... 89

Pacific Islands' Role in the Paris Agreement...................................................91 
COP23 and the Fijian Presidency............................................................ 92

Challenges in Future Governance.................................................................93

Chapter 4: Discursive Strategies of Climate Governance...........................95

Introduction

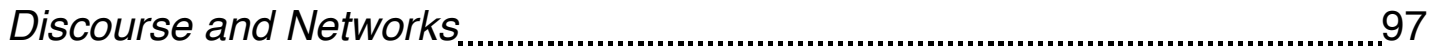

Discourses of Environmental Governance .................................................... 99

Bäckstrand and Lövbrand's Three Environmental Discourses.............100

Local/Global Elements of Environmental Discourse............................104

Implications of the Discourses for Climate Change Governance.........106

Social Network Analysis Methods...................................................................... 109

Interview Methods

Results

Global Governance of Science and Control.........................................116

Challenges to the green governmentality discourse .................121

Mixed Governance of Sustainable Development and the 'Win-Win'...123

Challenges to the ecological modernization discourse..............128

Local Governance of Traditional Knowledge and Participation ............131

Challenges to the civic environmentalism discourse..................135

Three Environmental Discourses in Conversation ...........................................137

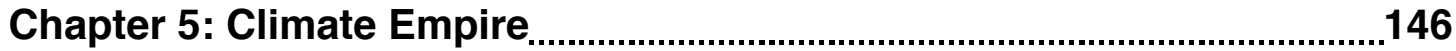

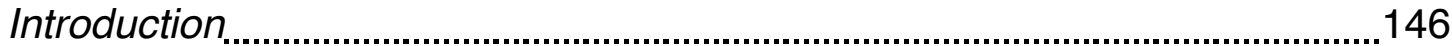

Empire

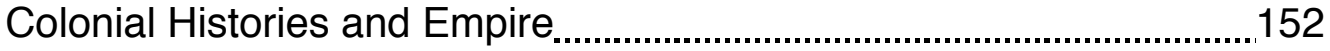

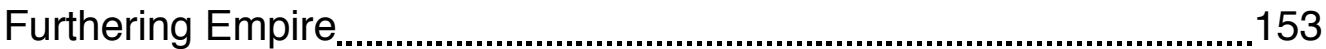

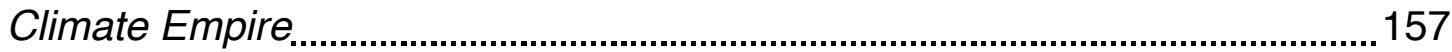

Local and Global Construction of Climate Empire...............................160

Building the Pacific Island Climate Empire ...................................................163

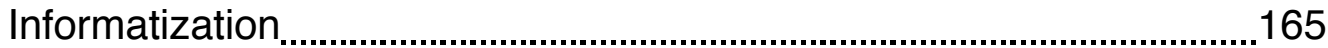

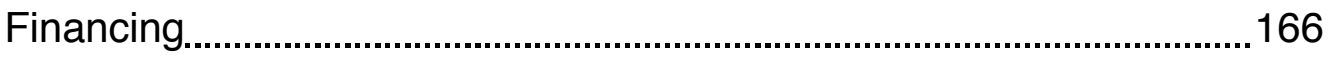

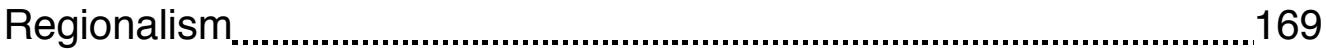

Climate Empire and Nature in the Pacific Islands .........................................172

Relocalization of Knowledge and Reshaping the Climate Empire....................175

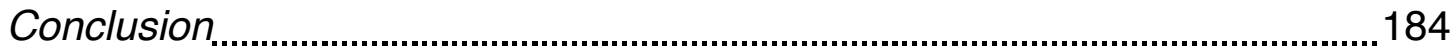

Chapter 6: Conclusion: Findings and Recommendations .......................185

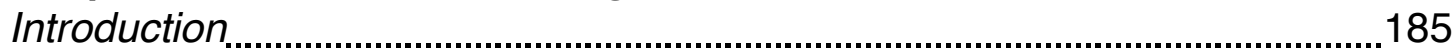

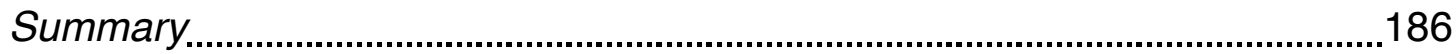

Drawing the Strands Together

What Now?

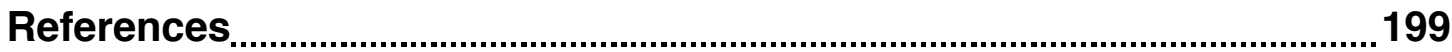

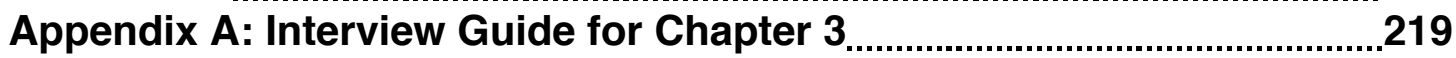

Appendix B: Social Network Analysis for Chapter 4................................221

Appendix C: Interview Guide for Chapter 4 ……..................................228

Appendix D: Interview Participants and Times for Chapter 4..................233 


\section{List of Tables}

Table 1: Chart of publications with "social network" in the title, retrieved from Web of Science

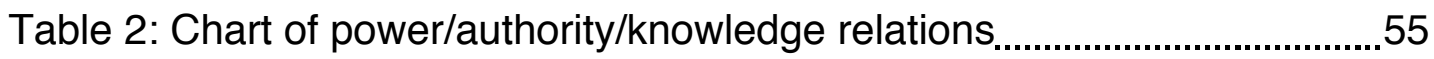

Table 3: Narrative analysis of the Pacific Islands Forum Leaders Declaration on Climate Change Action 79

Table 4: Narrative analysis of PIDF's Suva Declaration on Climate Change

Table 5: Chart of environmental discourses in relation to local/global strategies. Adapted from Bäckstrand and Lövbrand (2006)....................................105

Table 6: Power, authority, and knowledge in environmental discourses........140

Table 7: Narratives of Pacific Island climate diplomacy...................................191 


\section{List of Figures}

Figure 1: Map of the Pacific Islands 6

Figure 2: Network of attendance at the PIF Summit and PIDF Summit..........73

Figure 3: Pacific Island climate change network core 118

Figure 4: Pacific Island climate change network semi-periphery. 125

Figure 5: Pacific Island climate change network periphery 132

Figure 6: The relationship between green governmentality, ecological modernization, and civic environmental discourses

Figure 7: Diagram illustrating the knowledge transfer within

Climate Empire 162

Figure 8: Network visualizations of differing relations of power under colonial and Empire rule. 181

Figure 9: Outline of the global discourse within climate change governance and diplomacy in the Pacific Islands. 192

Figure 10: Outline of the local discourse within climate change governance and diplomacy in the Pacific Islands 193 


\section{List of Abbreviations}

$\begin{array}{ll}\text { COP } & \text { Conference of Parties } \\ \text { CROP } & \text { Council of Regional Organizations in the Pacific } \\ \text { FRDP } & \text { Framework for Resilient Development in the Pacific } \\ \text { IGOs } & \text { Intergovernmental Organizations } \\ \text { IPCC } & \text { Intergovernmental Panel on Climate Change } \\ \text { MET } & \text { Meteorological (Bureau/Services) } \\ \text { NGOs } & \text { Nongovernmental Organizations } \\ \text { PCCP } & \text { Pacific Climate Change Portal } \\ \text { PIDF } & \text { Pacific Islands Development Forum } \\ \text { PIFS } & \text { Pacific Islands Forum Secretariat } \\ \text { SDGs } & \text { United Nations' Sustainable Development Goals } \\ \text { SPC } & \text { Secretariat of the Pacific Community } \\ \text { SPREP } & \text { Secretariat of the Pacific Regional Environment Programme } \\ \text { UNFCCC } & \text { United Nations Framework Convention on Climate Change } \\ \text { USP } & \text { University of the South Pacific }\end{array}$




\section{Preface}

This material is based upon work supported by National Science Foundation IGERT Grant \#0966376: "Sustaining Ecosystem Services to Support Rapidly Urbanizing Areas," as well as generous support by the Institute for Sustainable Solutions. Any opinions, findings, conclusions, or recommendations expressed in this research are those of the author and do not necessarily reflect the views of these organizations. Chapter 3 draws substantially on work previously published in Denton, A. (2017). "Voices for environmental action? Analyzing narrative in environmental governance networks in the Pacific Islands." Global Environmental Change, 43. 


\section{Chapter 1: Introduction: Transnational Climate Change Governance}

Cyclone Winston tore through the islands of the Pacific in February 2016, leaving incredible damage and death in its wake. As the death tolls were particularly high, networks of government and nonprofit agencies associated with disaster management began to ask the communities what happened, "Did you get our warnings? Did you go to the evacuation centers?" What they found was that words like "knots" and "Category 5," unsurprisingly, did not mean much to these individuals. The communities, therefore, did not know what to expect and did not take precautions. In response, this network of agencies began to ask communities how they speak of these issues amongst themselves and to collaborate with them for solutions. The agencies found that communities had simple sayings that they utilized that could be used in weather forecasts-winds strong enough to blow bananas off trees or waves the height of the fales, the open-air buildings in which they gather and work. By speaking of storm warnings in this way instead of in technical terms, they might be able to save lives as local communities could understand their warnings and take necessary precautions.

As they were doing this work, the agencies also noted that communities have proverbs that they have been using for generations that indicate the timing of their interactions with nature: the times for harvesting, when they can expect storms or droughts, and how strong disasters are expected to be. The proverbs are based on the nature around them, such as when the ylang-ylang plant flowers and then the sea urchins are ready to harvest or when frigatebirds fly 
against the wind a storm is coming. ${ }^{1}$ While these local proverbs can increase the ability of islanders to read the world around them and reduce their vulnerability to disaster, these traditional systems that they have had in place are no longer entirely accurate in the midst of a changing climate. The ylang-ylang is now flowering at all times in Samoa. Elements of the 'seasons' have disappeared as climate change impacts weather patterns, taking with them the ability of the community to read their environment, predict upcoming disasters, and prepare for the challenges presented by living on small, somewhat isolated islands. There are approximately 110 permanently inhabited islands in Fiji alone. The Pitcairn Islands can go weeks without a passing ship. Connection to the outside world to even collect warnings from the weather service is limited, and climate change vastly exacerbates the vulnerabilities to which these islands are exposed.

\section{Governing the Climate}

Climate change has primarily been understood as occupying a global space - the global climate is changing due to the global emission of carbon that requires global solutions to fix the problem. While the global elements of climate change are vitally important to understand and to act upon the challenges ahead, experiences of climate change vary across scales and spaces. The way a farmer in the Midwestern United States experiences climactic changes will differ greatly from a fisherman on the Tuvalu coastline. While local-level practitioners and

\footnotetext{
${ }^{1}$ These were off-handed examples discussed by participants, not meant to be authoritative on the subject.
} 
decision-makers struggle to adapt to contextually changing environmental conditions, they must also acclimatize to governance standards and strategies decided upon at global levels. As Jasanoff has described, "Although the image [of the Earth] may have attained universal currency, the means of producing and reproducing [the Earth], as well as the ability to translate the mandate to 'think globally' into science and action, are unequally distributed around the world" (2004, p. 49). In other words, while the image of the globe may be nearuniversally known, the resources necessary to know the globe are limited, better yet to translate that knowledge to local needs. However, global strategies still mandate the world to 'think globally,' producing tensions in multi-scalar efforts. This is seen as local environmental projects must now meet global project goals and intensive tracking requirements for the SDGs, the Convention on Biological Diversity, United Nations Framework Convention on Climate Change (UNFCCC), and others.

Through this dissertation, I seek to draw into discussion the local and global elements of climate change governance. One way in which these conversations are organized and oriented is through networks of climate change practitioners and decision-makers situated at the local, regional (or transnational), and global levels. States, nongovernmental organizations (NGOs), intergovernmental organizations (IGOs), private enterprises, and knowledge producing institutions network together, either formally or informally, to meet environmental challenges. While these organizations seek to collaboratively 
achieve goals surrounding climate change, those goals and the solutions meant to meet them are regularly contested. These contestations are grounded in who has power in decision-making and practice, by what authority they have that power, and what knowledges are considered legitimate to create and uphold that authority (Barnett \& Campbell, 2010; Hulme, 2010; Jasanoff, 2004; Scott, 1998).

Networks are a useful way to explore the interactions of power, authority, and knowledge. Network theories assume that interactions between actorsindividuals or organizations - are grounded in the exchange of material and nonmaterial resources (Wasserman \& Faust, 1995). These resources could be finances, practical information, norms, standards, or understandings of the world. Previous theories of networked governance have often assumed somewhat power-neutral interactions between actors (e.g. Glasbergen, 1995; Goldsmith \& Eggers, 2004; O'Toole, 1997; Peters, 1998). Instead, this dissertation explores the way in which networks can be understood as regular interactions between actors who compete to secure legitimacy and viability in a complex, multi-scalar, and resource-constrained world. Therefore, networked governance, in this dissertation, is understood as a space of contested power relations where actors compete over decision-making capabilities (Lejano, Ingram, \& Ingram, 2013).

\section{Case Study: Pacific Islands}

In order to provide greater insight into the power, authority, and knowledge inherent in networked governance, this dissertation focuses on transnational climate governance in the Pacific Islands. The Pacific Islands are undergoing 
rapid biophysical transformation, which is decreasing the productivity of fisheries, reducing the likelihood that communities can subsist off of the land or water, and seeing a rapid loss of land into the ocean (Allen et al., 2014). Governance in this region faces challenges as many nations are small, isolated, and have had a long history of colonial control, which has left them lacking capacity in many ways (Wesley-Smith, 2013). However, Pacific Island peoples also have a long history of social and environmental adaptation that provides key knowledge and insights into these growing environmental needs (Govan, 2009), thus presenting unique opportunities for environmental governance.

\section{Who Are the Pacific Islands?}

The Pacific Islands are a collection of states located in the South Pacific Ocean (Figure 1). This geopolitical group includes the Cook Islands, Fiji, Kiribati, the Republic of the Marshall Islands, Nauru, Niue, Palau, Papua New Guinea, Samoa, Solomon Islands, Tonga, Tuvalu, and Vanuatu; as well as the US territories of American Samoa, Guam, and Northern Mariana Islands; the French territories and collectivities of French Polynesia, New Caledonia and Wallis and Futuna; the British overseas territory of Pitcairn Islands; and the New Zealand territory of Tokelau. ${ }^{2}$ Notably, Australia, New Zealand, and the Southeast Asian

\footnotetext{
${ }^{2}$ The territorial and collectivity status of each island is unique; however, the larger country is responsible for much of the governance of the islands in each case. Additionally, the Cook Islands and the Marshall Islands both have free association compacts with New Zealand and the US, respectively, but are still considered independent.
} 
countries of the Philippines and Indonesia are not considered Pacific Islands under this categorization. While Australia and New Zealand play important roles in governance and finance in the region, they are also considered external parties in most arrangements (apart from their status in regional IGOs that varies considerably and is discussed below). Timor-Leste is considered a Pacific Island in some arrangements.

Figure 1: Map of the Pacific Islands.

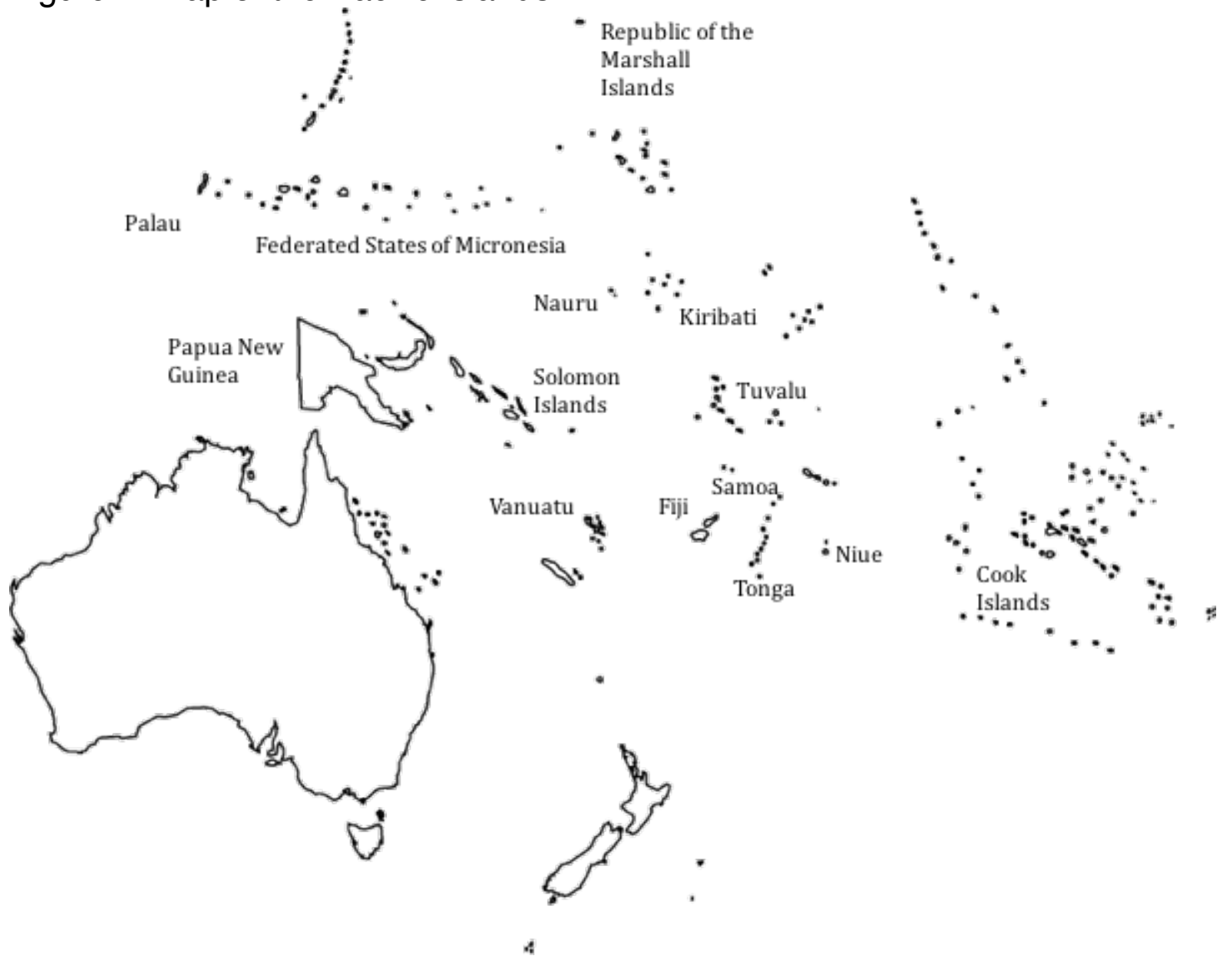

Papua New Guinea is the largest of the islands in terms of land mass $\left(462,840 \mathrm{~km}^{2}\right)$ and economy (GDP: US $\$ 29.189$ billion), with a population of over 8 million who speak 852 known languages. The Pitcairn Islands sits on the opposite end of the scale, sitting at $47 \mathrm{~km}^{2}$, a GDP of USD $\$ 149,248$, and a 
population of 57 . While geopolitically grouped, the Pacific Islands thus vary significantly in terms of political and economic independence, capabilities, and interests.

Pacific Island regional identity and governance has a complex relationship with the history of colonialism in the region, particularly with United States, Britain, France, Australia and New Zealand. For instance, nearly half of the inhabitants of Fiji are of Indian origin, brought about by the British need for labor in sugar cane fields in the late $19^{\text {th }}$ and early $20^{\text {th }}$ centuries (Robertson, 2012). The ethnic legacy of British colonial presence has plagued inter-ethnic relations in Fiji for generations, leading in part to a series of coups in which the Indo-Fijian government was overthrown by an indigenous Fijian, the most recent of which was a 2006 military coup, which installed Prime Minister Josaia Voreqe (Frank) Bainimarama (ibid.). The economies of Pacific Island nations are often tied to these colonial histories, as well, as many Pacific Island nations rely on foreign aid for significant portions of their budgets (Atteridge \& Canales, 2017). Not only are the Pacific Islands' complex relations with colonial powers unique challenges for their governance structures, these challenges are greatly exacerbated by their precarious environmental state.

\section{Pacific Island Environmental Struggles}

In the Pacific Island nations, environmental degradation is happening at a rapid rate, primarily due to global climate change (Bartlett, Maltali, Petro, \& Valentine, 2010). Climate change has had, and will continue to have, a 
disproportionate impact on the islands. The Intergovernmental Panel on Climate Change's (IPCC) Fifth Assessment Report argues that climate change endangers coastal settlements, infrastructure, economic stability, and the ecosystem services needed to ensure the success of the Pacific Islands into the future (Allen et al. 2014). As Barnett and Campbell point out, however:

The effects of climate change on islands and the communities that live on them are likely to be highly differentiated: not all places will experience the same changes; where changes are similar the magnitude and timing of them will likely differ; the sensitivity of ecological and social processes to changes differs from place to place; the capacity of social systems to adapt to these changes is not homogenous; and the significance of changes to the social systems will also differ (different communities value things differently). (2010, p. 22)

While the Pacific Islands as a whole face unique challenges in the face of climate change due to their size and position, they also face a wide variety of island-byisland challenges. This makes investment into adaptive environmental governance strategies even more crucial. However, with the capacity issues that Pacific Island countries face, resource-intensive adaptive governance presents its own set of challenges.

Atteridge and Canales (2017) found that finance to Pacific Island countries in 2010-2014 specifically aimed at climate change reached a total of US $\$ 748$ million. Climate change donors tend to be similar to traditional development 
partners (Webber, 2015), causing the spikes in funding brought about by a global interest in climate change to bring with them similar issues as are faced in traditional development practices. As these environmental (and other) challenges interact with small state governments and limited resources, regional efforts for governance have emerged in efforts to coalesce power and meet the region's growing needs.

\section{Regional Governance Efforts in the Pacific Islands}

Efforts for collective regional governance began in 1947 under the guidance of colonial powers (Fry, 1997). While many Pacific Island states have become independent, those relationships between the Pacific and colonial powers are still in place today and are now embedded in the decision-making and funding of governance in the region. As one individual with whom I spoke commented, the regional intergovernmental governance represents a "decolonization process that warped into technical assistance." These colonial relationships are particularly complex within the Council of Regional Organizations of the Pacific [CROP].

The CROP agencies include 10 regional intergovernmental organizations tasked with different areas of governance from fisheries to tourism to power. While each of the 10 agencies plays some role in climate change governance due to the pervasive nature of the topic, three agencies are specifically tasked with climate change mitigation and adaptation efforts-the Secretariat of the Pacific Community (SPC), the Secretariat of the Regional Environmental 
Programme (SPREP), and the University of the South Pacific (USP) - and the Pacific Island Forum (PIF) is involved with setting the broader political agenda around climate change. PIF represents the needs of independent nations in the Pacific and is the political head of the CROP agencies, tasked with the goal of improving functionality of regional intergovernmental governance of the Pacific Islands. PIF was established in 1971 under the name South Pacific Forum. The founding members were Australia, Cook Islands, Fiji, Nauru, New Zealand, Tonga, and Western Samoa (now Samoa).

While these organizations have long histories, they are regularly evolving to try to meet the changing needs of the region. For instance, PIF membership was recently changed to include two French territories-New Caledonia and French Polynesia. Despite their status as French territories and collectivities, they are now full voting members of PIF. Additionally, recent efforts have been made to make the CROP agencies' decision-making processes more inclusive through the Framework for Pacific Regionalism. Multiple interviewees from this study described the Framework for Pacific Regionalism as a "public policy revolution," where the 'black box' of regional intergovernmental prioritization has been opened up to public comment. However, these efforts are still very much in their infancy and the results of which are left to be seen (see Slatter, 2015).

Other organizations have emerged in the Pacific to meet the needs of the time. One of the more recent organizations is the Pacific Islands Development Forum [PIDF]. The formation of PIDF began in 2012 and was led primarily by the 
Fiji government. PIDF's emergence reflects a complex set of factors, including perceived failures of the regional governance system, the requirements of global governance under the UN's Sustainable Development Goals (SDGs), and Fiji's desire to regain power and legitimacy in the region. Fiji had a bloodless coup in 2006 (and subsequent constitutional crisis) that led to their dismissal from the PIF governing body in 2009 (Stewart, 2016). While they were readmitted to PIF in 2014 after Fiji held democratic elections, Fiji's relationship to PIF has remained strained. PIDF has since worked to distinguish itself from PIF by focusing on multi-stakeholder participation, inclusion of multiple local perspectives in decision-making, and not being reliant on colonial powers' aid which they understand as making them accountable to those colonial powers. As an emerging organization, PIDF is both a product of a transforming Pacific, and an ardent promoter of the transformation occurring in the Pacific.

As climate change has come to the forefront of environmental global governance efforts, the region has responded accordingly, seeking global funds and scientific support for adaptation and mitigation efforts. These funds have been primarily concentrated with states and IGOs, but the region has also seen the influx of non-state actors with their own projects. Local environmental governance efforts have also begun to include a climate change focus, creating a space where multiple actors in environmental governance are battling over funding, authoritative knowledge, and decision-making over governance. 


\section{Pacific Island Climate Change Governance Networks}

The impact of power, authority, and knowledge relations is evident in the socio-environmental history of the Pacific Islands' efforts to network around and contest the governance of climate change adaptation and mitigation. There is no doubt as to the environmental impact of climate change on the Pacific Islands (Allen et al., 2014). Recent news articles have discussed the loss of five of Solomon Islands' atolls into the ocean as sea level rise pushes onto land ("Five Pacific Islands," 2016). Yet, environmental challenges have made space for a "problem closure," which Hajer (1995) defines as the process of creating solutions to a set of well-developed unquestioned problems. In other words, it is the political act of limiting the options available for decision-making, thereby limiting the space for democratic discourse. This has restricted the Islands' ability to shape their own future by not allowing them to construct what they see as the actual problems to be solved. Barnett and Campbell argue that scientific models of climate change in the Pacific, as one approach to a 'well-defined problem,' have the effect of rendering climate change as an environmental fact against which actors can do little but suffer. They deny the agency of people at risk: to define the problem in their own terms; to apply their own systems of knowledge; to implement the solutions that are appropriate to their needs and values and which accommodate uncertainty; and to make knowledge claims of equal value to those of science. $(2010$, p. 2) 
Thus, constructions of environmental challenges have a distinct impact on governance within the Pacific Islands (Bartlett, Maltali, Petro, \& Valentine, 2010). Govan (2009) and Sievanen, Gruby, and Campbell (2013) have demonstrated the ways in which local knowledge construction can bolster the impacts of governance in the region. Yet, seemingly objective discussions about the desirability of global policy options in the region are "significantly affect[ing] the parameters within which future possibilities are worked out" (Fry, 1997, p. 27). In other words, the way in which environmental and social challenges are spoken of in organizations within the Pacific is delimiting the options that are available.

Transnational environmental governance networks in the Pacific are growing in prevalence and importance as organizations seek to meet environmental goals (Corlew, Keener, Finucane, Brewington, \& Nunn-Crichton, 2015; Gruby \& Campbell, 2013; Pietri, Stevenson, \& Christie, 2015). However, these networks struggle between the 'global kinds of knowledge' (Hulme, 2010) created by scientific and international advocacy NGOs and IGOs in the region and local, contextual knowledge (Lejano, Ingram, Whiteley, Torres, \& Agduma, 2007) that is a large part of the actual governance of the environmental challenges created by climate change. This has produced local/global struggles (Jasanoff \& Martello, 2004) that generate contestations between different appeals to power, authority, and knowledge.

In this dissertation, I explore these relations of power, authority, and knowledge through diplomatic efforts, as well as broader governance spaces. 
Diplomacy in the Pacific Islands has transformed in recent years as the world has tuned in to the climate impacts they are experiencing. Leaders such as former President Anote Tong of Kiribati and the late Tony de Brum of the Marshall Islands captured the world's attention by demanding that those most responsible, yet least impacted by climate change (developed states), demonstrate action to assist those least responsible, yet most impacted (developing states). They also demonstrated the capacity of Pacific Islanders to shape their own environmental future. This power was exhibited in the Conference of Parties meeting in Paris in 2015 [COP21]. However, while presenting a relatively unified voice at COP21, Pacific Islanders spent much of the lead-up to the conference struggling over power, competing authorities, and alternative ways of knowing and understanding social and environmental issues (Denton, 2017). These contestations were created through the disjointed nature of local/global needs and strategies.

As these decisions work their way into day-to-day environmental governance, these contestations continue in similar, yet distinct ways. Governance in the Pacific Islands has a long history of colonialism, external control, and a perceived or real lack of agency. Much of the governance moneys for Pacific Islands come from donors, namely Australia, New Zealand, the United States [US], the European Union [EU], and others. This has led to a lot of projectbased work in which locals are unable or seriously challenged to direct the flow of funds or make decisions on their own behalf. This dependency and lack of 
agency has begun to slowly transform in recent years, however, in light of the Islands' emphasis on local power. Similar to the diplomatic space, governance efforts have engaged in local/global contestations over access to power and authority, and the knowledges that legitimately uphold those power relations.

While many authors have either exclusively looked at diplomatic efforts (e.g. Carter, 2015; Corbett \& Connell, 2017) or at governance in the Pacific (e.g. Bartlett, Maltali, Petro, \& Valentine, 2010; Sievanen, Gruby, \& Campbell, 2013), this dissertation looks at the interplay between the two and provides insight into

the nature of power, authority, and knowledge in multi-scalar networked relations. The local/global framings and strategies are produced and reproduced within governance and diplomacy spaces, providing a kind of feedback loop that reinforces and transforms the work of networked Pacific Island decision-makers and practitioners. This dissertation takes global diplomatic efforts and on-theground governance strategies out of their respective silos and discusses the ways in which the decisions and actions at each level transform the options that are available to the other. In order to investigate these multi-scalar networked relations of power, authority, and knowledge, I utilized a mixed methods approach, described below.

\section{Research Strategy Overview}

While there are number of ways to approach climate change governance, I use power, authority, and knowledge relations within transnational climate 
change networks in the Pacific Islands to frame my discussion. My guiding research questions are:

- How and in what ways are power relations made manifest among the Pacific Islands' networked organizations?

- To what types and sources of authority do organizations appeal to access sources of power?

- What knowledges are produced and reproduced by these organizations?

- How do these patterns of power, authority, and knowledge align with within the broader history of the Pacific Islands, specifically, and climate change governance, in general?

To answer the first three questions on power, authority, and knowledge, I used a mixed-methods approach with Social Network Analysis [SNA] and interviews with Pacific Island climate change practitioners and decision-makers. First, in order to gain insight into the ways in which these issues play out in diplomatic spaces, a qualitative approach was used in which interviews and climate change declarations were used to form the foundation for the analysis of 'narrative networks' (Lejano, Ingram, \& Ingram, 2013) in Pacific Island climate change diplomacy. This analysis of 'narrative networks' was particularly useful due to the ability to take a cross-sectional approach, where the outcomes of diplomatic negotiations could be compared at a single point in time. This allowed for a simple comparison of the dual constructions of hero, victim, villain, and policy moral (Lejano, Ingram, \& Ingram, 2013) in two diplomatic spaces. I used a basic social network analysis to provide a qualitative visual representation for the engagement in diplomatic spaces of organizations in the region. 
For an exploration of power, authority, and knowledge in climate change governance in the region, I used a sequential mixed-methods design, where the quantitative portion of analysis informed the more important qualitative element (quant $\rightarrow$ QUAL design; Morgan, 2013). I conducted SNA using reports from the Pacific Climate Change Portal to graphically visualize and quantitatively assess the relationships between organizations engaged in transnational climate change governance in the Pacific Islands. This also allowed me to draw boundaries around the complex space of actors involved in climate change governance in the region, which set the framework for the qualitative portion of the analysis. I used the SNA graphic visualization in interviews in the Pacific, encouraging participants to respond to what they saw and how they felt power, authority, and knowledge works within governance in the region. These responses were not used to confirm or deny the validity of the SNA visualization, ${ }^{3}$ but rather as a focal point for our discussions.

For the qualitative analysis of approaches in both governance and diplomacy, I used thematic analysis (Braun \& Clarke, 2012) to analyze the interviews. This type of analysis uses six steps: (1) becoming familiar with the data, (2) generating initial codes, (3) searching for themes, (4) reviewing themes,

${ }^{3}$ Due to my use of a social constructivist approach (e.g. Porter, 1994), it would be challenging to say that the 'reality' of the interviews can confirm or deny the 'reality' of what is found in the Pacific Climate Change Portal dataset as each of these realities is produced and reproduced independently yet in conjunction with one another. That being said, the interviewees generally confirmed the SNA as being similar to their 'truth.' 
(5) defining and naming themes, and (6) producing the report. This was useful as both diplomacy and governance of climate change in the Pacific-particularly pertaining to power, authority, and knowledge as a whole-are understudied (see exception: Barnett \& Campbell, 2010). Thematic analysis encourages recursive and iterative processes, where the researcher moves regularly back and forth between elements of the data and themes (Braun \& Clark, 2012). This allowed me to be responsive to the lack of available literature by utilizing a more inductive approach, while still remaining true to my theoretical interests. As opposed to a rich description of the entire data set, this dissertation focused on detailed accounts of particular aspects of the interviews and documents associated with power, authority, and knowledge. A latent approach was used, going beyond the semantic content and looking to underlying meanings. In other words, I used narrative-network analysis for diplomacy (Lejano, Ingram, \& Ingram, 2013) and discourse analysis for governance (Howarth, 2010) to situate the participants' discussions in a broader social and historical context. More details on these methods are located in Chapters 3 and 4.

I address my final question of how these relations of power, authority, and knowledge fit within broader histories of environmental governance by pulling from both the analysis of diplomacy and governance. Chapter 5 relies heavily on a theoretical overview and critical update of the concept of Empire (Hardt \& Negri, 2000) that draws together the threads of local/global narrative and discourse in this dissertation. 


\section{Chapter Overview}

The next two chapters will provide key background information in order to set the stage for this research. In Chapter 2, I will provide a theoretical framework for the exploration of power, authority, and knowledge within transnational environmental governance networks in the Pacific Islands. I use threads of literature from international relations, network governance, and science and technology studies in order to form a holistic foundation for my research.

To gather the information presented in Chapter 3, I spent time in Suva, Fiji, and Apia, Samoa, in August and September of 2015, a few months before COP21 in Paris. In this chapter, I discuss the diplomatic efforts of the Pacific Islands in the lead-up to COP21, particularly the declarations presented at the Pacific Island Forum [PIF] Summit and Pacific Islands Development Forum [PIDF] Summit. These declarations are explored from a narrative-network approach, where both representation and narrative construction differed between the two groups. The PIF Summit included a limited representation of states and IGOs, producing what I refer to as a global technical narrative that emphasizes the technical solutions to climate problems. Alternatively, the PIDF Summit had broader participation that included more states and wide variety of domestic and international NGOs, producing what I refer to as a local power narrative that advocated local decision-making and information. The consequences of these differing narrative-networks for diplomacy-including the COP21 agreement and Fiji's leadership of COP23-are also discussed. 
To gather the information that serves as the basis for Chapter 4, I returned to the Pacific Islands for a trip that included Honolulu and Hilo, Hawai'i; Melbourne, Australia; Suva, Fiji; Apia, Samoa; and Rarotonga, Cook Islands. During this 7-week trip, I spoke with climate change practitioners and decisionmakers from government agencies, NGOs, and IGOs about their work. By analyzing these interviews, I have seen the way in which the global/local contestations from diplomacy are replicated, reproduced, and contested within the Pacific Islands' project-based governance efforts. I use Bäckstrand and Lövbrand's (2006) three environmental discourses-green governmentality, ecological modernization, and civic environmentalism - to further explore the use of discourse in producing and reaffirming the local/global contestations over the power, authority, and knowledge of Pacific Island climate change governance efforts.

In Chapter 5, I seek to integrate these discussions of power, authority, and knowledge within the local and global efforts of Pacific Islands climate change diplomacy and governance. Using the concept of Empire as developed by Hardt \& Negri (2000) with a critical update by Miller (2004), this chapter analyzes the role of discourse in producing and reproducing Climate Empire within the Pacific Islands and globally. Importantly, the local and global elements of climate change diplomacy and governance are connected in the relocalization processes inherent in global knowledge (Miller, 2004). In climate change spaces, data is locally collected, globally analyzed, and relocalized within polices and projects. 
Chapter 5 explores the way in which this relocalization process impacts climate governance and diplomacy in the Pacific Islands and globally.

Finally, Chapter 6 will conclude by summarizing and discussing themes from the dissertation that will form the foundation for recommendations for governance in the Pacific Islands. While issues of power, authority, and knowledge are highlighted due to the small size and big presence of the Pacific Islands on the global stage, their situation is not wholly unique. This chapter integrates the global and local approaches to create a more systematic approach to understanding climate governance, while also describing the recommendations put forward by participants. 


\section{Chapter 2: Power, Authority, and Knowledge in Networked \\ Governance}

Transnational environmental issues - water scarcity, sea level rise, biodiversity loss, and others - are pushing their way into governance priorities at unprecedented rates, ensuring that single states alone cannot accomplish the goals of governing (Biermann \& Pattberg, 2012). Due to the nature of these environmental challenges, a decentralization of governance is occurring in which power and authority are distributed across multiple arenas that function between and outside of state boundaries (Rosenau, 2007). These polycentric governance spaces (Ostrom, 2010) ${ }^{4}$ include nonstate actors that face very different challenges than states when trying to impact governance.

Networks are growing in prominence as one way of investigating these complex spheres of authority within transnational environmental governance (e.g. Andonova, Betsill, \& Bulkeley, 2009; Hadden, 2015; Keck \& Sikkink, 1999; Stone, 2008). Acknowledging the role of networks in international decisionmaking takes the conversation away from the dyadic, behavioral, state-centric focus that has taken up much of the scholarship in international relations, and allows for a more relational and holistic view of political interactions among state

\footnotetext{
${ }^{4}$ While some would argue for a heavier reliance on Ostrom's work in this dissertation, I find that transnational environmental governance lacks the localized institutions and face-to-face interactions that are necessary for the norm coherence fostering collective action in Ostrom's work. Thus, her work will not be dealt with directly.
} 
and nonstate actors. Thus, international relations theories would benefit from a greater understanding of networked relations.

At the same time, while emphasizing vital elements of relationality, many authors of networked governance have put forward a view of networks that is primarily nonhierarchical and voluntary (e.g. Glasbergen, 1995; Goldsmith \& Eggers, 2004; Kickert, Klijn, \& Koppenjan, 1997; O’Toole, 1997; Peters, 1998). Under this set of assumptions, the networked organizations work toward collective action under a set of commonly agreed-to goals (Peters, 1998). However, as Eilstrup-Sangiovanni explains, "Although networks are often described as fundamentally flat and decentralized, in reality many social networks entail elements of both centralization and de facto hierarchy" (2017, p. 692) that influence the flow of power within the network. Thus, this dissertation seeks to call greater attention to the power, authority, and legitimizing knowledge that are contested in arenas of decision-making and which create distinctly unequal governance structures (Davies, 2012).

In addition to the literatures on international relations and networked governance, the Science, Technology, and Society (STS) literature brings key insights into the study of international environmental governance. STS scholars have explored the complex interactions between science, policy, and society under the lens of a power/knowledge relationship (Foucault, 1980), or the ways in which knowledge is interlaced with the production of power relations in the social order. Scholars of science have worked to open up the "black box" of 
scientific knowledge production by questioning the construction of science, playing it against the political and subjective elements of knowledge creation (Agrawal, 2005; Bocking, 2004; Hajer, 1995; Jasanoff, 2004; Litfin, 1994). These authors seek to deconstruct the taken-for-granted character of normalizing, categorizing, and standardizing science by looking to the way that discourses, values, political economic drivers, and social constructions of nature impact the scientific process. This dissertation integrates the investigation of science and power found in the STS literature with questions of networked authority emerging in international environmental governance.

In this chapter, I position this dissertation within the existing literature regarding the various elements of power, authority, and knowledge within transnational environmental governance networks. First, I situate my understanding of transnational governance as a multi-actor space that includes non-state actors. Next, I explore the ways in which this understanding of multiactor governance is embedded in an understanding of power that is productive (rather than merely restrictive), relational (rather than held by a specific actor), and distributed throughout society (rather than exclusive to the state). I describe how this power is expressed through the text and practices of discourses. This leads to a discussion of power/knowledge-or the ways in which this productive, relational, and societal discursive power is heavily embedded in regimes of knowledge and ways of understanding the world-and is further explored through local and global constructions of knowledge. Next, I introduce the role of 
networks in organizing the complexities of this dynamic, multi-actor space. Specifically within transnational environmental networks, I explore the ways in which power, authority, and knowledge are organized according to traditional, bureaucratic, scientific, and practical relations. These discussions set the stage for the investigation of climate change diplomacy and governance in the Pacific Islands undertaken in this dissertation.

\section{Transnational Governance}

There is a growing level of acknowledgement that transnational issues, such as environmental degradation, security, economic processes, etc., are in need of transnational governance solutions. It is important to be clear that transnational governance differs from transnational government (Rosenau 2007), though the two could, theoretically, be one and the same. Governance is "the broader system of formal or informal institutions in which the management actions are embedded and which provide the essential direction, resources, and structure needed to meet the overarching governance goals" (Bodin \& Prell, 2011, p. 45). While many authors point to the continued strength and sovereignty of states (e.g. Keohane, 1982; Krasner, 1999), multi-actor governance is gaining authority and legitimacy on the global stage (Andonova, Betsill, \& Bulkeley, 2009; Betsill \& Corell, 2001; Biermann \& Pattberg, 2012; Boström \& Hallström, 2010; Gulbrandsen \& Andresen, 2004; Hadden, 2015; Keck \& Sikkink, 1998). These governance efforts are the attempt by states and other nonstate actors to create order amidst the disorder inherent in transnational problems. 
Conceptualizing transnational governance in this way takes the conversation away from the centrality of the state, and groupings of states, and includes a realm of diverse organizations and mechanisms to take on the problems and solutions of governance. This is not to say that the territorially defined state does not retain certain unique privileges and authorities, but rather that authority can also be found, in varying degrees, in the hands of civil society (e.g. Wapner, 1995), powerful individual actors (e.g. Cooper, 2008), market forces (e.g. Cashore, 2002), and intergovernmental organizations that have a bureaucratic power of their own (e.g. Jinnah, 2010).

The state, civil society, and private entities can all be key players in efforts toward transnational governance. In this understanding of governance, power and authority is distributed across multiple arenas, or 'spheres of authority' (Rosenau, 2007, p. 88) that function between and outside of state boundaries. The spheres of authority, for Rosenau, are concerned with directives being issued and adherents complying. However, "compliance can be intentional or unintentional, conscious or subconscious, or immediate or halting, the result of a host of interactive and reinforcing dynamics" (ibid., p. 90). In other words, compliance is not reliant on the ability to coerce, but could be indicative of the diffusion of norms or standards. This latter element of compliance will be dealt with most extensively in this dissertation, and is directly related to the way in which power is understood. 


\section{Views on Power}

Lukes argues that power is an "essentially contested" concept (2005, p. 63). In other words, the very act of discussing and defining power is fluid and rests heavily on the ontological and epistemological perspectives of the researcher. Due to this, conceptualizations of power have fractured in a variety of ways-agentic versus structural power, power held in the sovereign versus power held in society, power as capacity versus relational power, and others. This dissertation focuses on the last debate, particularly the ways in which Foucault's relational ontology has transformed the study of power.

The tradition of power as capacity began as a focus on the state, or sovereign power. This is a juridical power, where power is possessed as a right, similar to the way in which one possesses a commodity. These descriptions see power as embedded within the capacity to enact the sovereign will. Hobbes' (1651) theories of the Leviathan, Locke's (1689) social contract, Rousseau's (1762) formation of the "general will", and Mill's (1896) process of utilitarianismwhile having their own set of divergences on issues of legitimacy and decision making-all focus on the mechanisms by which the sovereign gains, keeps, and uses power.

Other theorists have expanded this definition of power further out in society, while still understanding power as a capacity. Waltz (1979), for instance, draws a distinction between the legal, sovereign authority to compel and the broader capacity to influence others' behavior. Marxist tradition looks to what 
Foucault refers to as the 'economic functionality' of power (2003, p. 14). Power is structural in that it is embedded within the broader societal system, but it is still a capacity that is used by way of mode of production. The capitalist has power based on the ability to direct the flow of capital; the proletariat only has her own capacity for labor (Marx \& Engels, 1978).

Another key reading in regards to power as capacity is found in Lukes' (2005) "three faces of power." The first face comes from Dahl, where "A has power over $B$ to the extent that he can get $B$ to do something that $B$ otherwise would not do" (1957, 202-03). The second comes from Bachrach and Baratz (1962) where non-decision making or agenda setting is also considered powerthe power to enact one's will by keeping an item off the decision-making agenda. The third face is a bit more ambiguous, were one enacts power through structuring decision, thereby impacting the preferences of others by delimiting the options available. Similarly, within the realist IR tradition, Krause (1991) draws on distinctions between states' bargaining power (through treats of punishment and/or promises), structural power (by altering the range of options), and hegemonic power (by determining the rules of the game), while Nye (2008) introduces "soft power," or the ability for states to get other states to want what they want through cooption rather than coercion. While Lukes, Krause, and Nye further expand the mechanisms of power, power is still a capacity that is held and enacted to change others' actions and minds. 
Power as capacity has a long history in political thought; however, it has its limitations. Understanding power as capacity assumes that given $x$ set of traits and capabilities, the user will be able to exercise $y$ power. It is a quantitative understanding of power that can succumb to reductionism and essentialism. Whether by appealing to objective interests (e.g. Rawls' (1971) 'primary goods' or Sen's (2009) 'basic human capabilities'), pre-structured identities (Marx \& Engels' (1978) class-based interest), or constraints on decision-making (Lukes' (2005) third face of power), analysis of this type of power can only occur if the researcher knows the true interests of the individual on the receiving end of power, which effectively flattens the human into a unidimensional being. In so doing it pays limited attention to the way that norms, identities, and relations constantly are shaped by and shape interactions-effectively the way that power fluidly moves in and through societies to construct and actively change interests, identities, and conditions for decision-making.

Barnett and Duvall (2005) have called upon IR to broaden its view of power. Power, then, is understood through the filter of, "(1) the kinds of social relations through which actors' capacities are affected (and effected); and, (2) the specificity of those social relations" (ibid., p. 45). They argue that that understandings of power need to move beyond analyses of the (still necessary) compulsory, institutional, and structural powers, to include productive power. Productive power is further explained below via the work of Michel Foucault. 


\section{Productive, Relational, and Societal Power}

Foucault understands power as productive-it not only constrains A from doing something B does not want done, it also creates new relations and subjectivities, or subject identities in relation to power. This includes the beliefs, attitudes, orientations, and understandings that a person may hold. It fundamentally transforms both A and B. It is not located in a person or place, but is rather diffused throughout all relations in society. Power "is deployed and exercised through a net-like organization," suggesting that both $A$ and $B$ are wrapped up in its circulation (Foucault, 1980, p. 98). In other words, Foucault's conception of power is not a capacity one has or exercises, but rather it is inescapable, ever present, and constantly producing new relations. Instead of starting with preformed subjects, interests, or material realities, Foucault starts with the relationship itself and asks how these particular social relations produce power.

This can be seen, for example, in the way that climate change as a concept has formed new interests and power relations in the Pacific Islands. As climate change mitigation and adaptation have been taken up as a cause by the developed world, resources have been directed toward the scientific information, professional development, and capacity building deemed necessary by outside funders for the Pacific Islands to meet its climate change challenges (Atteridge \& Canales, 2017). As Foucault argues, "Power never ceases in its interrogation, its inquisition, its registration of truth; it institutionalizes, professionalizes, and 
rewards its pursuit” (1980, p. 93). In the pursuit of climate 'truths' meant to govern the globe, many actors-Pacific Islanders, development partners, INGOs, etc. - have experienced a new form of power where global scientific knowledge and bureaucratic structures now govern much of their decision-making.

These types of power are produced through the governmentality of everyday lives. Governmentalities are the ways of thinking about governing, or the "conduct of conduct" (Foucault, 2009). Governmentalities that support the modern administrative state do not rely solely on the juridical sovereign state-or the legal arm of state coercion-but rather dictate conditions of normality within every home, every workplace, every school, and every relation therein. Governmentalities are enacted through dispotif, defined as, "A thoroughly heterogeneous ensemble consisting of discourses, institutions, architectural forms, regulatory decisions, laws, administrative measures, scientific statements, philosophical, moral and philanthropic propositions-in short, the said as much as the unsaid" (Foucault, 1980, p. 194). The system of relations formed under the dispotif produces a particular set of power apparatuses and a series of knowledges that transform the subjectivities of individuals (Foucault, 2009). Thus, looking at the full range of institutions, procedures, and tactics at work in a given society can give greater insight into how power is produced and upheld. 
While the critiques lodged against Foucault are important-primarily the lack of attention to both agential possibilities for resistance ${ }^{5}$ and empirical guidelines-looking to the productive and relational power within society remains an important goal for, as Foucault states,

it is interested in defining and discovering, beneath the forms of justice that have been instituted, the order that has been imposed, the forgotten past of real struggles, actual victories, and defeats which may have been disguised but which remain profoundly inscribed. (2003, p. 56) In other words, by exploring power in this way, political discourse is reopened for negotiation. This is important as, many times, decisions within governance can be presented as apolitical, or just a matter of course, when in fact their histories are fraught with politics, now hidden. An example of this is the scientific method:

${ }^{5}$ The quote most often used to signal the agent within Foucault's writing, and then to grossly critique it, is "Where there is power, there is resistance, and yet, or rather consequently, this resistance is never in a position of exteriority in relation to power" (1984, p.95). However, while most critiques (e.g. Lukes, 2005; Grewal, 2008) dismiss this as positioning the choice of the agent as useless combat power, or as Giddens states, "Foucault's 'bodies' are not agents" (1984, p. 154), it is important to address this quote within the field of literary studies out of which Foucault emerged. Saussure's theory of language was based on the relational and differential conceptions of language, by which one is created in relation or in differentiation of the "other". This was further expanded by Derrida, breaking down binaries but imbuing linguistic rationality and difference with power. Coming from this genealogy, this interpretation of the role of the agent through resistance can easily be interpreted being constructed in relation to power. In other words, the form of the resistance is necessarily constructed in relation to the mechanisms of power employed against it, which then directly impact the nature of power, itself. This does not take away the power of the agent to resist, but rather directs resistance-and power-through their relations. 
once debated, it is now taken for granted as the only way for true scientific discovery, which hides the ways in which this is productive of certain privileged forms of knowledge (Shapin \& Schaffer, 1985). Thus, it is critical to understand the ways in which power is produced and reproduced through the discursive practices of actors.

\section{Discursive Power}

Discourse, as a concept within social sciences, is understood under a number of different frameworks. The primary split between understandings of discourse is whether it is narrowly defined as talk or defined a system of representation (Howarth, 2000). The way in which one defines 'discourse' is many times embedded in one's theoretical home. Howarth (2000) explains that positivists and empiricists tend to view discourses as talk, where 'frames,' or instruments for common and strategic discussion, are the focus (e.g. McAdam, McCarthy, \& Zald, 2006). Realists, ${ }^{6}$ on the other hand, tend to view discourses as objects both with their own structure and within the structure of the social world (e.g. Harré, 1975). The goal of these ways of knowing is to expose the 'true' work of discourse.

While substantial work has been done understanding discourse as talk, this dissertation follows an understanding of discourse as a system of representation. Even within this categorization, there is a broad range of

\footnotetext{
${ }^{6}$ This refers to scientific or critical realists, not specifically to realists of IR theory.
} 
ontological approaches, as described by Howarth (2000). Marxists take the realist foundation and focus on the ideological systems at play within the processes of economic production and reproduction (e.g. Zižek, 1994). Additionally, there is the work of Norman Fairclough (2014) and his introduction of a school of thought called critical discourse analysis [CDA]. In this look at discourse, Fairclough and his school investigate the way in which discourse relates to both the linguistic (text) and non-linguistic (material practices, institutions, etc.) elements of social reality. Giddens' (1984) theory of structuration-or the production and reproduction of social systems through both structure and agency-comes out of this school of thought. The goal of CDA is to uncover the ways in which discourse is used by the powerful to oppress and to give the oppressed tools to overcome their oppression.

Finally, Howarth (2000) describes the post-structural turn of discourse. Under this school of thought, contingency and ambiguity are elements of an inherently incomplete discourse. Instead of a structured ideology of Marxist discourse or the hegemony of Antonio Gramsci, the power of discourse here runs throughout all relations in society and, while still subject to dominance, is never fully formed. Michel Foucault, Jacques Derrida, Ernesto Laclau, and Chantal Mouffe form the groundwork of post-structuralist discourse. Under these theoretical assumptions, "discourses constitute symbolic systems and social orders, and the task of discourse analysis is to examine their historical and political construction and functioning" (Howarth, 2000, p. 5). In other words, this 
school of thought considers the way some discourses have gained dominance in society, and looks to how they got to be in the position of dominance. Within this camp, there are divisions between analytical styles. Foucault has produced archeological and genealogical analytic approaches to analyze power/knowledge. Laclau and Mouffe have approached the analysis of discourse from a post-Marxist perspective in order to draw into conversation the full range of political identities. As this approach assumes, "political identities are not pregiven but constituted and re-constituted through debate in the public sphere" (Laclau \& Mouffe, 1985, p. xvii).

This dissertation draws directly from a post-structural approach to discourse to understand power in transnational environmental governance. I look to Foucault's genealogical approach to "entertain the claims to attention of local, discontinuous, disqualified, illegitimate knowledges against the claim of unitary body of theory which would filter, hierarchize, and order them in the name of some true knowledge and some arbitrary idea of what constitutes a science and its objects" (1980, p. 83). Thus, this dissertation seeks to deconstruct, if only partially, the power/knowledge complexes at work in climate change governance in the Pacific Islands. I also pay key attention to Laclau and Mouffe's partially fixed spaces of meaning, and their ability to produce dominant discourses but remain open for negotiation. As they put it, "The practice of articulation, therefore, consists in the construction of nodal points which partially fix meaning; and the partial character of this fixation proceeds from the openness of the social, as a 
result, in its turn, of the constant overflowing of every discourse by the infinitude of the field of discursivity" (Laclau \& Mouffe, 1985, p. 100, italics in original). This is important as I explore the plurivocity, or the space for multiple voices and multiple stories, at play in Pacific Islands climate change governance. ${ }^{7}$

\section{Discourse in Environmental Governance}

While theories of discourse can be abstract, their application to environmental policy can bring a certain level of concreteness. From the release of Maarten Hajer's (1995) well-known book The Politics of Environmental Discourse: Ecological Modernization and the Policy Process to today, Hajer and colleagues have led the way on clarifying the role of discourse in environmental policy. He defines discourse as, "an ensemble of ideas, concepts and categories through which meaning is given to social and physical phenomena, and which is produced and reproduced through an identifiable set of practices" (Hajer \& Versteeg, 2005, p. 175). Thus, in the post-structural tradition, Hajer and Versteeg consider discourse more broadly than a set of speech acts or a collection of texts, but rather emphasize way in which power is practiced throughout social and physical systems through discourse. They describe discourse in more detail:

[Post-structural Discourse Theory] has an anti-essentialist ontology; it assumes the existence of multiple, socially constructed realities instead of a single reality, governed by immutable natural laws. Characteristically,

\footnotetext{
${ }^{7}$ This is an admittedly limited exploration into a broad and deep history of discourse. For greater detail, pleases refer to Howarth (2000).
} 
the approach takes a critical stance towards 'truth' and puts emphasis on the communications through which knowledge is exchanged. Because reality is seen as socially constructed, the analysis of meaning becomes central; for interpretative environmental policy research, it is not an environmental phenomenon in itself that is important, but the way in which society makes sense of this phenomenon. Dying forests do not contain in themselves the reason for the public attention and concern they receive. The fact that they do receive this attention at a specific place and time cannot be deduced from a natural-scientific analysis of its urgency, but from the symbols and experiences that govern the way people think and act (Hajer \& Versteeg, 2005, p. 176)

This post-structural, interpretative approach to discourse in environmental policy thus analyses the underlying practices and knowledges that produce and reproduce power relations throughout society.

The power of discourse, then, comes in the ability to both frame the problem and structure the 'solution' within environmental challenges through the production, dissemination, and legitimation of knowledge (Foucault, 1980) including information about processes and procedures (Barnett \& Finnemore, 1999), knowledge about the physical and social world (Miller, 2007), and the limits of what is considered acceptable (Hulme, 2010). While particular environmental discourses may gain more or less ground in a particular situation (Bäckstrand and Lövbrand, 2006; Hajer, 1995; Litfin, 1994; Wesselink, 
Buchanan, Georgiadou, \& Turnhout, 2013), they are never final as they are always open for renegotiation (Butler, 1997; Laclau \& Mouffe, 1985). This negotiation over knowledge is further explored in the next section.

\section{Power and Knowledge}

A key element of environmental governance is the production and reproduction of scientific knowledge. Foucault discusses science as embedded in "regimes of truth" which designate which ideas are deemed valid or false (2010, p. 36). These regimes of truth are not simple reflections of the natural world, but rather are produced by and produce power relations within society as they engage with political struggles over legitimate knowledges. As Foucault (1980) has discussed, the cornering of a single 'truth' is a discursive strategy that is meant to stifle and delegitimize alternative ways of understanding the world. Thus, he advocates for an exploration into the ways in which these 'truths' come to be under particular power/knowledge complexes. He provides a number of examples of this, from the construction of sexuality (Foucault, 1984) to the way in which madness came to be understood (Foucault, 1988). With sexuality, he explored the way that confession-and the admission of guilt-brought about the existence of sexuality as a discursive object, known through efforts to surveil, analyze, and eventually medicalize sexuality. This lent itself to a power/knowledge complex that circumscribed certain sexualities as normal or abnormal through adherence to a particular set of knowledges. 
Additionally, Jasanoff (2004) describes this power/knowledge relationship as coproduction. Coproduction, according to Jasanoff, is concerned with the ways in which the social and natural orders are being constructed together, inextricable from one another. She argues that analyzing knowledge as coproduced through interactions of material and social systems, "offers new ways of thinking about power, highlighting the often invisible role of knowledge, expertise, technical practices, and material objects in shaping, sustaining, subverting, and transforming relations of authority" (ibid., p. 4). She explains, "Scientific knowledge, in particular, is not a transcendent mirror of society. It both embeds and is embedded in social practices, identities, norms, conventions, discourses, instruments, and institutions" (ibid., p. 3). Thus, looking to power/knowledge through a coproductive lens clarifies the ways in which particular understandings of the world are privileged in questions of what is being studied, why it is being studied, and how it is being studied-through what tools and methodologies (Jasanoff, 2004; Porter, 1994; Scott, 1998).

Understanding the coproduction of human/environmental relations can reveal the power inherent in management strategies. As Engel-Di Mauro argues, "Without taking into account that the biophysical also entails a social understanding, there will continue to be a reinforcement of socially predominant ideologies, a passively political act" (2014, p. 33). Choices about environmental use, even those perceived by many to be 'apolitical,' in fact have power. For instance, the use of scientific forestry in late eighteenth-century Germany used a 
technical approach to produce high timber yields that allowed them to ignore the "vast, complex, and negotiated social uses of the forest for hunting and gathering, pasturage, fishing ..." (Scott, 1998, p. 13). As Hull and Robertson articulate, "the constructs of ecological science necessarily serve double duty: they are both descriptive (scientific) and prescriptive (political); they are used to describe what is and to prescribe what ought to be" (2000, p. 98). In other words, understanding nature according to realist, positivist, and empiricist approaches, where authoritative science is simply used to find the 'truth' of the natural world, can obscure political choices that take place when understanding and studying the environment.

These underlying political choices are further explored through Agrawal's (2005) analysis of environmentality. Environmentality is a play on 'environment' and 'governmentality,' and is "an approach to studying environmental politics that takes seriously the conceptual building blocks of power/knowledges, institutions, and subjectivities" (ibid., p. 8). He argues that environmentality produces new subjects under the totalizing, or all-encompassing, statistical discourses of conservation in Indian forests, making decision-making less democratic. It also transforms the very individuals themselves, forcing them to appeal to statistical measurements to have their voices be heard. As Agrawal argues, "once precise, statistical, generalizing arguments are invoked in the service of polity, it is difficult to counter them with vague, descriptive, anecdotal evidence. It is in this characteristic of statistical representations...that their colonizing effects are to be 
found" (ibid., p. 35). In other words, the authority of statistical knowledge in environmental governance makes it challenging to introduce other ways of understanding the world. This is further explored in the challenges of global and local knowledge divisions.

\section{Global and Local Knowledge}

Power/knowledge, while it takes many forms, is here explored in the divides between the 'globalizing' effects of scientific knowledge production and local, or situated, knowledge construction. As Hulme describes global knowledge,

Knowledge about multi-scalar processes and globally-aggregated outcomes that is insensitive to the peculiarities of place and context opens the way for unitary globalised explanations and predictions of environmental change. Masquerading as universal truths, these assert themselves as the unassailable view from everywhere. (2010, p. 559) In other words, global types of knowledge are unconcerned with the context in which they are created. The geographic locales and economic statuses of researchers, the ontological location of the project, the priorities of funders, the choice of what to study and how to study it, etc., are considered to not considerably impact the outcome of the research. Instead, global knowledge produces outcomes meant to predict change across time and space, irrespective of the context in which it was created. 
Global knowledge, then, creates a power/knowledge complex through delimiting the options that are considered legitimate in decision-making and governance. As Turnhout, Dewulf, and Hulme describe it, "Knowledge and power embrace tightly as globalized knowledge conditions the political imaginary of global environmental governance and vice versa: how one knows constrains how one governs and how one governs shapes what one needs to know" (2016, no page). This creates a space in which only the problems that are identified and solutions supported by globalized knowledge are considered legitimate. In this way, authoritative science-knowledge that is unanimous, quantitative, generalized, and conducted according to scientific process (Bocking, 2004) -is many times the only form of knowledge that is considered within discussion of environmental issues. For instance, this can be seen in many conversations surrounding epistemic communities (Adler \& Haas, 1992; Haas, 1989). Many times, the negotiations between these communities are seen as the only spaces for dissent, as opposed to any dissent that might question the basis of globalized knowledge.

By contrast, the construction of local knowledge denies the "view from everywhere" (Hulme, 2010, p. 559), and rather captures the nuance of local situations. This type of knowledge aligns with Lejano and Ingram's definition of ways of knowing: an "active process of meaning construction" within a policy space, where actors interact with one another and objects in ways that either confirm or reshape their relation to the world $(2009$, p. 656). These objects can 
include scientific reports, forums, rules, etc., that are interpreted by an actor/organization through their own understanding of the world. Defining knowledge in this way opens up the conversation to understand the ways in which multiple knowledges besides global, authoritative science may find authority within decision-making spaces. While multiple ways of knowing are considered and discussed within this dissertation, they are not on an even playing field within governance, a topic further explored in subsequent chapters. Construction of the "local" has taken different definitional and normative forms. Many writers that advocate for "community" or "local" solutions tend to have a set of assumptions - spatial smallness, social homogeneity, and norm similarity (Agrawal \& Gibson, 1999) or flat power dynamics and a focus on civil society (Mohan \& Stokke, 2000) -that are not shared here. Thus, it is important to distinguish between an acknowledgement, inclusion, and study of the local through multiple ways of knowing, such as is the goal here, and a valorization of a static and singular "local" that is inherently normatively good (Martello \& Jasanoff, 2004). While the term local will be used throughout this dissertation, it will be used along the lines of Haraway's (1988) concept of situated knowledge. Situated knowledge is removed from scale, and is rather understood to be contextually specific and produced in-situ, impacted by the researchers' ontology and experience in a specific place and time. Therefore, instead of an overlysimplified and naïve understanding of the local, this dissertation sees local 
knowledge as simply an approach to knowledge generation in which context and nuance are considered in its production.

This global/local distinction is especially important in the realm of environmental governance, and specifically climate change. Martello and Jasanoff (2004) have argued that while globalization has been extensively covered in social science research, research on the relationship between globalization and localization has been limited. They give a few reasons why this could be. First, the global and local tend to be investigated by different disciplines, which have little overlap. Additionally, studies tend to see the local as doomed from the beginning due to its being the "other" to the inevitable wave of globalization. Finally, the local and the global are many times presented as static instead of dynamic and open for reinterpretation. In light of these issues, Martello and Jasanoff argue that more should be done to draw the local and global into conversation. One way in which this can be accomplished is through the introduction of network approaches into the study of local and global relations.

\section{Network Approaches}

Over the last three decades, social networks have been explored conceptually, visually, and mathematically, leading to a plethora of research agendas seeking to advance understanding of the social world. Social networks have seen a substantial increase in the last 10 years both with the uptake of social network theory in a variety of fields and the methodological development of computer technologies and analysis tools (Table 1). Instead of behavioral 
science that seeks to analyze decision-making based on individual attributesage, gender, political affiliation, etc. - network studies approach analysis from a relational perspective (Wasserman \& Faust, 1994). In other words, people are understood to make decisions based on more than their individual attributes, but also based on the exchanges that take place according to their social ties to others.

Table 1: Chart of publications with "social network" in the title, retrieved from Web of Science (19 Jan, 2017).

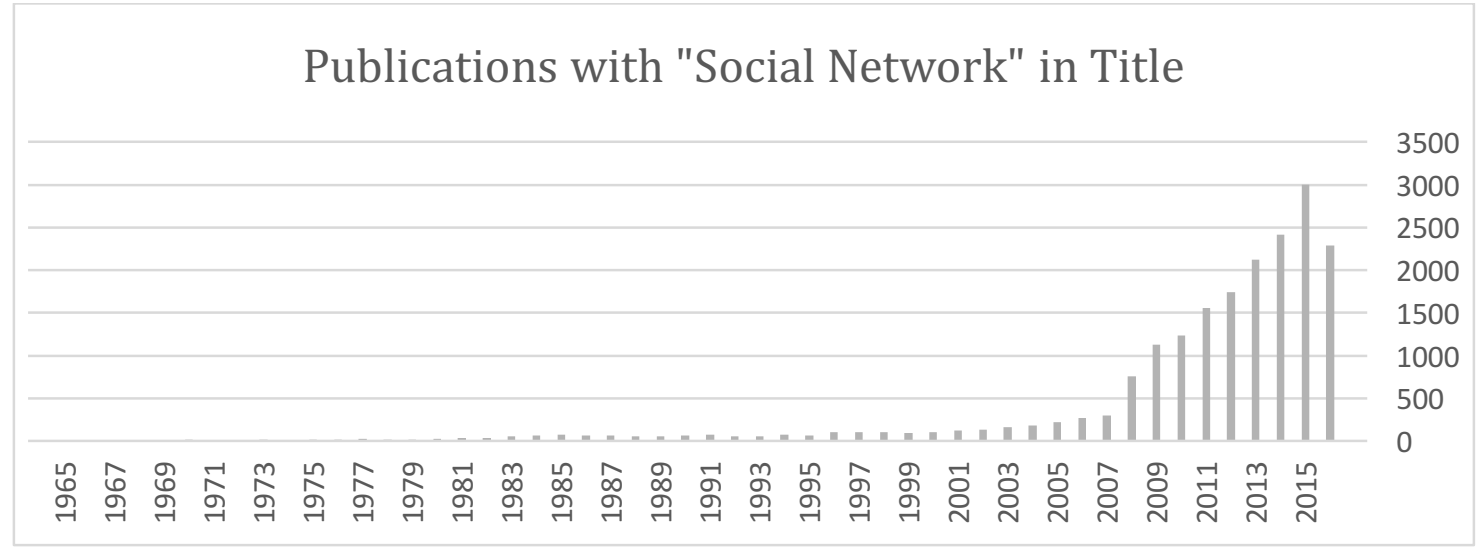

Wasserman and Faust define the network as: "a finite set of actors connected by a set of ties" (1995, p. 20). Based on this definition, however, one could see networks everywhere-interactions at the bus station, shopping cart collisions at the grocery store, and more. In order to add specificity and rigor, they note the following assumptions as fundamental to the social network perspective:

- Interdependence of actors and their actions;

- Material and non-material resources can/do flow through relational ties/links;

- Patterns of interaction produce the network structure, and this structure then impacts the behavior of individuals and groups; and 
- Network structure has relative longevity (it may change over time, but it is rather stable).

The boundaries that these assumptions place on the network ensure that the phenomena being studied are, in fact, social phenomena, rather than happenstance encounters.

Utilizing social network approaches to study transnational environmental governance has distinct advantages. First, with the decentralization of authority occurring within transnational governance, networks more accurately mirror the reality of these governance arrangements than other state-centric investigations. Networks also form a useful tool by which to analyze and visualize a complex set of interactions among a large number of actors. This can facilitate a greater understanding of the structural elements of interactions by looking to the locales in which various organizations are situated within the network. Additionally, the relational focus of networks allows for a shift away from a static, behavioral approach and considers the way that actors' ways of understanding problems and solutions to environmental challenges can change over time according to their interactions with other actors.

Networks are also useful in capturing the multiple scales in which transnational environmental governance efforts work and interact. As opposed to single-level analyses, such as Keohane's (1982) analysis of international regimes, network approaches can capture actors at multiple scales that include both local and global understandings of the world, and demonstrate the ways in 
which actors in these scales link together. Thus, networks are useful theoretical and methodological tools for understanding relationships of power, authority, and knowledge within transnational environmental governance at all levels.

\section{Power, Authority, and Knowledge in Transnational Networks}

Traditionally, international environmental decision-making has focused on the power of the state to achieve state interests (e.g. Abbot \& Snidal, 2000; Keohane, 1982; Krasner, 1999; Vaubel, 2006). However, a relational ontology of power provides a different set of foci, such as the ways in which nonstate actors shape what is possible by generating norms to which states adhere (Finnemore \& Sikkink, 1998; Keck \& Sikkink, 1999; Mitchell, 1998; Rosenau, 2007), producing and sharing information on which decisions are based (Jasanoff, 2004, 2005; Keck \& Sikkink, 1999; Miller, 2007; Scholte, 2004; Wapner, 1995), creating and maintaining processes and procedures (Barnett \& Finnemore, 1999), and providing practical support for program implementation and on-the-ground legitimacy (Abers \& Keck, 2013; Cooper \& Vargas, 2004). For instance, Keck and Sikkink's (1999) transnational advocacy networks use the boomerang effect, where the networks of organizations investigate perceived injustices in national contexts, then put pressure on other nations to force the transgressing nation to change its ways. This is particularly seen in humanitarian issues, but they also talk about it in the realm of environmental governance. Additionally, Wapner's (1995) transnational environmental advocacy groups actively change state and 
nonstate decision-making through expanding discourse, changing market conditions, and establishing legitimacy of environmental programs.

This impact on decision-making is not limited to activist NGOs, either; power is evident in the bureaucracies and secretariats of international organizations (Barnett \& Finnemore, 1999, 2004; Jinnah, 2010), knowledgeproducing institutions (Miller, 2007; Miller \& Edwards, 2001), and standardsetting institutions (Böstrom \& Hallström, 2010; Cashore, 2002), all of which take part in and form the networks of environmental governance. These organizations produce new ways of knowing about environmental issues including information about processes and procedures, knowledge about the physical and social world, and the limits of what is considered acceptable. These things can help to facilitate cooperation and shared understanding among network members, and at times the global polity; however, as with all power, there are risks. Hulme (2010) gives the example of the way in which the $2^{\circ}$ limit on global warming has been used by the IPCC to stabilize normative goals around the climate and delimit the storyline on which the public's imagination must be built. However, he argues that this framing may damage local communities as they seek to write their own narratives and seek their own futures.

The primary challenges around issues of power and authority within networked environmental governance are due to the potential for undemocratic governance. These multiple and diffuse authorities have implications as powerful actors in networks can potentially be less transparent and accountable than the 
state (Biermann \& Gupta, 2011; Vaubel, 2006). Transnational governance is semi-private or quasi-public and dispersed through restricted sites, where boundaries are "indeterminate and opaque" (Stone, 2008, p. 22). Networks are at times used to mobilize dominant liberal ideology at the expense of other value systems (Friedrichs, 2005) or to stifle the voice of the global South (Glenn, 2008). In other words, the power and authority held by nonstate actors that work in and through transnational environmental governance networks can shift power away from the public.

This challenge to accountability extends to the knowledge utilized within decision spaces as well. The control over technical expertise and information creates a situation in which these networked organizations, especially when working in transnational space, can leave local communities out of environmental decisions that impact their lives, thereby breaking down democratic processes. In an aptly titled book, Conservation is Our Government Now, West (2006) provides a vivid example of the ways in which conservation efforts transformed the power relationships and ways of life in local communities within Papua New Guinea. West argued, "Local historic subsistence practices were curtailed or were to be curtailed so that the local people, who through these practices were a threat to biodiversity, could engage in economic and subsistence practices sanctioned by conservation biologists and development practitioners as environmentally appropriate" (ibid., p. 35). The use of expertise to put the conservation of nature outside of and above human interactions of the lands seriously damaged the 
opportunities for a more public participation, as well as the resilience of these communities.

Additionally, Sievanen, Gruby, and Campbell (2013) look at the way that the Fijian marine protected areas put in to meet the needs of the Convention on Biological Diversity have slowly pushed the management practices of those areas from serving the local population to excluding them through standard practices. These authors demonstrate the ways in which expertise, bureaucratic frameworks, and universalizing standards set by transnational and global environmental organizations that work in and through governance networks can shift power away from local communities, and even democratic states, and into the hands of nonstate actors.

Within networks of environmental governance, organizations appeal to various types of authority and ways of knowing to legitimize their power position. The power, authority, and knowledge relations tend to organize in particular ways, each with their own facilitative and restrictive elements. Below I explore elements of traditional, bureaucratic, scientific, and practical power, authority, and knowledge relations (Table 2).

\section{Typology of Power, Authority, and Knowledge Relations}

Sovereign power is grounded in the authority of the state or those to whom the state delegates that authority. With the state-centric concentration of international relations, much of the focus in understanding decision-making and action has been on traditional authority, such as the sovereignty of the state 
(Krasner, 1999), juridical or disciplinary power (Foucault, 1980), or the appeal to delegated authority by intergovernmental actors (Jinnah, 2010). Under a traditional framework of power, authority, and knowledge, the state and those to whom the state has delegated power appeal to knowledges that produce and uphold the sovereign. However, in an era of networked governance relations, these knowledges are many times delegated to nonstate actors for their production. While sovereign power has potential advantages on issues of transparency, accountability, and legitimacy of environmental governance as it is open to democratic procedures in most Pacific Island states, current trends in both global governance (Biermann \& Pattberg, 2012) and decentralization into networks (Bodin \& Prell, 2011) are expected to limit the scope of sovereign power. This is not to say that states and those to whom states delegate authority do not have a premiere role to play in transnational environmental governance, but rather that governance trends are making space for other organizations to play key roles in environmental decision-making, such as bureaucratic, scientific, and functional relations.

Networked relations call to attention the multiple different types of authority that are employed by organizations in transnational environmental governance. In addition to sovereign power, bureaucratic power is found in rational-legal authority and the authority gained through control over technical expertise and information by organizations outside the state (Barnett \& Finnemore, 1999, 2004). This authority is "invested in legalities, procedures, and 
rules and thus rendered impersonal" through bureaucratization in the classification, fixing of meanings, and diffusion of norms (Barnett \& Finnemore, 1999, p. 707). While the process of creating procedures and seemingly depoliticizing decisions can streamline the broader governance process, access to bureaucratic authority and knowledge of legalities and procedures can be inaccessible to the broader public. Barnett and Finnemore argue, "The irony in ... these features of authority is that they make bureaucracies powerful precisely by creating the appearance of depoliticization" (1999, p. 708). In other words, as decisions are focused on the legalities, procedures, and rules of governance, deep political divisions are washed over or ignored. While streamlining some processes bureaucratic governance mechanisms can increase efficiency, there are tradeoffs as democratic access to these spaces of decision-making is limited.

Additionally, contestations over authority within environmental governance are intertwined with the scientific power gained through the control of legitimate knowledge, or expert authority. One of the primary divides within climate governance comes in the local and global strategies and knowledges and their struggles to be authoritative (Jasanoff \& Martello, 2004; Hulme, 2010). In this space, authoritative science (Bocking, 2004) meets the challenges of scaling knowledge to a global level by collapsing the nuance of local conditions. The objectivity of scientific procedure is used as a strategy to gain authority for decision-making, thus giving scientific knowledge, and those who employ it, the power to shape decision-making. While standardization and expert-driven 
knowledge creation can create significant innovations and technological successes, it has risks. Scientific information is costly, both in terms of finances and time resources, and can delegitimize other forms of knowledge (Agrawal, 2005; Bocking, 2004; Hulme, 2010; Jasanoff, 2005; Jasanoff \& Martello, 2004; Miller \& Edwards, 2001). As Porter reminds us, "the form of life epitomized by quantification depends on the art of forgetting" (1994, p. 396). Forgetting local and contextual knowledge can create governance that is ill-fitting for the nuances of the social and environmental system in which it is being employed. Therefore, expertise can provide key insight into environmental realities, but can be costprohibitive and be used to delegitimize other forms of knowledge for decisionmaking if not properly considered.

A final understanding of authority is found in the appeal to functional power through practical authority. Abers and Keck define practical authority as "a kind of power in which the capabilities to solve problems and recognition by others allows an actor to make decisions that others follow" (2013, p. 7). This authority is not based solely on delegation from the state, positionality, or on externally defined expertise. Instead, this authority is found in the capability to provide tangible recommendations that are borne out through practice. Cooper and Vargas (2004) take a similar approach when analyzing the implementation of sustainable development, focusing on feasibility requirements, such as technical and administrative capacity, legal frameworks, political acceptance, and more. Appeals to functional authority tend to shift away from authoritative science by 
appealing strongly to the contextual nature of knowledge production (Haraway, 1988; Lejano \& Ingram, 2009). Functional power through access to practical authority and local, contextual knowledge relies on governance that is entrusted to those who have shown themselves to be capable and knowledgeable.

However, gaining this type of authority is challenging on a transnational scale, as it is grounded in reputations, relationships, and experience with particular locales (Abers \& Keck, 2014). Building those foundational elements of functional power are challenging even at the local level, better yet when governance is concerned with environmental challenges crossing state borders. Finding ways to connect the local/global elements of power, authority, and knowledge, however, could provide insights into possibilities for environmental governance. 
Table 2: Chart of power/authority/knowledge relations.

\begin{tabular}{|c|c|c|c|c|}
\hline 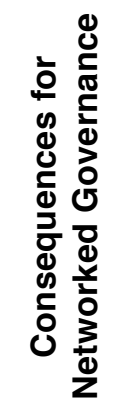 & 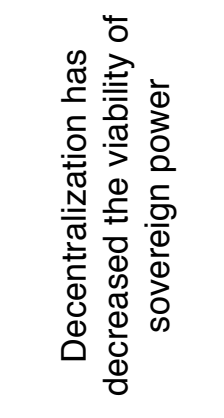 & 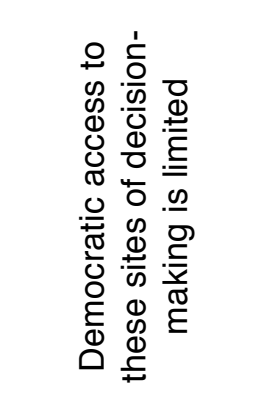 & 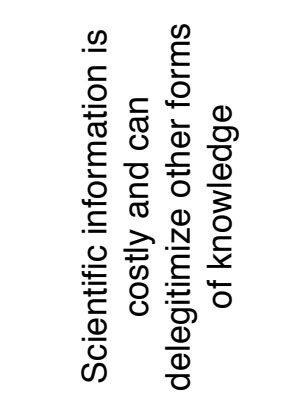 & 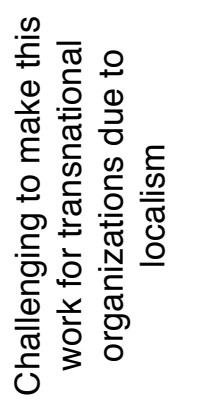 \\
\hline 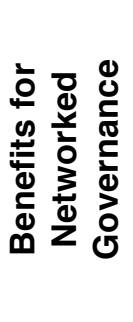 & 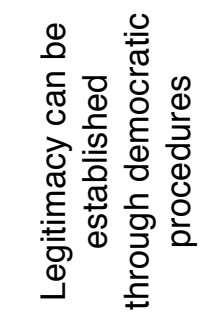 & 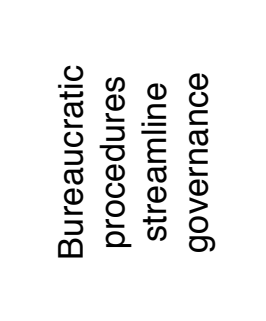 & 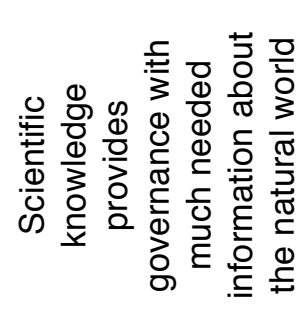 & 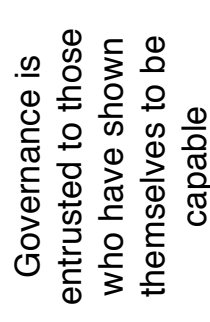 \\
\hline $\begin{array}{l}\text { g } \\
\text { og } \\
\frac{0}{d} \\
\frac{0}{3} \\
0 \\
\frac{1}{\Sigma}\end{array}$ & 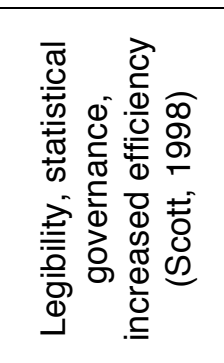 & 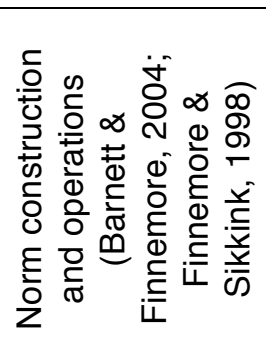 & 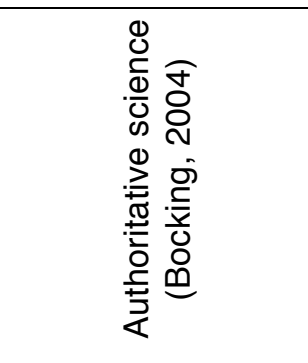 & 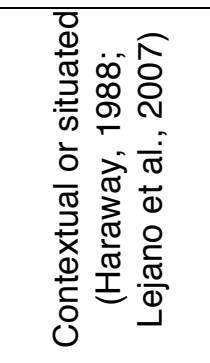 \\
\hline 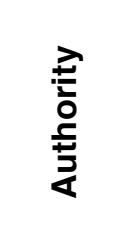 & 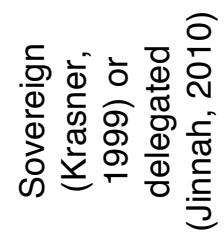 & 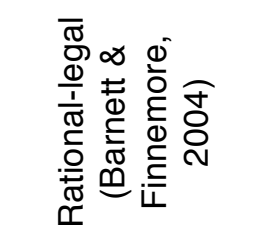 & 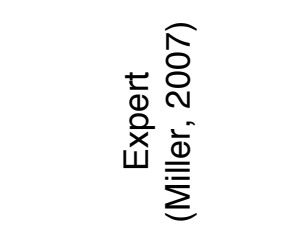 & 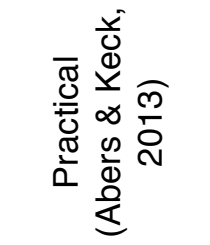 \\
\hline 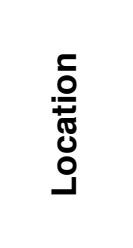 & 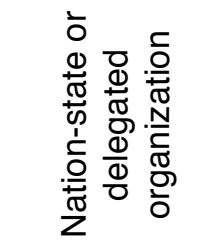 & 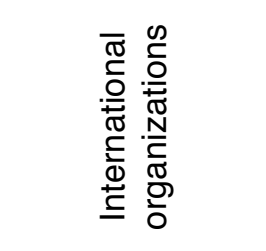 & 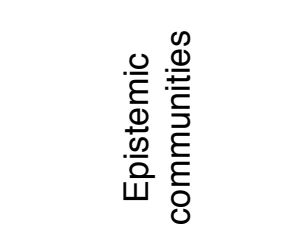 & 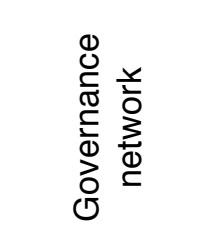 \\
\hline 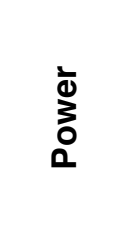 & 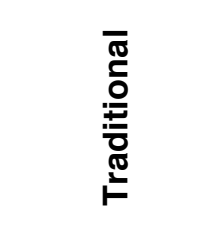 & 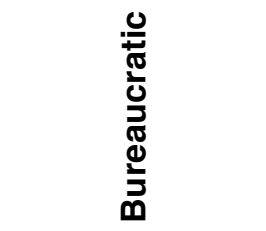 & 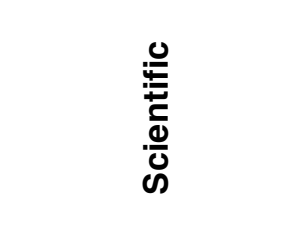 & 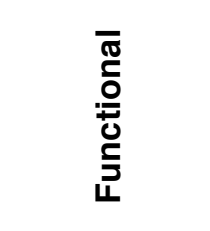 \\
\hline
\end{tabular}


These multiple appeals to authority and legitimizing knowledgestraditional, bureaucratic, scientific, and functional-can bring about consequences for governance. Using the Pacific Islands as a case study, I will further explore the interactions between power, authority, and knowledge in transnational environmental governance.

\section{Conclusion}

The role of transnational governance in mitigating the effects of climate change and environmental degradation is complex, fraught with contradictions, and yet vitally necessary in order to avoid both environmental and social catastrophe. States have traditionally been defined as the supreme legal authority over a territory; however, while states may still play central roles in decision-making and regulatory mechanisms, the territorially limited state is no longer sufficient to meet the growing need for governance across state borders. Transnational governance, then, has developed as an outgrowth of the inadequacy of the state in dealing with transnational problems.

Understanding governance in a multi-actor space, inclusive of the bureaucracies and secretariats of international organizations (Barnett \& Finnemore, 1999, 2004; Jinnah, 2010), knowledge-producing institutions (Miller, 2007; Miller \& Edwards, 2001), standard-setting institutions (Böstrom \& Hallström, 2010; Cashore, 2002), and others, requires an understanding of power, authority, and knowledge that is broad enough to include the various facets of governing that these organizations bring to the table. Thus, 
understanding power as productive, relational, and distributed throughout society through networks of discursive practices can bring to light the less visible elements of power.

Specifically, the authority of various power/knowledge complexes-such as authoritative science regimes - can create challenges between local and global ways of knowing the earth. This makes it vitally important to explore the ways in which power, authority, and knowledge are organized. These discussions set the stage for the investigation of climate change diplomacy and governance in the Pacific Islands undertaken in this dissertation. 


\section{Chapter 3: Narrative-Networks in Diplomatic Spaces}

\section{What I will tell my daughter}

They say there are no mountains

in the Marshalls - our island

that is so close

to an expiration date

But I will tell you there were mountains who were men giants who walked across the sea sounding the call for the world to hear our story.

-Kathy Jetñil-Kijiner, Marshallese Poet

\section{Introduction}

Transboundary environmental problems have been on the forefront of the agenda since the 1992 Earth Summit in Rio de Janeiro, where the UNFCCC was adopted. Parties to the convention have met yearly at the Conferences of the Parties [COP], which has led to the 1992 Kyoto Protocol, the 2010 Cancún agreements, and the 2012 Doha Amendment. These agreements have held varying degrees of weight in the international sphere, but none have shown a significant commitment to address the immediate and long-term impacts of climate change (Ivanova, 2016).

This chapter discusses the Pacific Islands' diplomatic efforts in the lead up to the 2015 Paris COP (otherwise known as COP21). COP21 produced the strongest climate change agreement thus far. As Ivanova describes it: 
[The Paris Agreement] meets the core criteria for effectiveness of an international treaty as outlined by scholars, researchers, and the UN Secretary-General: universal participation, significant emission reduction commitments, transparency and accountability, finance, and high compliance rates... The agreement is ambitious and universal; it possesses a binding, yet flexible legal nature, clear procedures for accountability, and a credible financial structure. (2016, p. 412) While still having room for improvement, ${ }^{8}$ the Paris Agreement represented a dramatic shift in the international commitment to reducing the causes and impacts of climate change. The ability to accomplish this agreement did not occur overnight, but rather was a product of a long history of contestation around transnational environmental governance. Whether through delineations among developed vs. developing countries, producers vs. consumers of climate challenges, the wealthy vs. the poor, negotiations around climate change have drawn a series of lines that define who should be "for" or "against" climate strategies, although these lines shift through time. One element of this process is the narrative utilized by individuals as they network with others.

The narrative of a network is the shared story it tells when working to shape and accomplish its goals - the heroes, villains, and victims, both human

${ }^{8}$ For instance, the Paris Agreement did not address compensation for loss and damages, actionable discussion of indigenous participation, or a call to end fossil fuel extraction, and also lacks sanctions for those who do not meet their goals. Also, the Trump administration has vowed to withdraw from the accord. 
and nonhuman, that form the basis of the larger fabula, or tale of the issue at hand (Lejano, Ingram, \& Ingram, 2013). Narrative does productive work within the process of governance in a variety of ways -it determines the goals and problems to be solved, identifies tools to solve the problem, distributes the benefits and burdens of policy and implementation, creates rules for inclusion and exclusion, and generates rationales that legitimate these choices (McBeth, Jones, \& Shanahan, 2014). In other words, narrative not only limits what is possible within governance, it also works to create the possible. Identifying the role of narrative provides key insights into the ways in which networks emerge and establish their authority for governance. As networks work across local/global divides, the power of narrative is both a strategy of negotiation in this multi-scalar space and a product of this negotiation. In other words, narrative is used to bolster the authority of networks of organizations as organizations transform the narrative to meet their own ends, and is also a durable product of that negotiation that has been institutionalized into dominant discourses. Therefore, it is informative to study the way in which various actors are employing narratives, as well as how those narratives came to be.

During the COP21 climate change negotiation preparation, two dominant narratives were employed in the Pacific Islands that distinguished two network constructions for negotiation stances. Using a narrative-network approach (Lejano, Ingram, \& Ingram, 2013), this chapter will further explore what I call the global technical narrative employed by many regional intergovernmental 
organizations that manifested in the Pacific Islands Forum [PIF] Summit's Pacific Islands Forum Leaders Declaration on Climate Change, alongside the local power narrative employed by local NGOs during the writing of the Pacific Island Development Forum [PIDF] Summit's Suva Declaration on Climate Change. Through this chapter, I will consider the way in which international climate networks are emerging and establishing authority in transnational environmental governance. I will then look to the way that, as organizations network around environmental issues, struggles over local and global knowledges work through the narrative used by these networks. Finally, I will consider the implications of these narrative-networks for climate change governance in the Pacific Islands and in future diplomatic efforts.

\section{Scientific Authority in Multi-Scalar Space}

Contestations over authority within environmental governance are intertwined with what is considered legitimate knowledge. One of the primary divides within climate governance comes in the local and global strategies and knowledges and their struggles to be authoritative (Jasanoff \& Martello, 2004; Hulme, 2010). Global knowledges tend to emulate what Bocking (2004) refers to as authoritative science-knowledge gained through procedures that are unanimous, quantitative, generalized, and conducted according to scientific process. This type of knowledge meets the challenges of scaling knowledge to a global level by collapsing the nuance of local conditions. The objectivity of scientific procedure is used as a strategy to gain authority for decision-making, 
thus giving scientific knowledge, and those who employ it, the power to shape decision-making. As Turnhout, Dewulf, and Hulme describe it, "Knowledge and power embrace tightly as globalized knowledge conditions the political imaginary of global environmental governance and vice versa: how one knows constrains how one governs and how one governs shapes what one needs to know" (2016, no page). In other words, the use of global, objective, authoritative science can shape what is perceived as possible within transnational environmental governance.

This type of global scientific knowledge plays a vitally important role in the governance of the climate due to the nature of global atmospheric change. By appealing to authoritative science, however, transnational environmental networks can leave local communities out of environmental decisions that impact their lives, thereby breaking down democratic processes. As Hulme describes it, this type of science makes 'global kinds of knowledge,' or 'knowledge which erases geographical and cultural difference and in which scale collapses to the global" (2010, p. 559). He gives the example of the way in which the $2^{\circ} \mathrm{C}$ [Celsius] limit on global warming has been used by the IPCC to stabilize normative goals around the climate and delimit the storyline on which the public's imagination must be built. He argues that this globalizing knowledge may damage local communities as they seek to write their own narratives and pursue their own futures. 
With these challenges presented by global, objective, authoritative science in transnational environmental governance, many environmental governance scholars are exploring the authority of local, practical, contextual knowledge. Bocking argues, "tacit prescriptive commitments embedded in scientific knowledge, especially relating to controlling and transforming nature, may fit poorly with local attitudes that emphasize adaptation and coexistence" (2004, p. 28). In this way, Bocking argues that authoritative science can be used in efforts to reform nature that may be in contrast to the adaptive and coproduced values of local communities in regards to nature. Instead, Lejano, Ingram, Whiteley, Torres, and Agduma (2007) provide an argument for how particular environmental governance efforts may need to undergo contextualization in order to have institutional coherence with the everyday patterns and practices of localities. In other words, governance is to be adaptive to both the environmental and social contexts in which it is being embedded. However, in climate change governance, this local knowledge must compete for legitimacy with global ways of knowing. This struggle over the authority of knowledge in local and global space is played out in the narrative employed by networks of environmental organizations.

\section{Narrative-Networks}

Authority within the network can be created and bolstered through the use of narrative strategies, such as is found in advocating the use of global scientific knowledge production and the need for local input. Struggles between the 
authorities of global and local knowledge production play themselves out through narrative-networks. Previous discussions of networks have focused primarily on evidence of interactions between actors, but how those interactions shaped the actors in the network and how actors shape interactions in the network have been left "black boxed" in much of the literature. Instead, narrative-networks, as discussed by Lejano, Ingram, and Ingram (2013) form as actors write themselves into the larger story of the environmental issue. In a narrative-network, network actors and network narratives are mutually constituted. In other words, a narrative-network is created by the common use of a narrative by actors in the network, and the narrative-network is made possible by the existence of a community that fosters the narrative. This allows for narrative-networks to be understood as produced by both the actors and the narrative.

In the analysis of policy, narrative is the basic underlying storyline on which the legitimation of decision-making relies. Policy narratives incorporate identity, trust, and alterity - or the creation of the "other" that the network must be working against. The use of characterization-heroes, villains, and victims, both human and nonhuman-lends itself to an "us" and "them" that works to strengthen organizational ties to the network. It also prescribes policy morals, where 'solutions' are given to the problems at hand based on who is considered the hero, villain, and victim. Additionally, gaps in the conventional narrative are employed by some narrative-networks to offer alternatives to the dominant network. This allows narrative-networks to bridge, integrate, translate, and 
generate knowledge across various sources and value perspectives, while also allowing for their own narrative to be employed. While nonhumans' roles in the network are also important to understanding the narrative-network, this chapter will focus on the human elements of the network.

Evaluating emergent climate networks as narrative-networks can provide opportunities to trace their narratives throughout the policy process. As they work to impact diplomacy at a transnational level, the narratives of various networks struggle to be represented. Looking to the impact of networks' use of heroes, victims, and villains on transnational policies, one can see where voices were heard, and where they were underrepresented. In the case of the Pacific Islands, these struggles are playing out as local and global voices are being made the hero or villainized to meet particular ends.

\section{Narrative-Networks in the Pacific Islands}

In order to combat the growing threat of environmental degradation, transnational environmental diplomatic networks are emerging that include the Pacific Island nations, regional intergovernmental organizations, civil society, private sector participants, and states that are external to the region (Corlew, Keener, Finucane, Brewington, \& Nunn-Crichton, 2015; Gruby \& Campbell, 2013; Pietri, Stevenson, \& Christie, 2015). These networks struggle between the 'global kinds of knowledge' (Hulme, 2010) created by agencies in the region and local, contextual knowledge (Lejano, Ingram, Whiteley, Torres, \& Agduma, 2007) that is a large part of climate change adaptation and mitigation. Battles over climate 
change negotiation stances, the use of traditional knowledges and methodologies, and the inclusion or exclusion of particular voices have caused networks in the region to work to establish their own narrative strategies for authority.

Particularly when it comes to climate change diplomacy, dominant scientific narratives have worked to set the parameters of decision-making under a "problem closure," which Hajer (1995) defines as the process of creating solutions to a set of unquestioned, well-developed problems. Thus, narrative constructions of the challenges presented by climate change-including the scientific models, classifications, and regulations-impact climate change diplomacy and governance within the Pacific Islands by producing problem closure. Even as scientific narrative constructions have gained dominance within transnational climate diplomacy in the region, networks of organizations that favor local constructions of knowledge are resisting the narrative hegemony of this problem closure. While Govan (2009) and Sievanen, Gruby, and Campbell (2013) have demonstrated the ways in which local knowledge construction can bolster the impacts of governance in the region, more should be done to explore these narrative-networks of global/local knowledge and governance within the Pacific Islands. This chapter seeks to investigate these narrative-networks as they manifested in climate change diplomacy surrounding the 2015 PIF and PIDF Summits leading up to the COP21. 


\section{Pacific Islands Climate Change Diplomacy}

The Pacific Islands - through governments, intergovernmental organizations, or civil society organizations -were some of the most highly vocal proponents of a climate change mitigation agreement at COP21 (Carter, 2015). At the United Nations Third Small Islands Developing States Conference in 2014, Enele Sopoaga, Prime Minister of Tuvalu, stated "Pacific negotiators need to be in sync at the UNFCCC"; Tony de Brum, Minister of Foreign Affairs of Marshall Islands, asserted that "there has been a failure of traditional diplomacy at the UN ... we need a new brand of diplomacy ... one voice diplomacy"; and President Anote Tong of Kiribati argued "we need to establish alliances that are nontraditional, that serve our best interest” (as cited in Carter, 2015). Efforts to speak with one voice were also evident through the 3rd Annual PIDF Summit, with civil society and government leaders emphasizing the "one family" of the Pacific Islands, stating "our lives and our destinies are intertwined," and encouraging one another to be "singing together the same song." These pledges of collaboration ran throughout the meeting. However, even with these longstanding efforts to speak with one voice, the multiple climate change declarations that came out of the Pacific during the final months leading up to COP21 showed important differences. This chapter further explores the opportunities and challenges for narrative-networks in climate change diplomacy efforts in the Pacific Islands. 


\section{Materials and Methods}

While the Pacific Islands have a diverse and comprehensive network of state and nonstate actors (as is demonstrated in the next chapter of this dissertation), this chapter focuses on this simplified network of transnational organizations that participated in the PIF and PIDF Summits to demonstrate the differentiation of narrative within climate change negotiation stances. In order to gain information on the process of transnational environmental diplomacy in the Pacific Islands, I conducted interviews with 22 key regional players (interview guide in Appendix A); attended 3rd Annual PIDF Summit, 1-4 September, 2015, that was attended by delegates from 15 of the Pacific Islands including heads of state; and collected grey papers and other archival data on regional environmental work in the Pacific in both Apia, Samoa, and Suva, Fiji. I then compared the interviews to participation in the PIF and PIDF Summits, and to their respective outcomes in the form of declarations. Participation in the PIF and PIDF Summits was visualized using a basic qualitative network for further clarity. The methods are further described below.

\section{Thematic and Narrative Analysis of Interviews}

For the analysis of the interviews, I used thematic analysis (Braun \& Clarke, 2012). This type of analysis uses six steps: (1) becoming familiar with the data, (2) generating initial codes, (3) searching for themes, (4) reviewing themes, (5) defining and naming themes, and (6) producing the report. I began by organizing the data around themes generally following the topics of power, 
authority, and knowledge that run throughout this dissertation, then working toward more specific thematic areas. These included agenda-setting, capacity opportunities and challenges, knowledge use, and collaboration strategies. There was a notable distinction between the language used by organizations in two groups, which aligned closely with the participation in the PIF and PIDF Summits. In order to further analyze this division, I then organized the interview responses based on participation in the PIF and PIDF Summits. For interviewees that were part of organizations that attended both summits, their interviews were associated with the summit for which their organization's participation was weighted more heavily. For instance, a CROP agency that participated in both summits would be associated with the PIF summit due to their heightened role in that network. No state leader was interviewed for this study; however, statements made by state leaders at the PIDF Summit were included in the PIDF network, as their statements were associated with that event. As the interviews were conducted under the assurance of anonymity, all individual and organizational identifiers have been removed. Those statements made at the PIDF Summit, as they were made in a public forum, may be attributed to their speaker.

The findings from the thematic analysis were then compared to the wording seen in the Summit Declarations - the Pacific Islands Forum Leaders Declaration on Climate Change Action and the Suva Declaration on Climate Change-and found to have distinct similarities. While the thematic analysis highlighted the differences between the two groups and their respective 
declarations in regards to perceptions of power, authority, and knowledge, their differences remained rather vague. Narrative analysis, particularly through characterization-or the act of determining the hero, victim, and villain-brought clarity to these differences. Successful characterization, according to Lejano, Ingram, and Ingram (2013) involves simultaneous individuation and categorization, where the character is both uniquely believable and archetypically recognizable. Thus, while the characterization presented in this chapter is organized categorically, the actual language used by participants included individual nuance that is not fully captured in this type of analysis. In other words, each participant brought their own unique perspectives to the overall story told by the narrative-networks. It should be noted here that, although I borrow heavily from Lejano, Ingram, and Ingram's (2013) work, this analysis does not deal with the depth of their nuance with narrative-networks. Future work would benefit from a more complete use of their framework.

\section{Network Visualization}

For the qualitative visualization of the network in the Pacific Islands, I used a simple affiliation network of attendance at the PIF Summit and the PIDF Summit in the months leading up to the COP21 negotiations in Paris in December 2015. I accomplished this using what is known as a bipartite network, where the organizations are connected to the event that they attended and not to each other (Wasserman \& Faust, 1994). This can make it clear which organizations participated in only one summit or both summits. The level of 
participation in the summit was also weighted to demonstrate the level of impact an organization could be expected to have on the summit. This is described below.

Participation was weighted using a classification system generated by PIF and PIDF. For PIF, the independent and self-governing states of the Pacific Islands, along with Australia and New Zealand, held central positions in the Summit, along with the CROP agencies, of which PIF is the political head. Thus, these states' and agencies' tie to the PIF Summit received a weighting of 3 for their central role in decision- making. The territory and collectivities in attendance-French Polynesia, New Caledonia, and Tokelau-are described as "associate members" due to their secondary involvement, and thus their tie to the PIF Summit is given a 2 weighting. A number of intergovernmental organizations and Timor-Leste are listed as "observers" for their background involvement in the Summit, and thus their tie to the PIF Summit receives a 1 weighting. This is reflected in the weight, or thickness, of the lines associated with these actors' connection to the PIF Summit node.

For the PIDF Summit, all Pacific Island states that were in attendance and involved in discussions around the Suva Declaration on Climate change received a 3 weighting for their tie to the PIDF Summit. Organizations that have signed memoranda of understanding of cooperation with PIDF-the Secretariat for the Pacific Community, the Melanesian Spearhead Group Secretariat, the University of the South Pacific, the International Union for Conservation of Nature, and the 
World Wide Fund for Nature-received a 2 weighting for their tie to the PIDF Summit due to their heightened engagement in decision-making in the summit. Other nonprofits and non-Pacific Island states in attendance were given a 1 weighting for their tie to the PIDF Summit. Attendance and level of participation of state and nonstate actors in each of these summits is represented below (Fig. 2). 
Figure 2: Network of attendance at the PIF Summit and PIDF Summit.

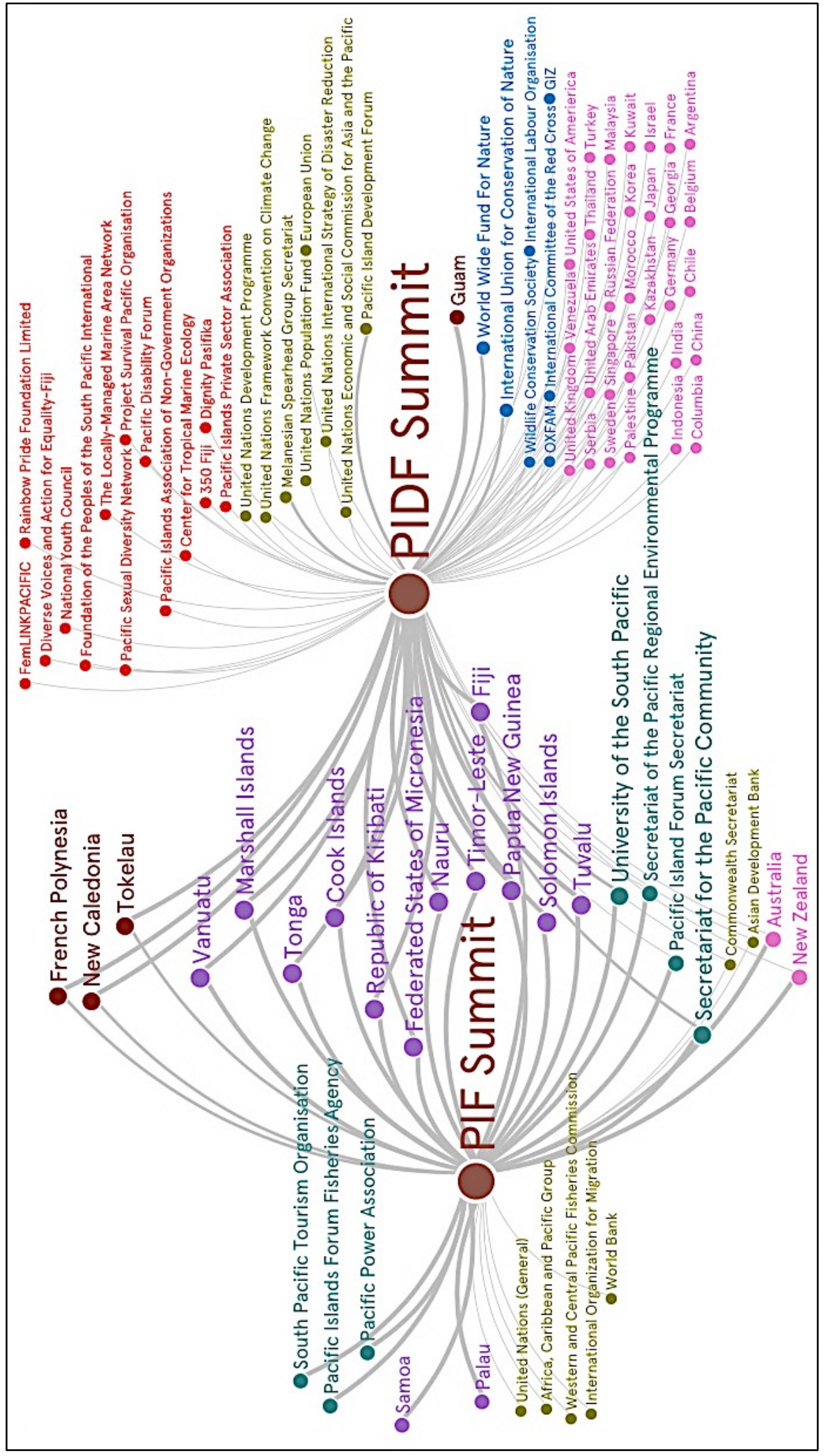


Organization Key:

Pacific Island States

CROP Agencies

Local NGOs
Intergovernmental Organizations International Organizations Non-Pacific Island States

Pacific Island Territories and Collectivities

Looking at the attendance and participation in the PIF Summit, decisionmaking was limited to governments and to CROP agencies, with some other international organizations in attendance. Also of note is the strength of participation of Australia and New Zealand-who are considered core members - as well as the lower levels of participation among French Polynesia, New Caledonia, and Tokelau - who are only associate members due to their status as territories and collectivities. The PIDF Summit, in contrast, included representatives from 14 domestic NGOs and 7 international NGOs alongside numerous governmental and intergovernmental organization representatives. Private citizens and university personnel from the Pacific Islands also played key roles in deliberations. While these organizations did not have a vote on the final declaration, their participation was largely considered in transforming the PIDF Summit's final declaration. Australia and New Zealand were in attendance, but not given membership in PIDF, whereas French Polynesia, New Caledonia, and Tokelau were given full membership.

The next sections will explore this cross-section of the narrative-networks in the Pacific Islands in more detail, paying particular attention to the characterization used by the two networks. While, again, this network is a 
simplified representation of much larger networks of organizations surrounding transnational environmental diplomacy in the Pacific Islands, participation in the PIF and PIDF Summits is a useful differentiation for exploring the divergence of narrative-networks in the Pacific Islands surrounding climate change strategies.

\section{Pacific Island Forum Summit Narrative}

Based on interviews and analysis of archival data, those in leadership positions at the PIF Summit follow what I refer to as a global technical narrative. These regional environmental organizations discuss the limited funding, projectbased management, and high levels of bureaucracy in transnational governance. In this narrative, the Pacific Island states are the victim of environmental or social disaster, and are primarily powerless without the aid of colonial powers. Lack of capacity, resources, and scientific information play the villain, causing efforts to achieve sustainability-environmental, social, and economic-to fail. Regional environmental organizations are thus poised to write themselves in as the hero, where better science, more resources, and standardized procedural mechanisms are necessary to overcome capacity deficits. This creates a policy moral, or policy-driven solution, that pushes for greater regional functionality in the form of increased resources, greater access to information, and greater decision-making capability in the hands of the regional environmental organizations.

Through this narrative, the regional organizations privilege global kinds of knowledge (Hulme, 2010) and authoritative science (Bocking, 2004). Multiple individuals working in the major regional organizations with whom I spoke 
emphasized their role in controlling knowledge within the network. They discussed their efforts to "manag[e] the flow of information," "interpret proposals," act as "gatekeepers" and a "clearinghouse for information," in order to ensure "quality control of information." One of the participants in the PIF Summit stated during an interview:

It's that informal authority with the countries, because we have no authority at all. They have authority over us, but we have a lot of informal authority over them. And respect because we hold so much expertise. And we're a pathway to other sources of help, funding, and success.

The control over authoritative science and resources is seen as giving regional organizations their authority to hold some power over states. These regional organizations, particularly those involved in climate governance (SPC, SPREP, USP, and PIFs) can thus be described as boundary organizations (Cash et al., 2006), or organizations that mediate and facilitate the coproduction of knowledge. As one interviewee stated:

I think one of the challenges, though, with opening up all of these alliances and stakeholder consultation groups is that you still need to have some quality control of information. So, if you open up these things, and you open up the door, and you just accept information, there is a risk that that information is wrong. And that's where I think really the role of the CROP agencies as the regional technical experts have a role in scrutinizing information, too. To say, "well, this advice came from stakeholders, and 
it's great to get different views, but actually these are maybe some points of clarification." Because that open door can bring in some interesting ideas. \#laughs\# ... It's just a risk, but I think it's a manageable risk within our regional architecture. And that's really what the role of the CROP agencies are selected to be. These are the technical advisory bodies for the region.

They act as scientific authorities, judging the legitimacy of funding proposals and managing the quality and flow of information. Their role as boundary organizations is also tied to the role of colonial states as external funders. Due to their perceived low levels of capacity, they rely on colonial states for resources and in turn provide a space for them in decision-making.

While these boundary organizations can serve important efficiency functions within regional environmental diplomacy and governance, these can also serve to stifle, delegitimize, and displace certain forms of knowledge (Lejano \& Ingram, 2009), including the local practical knowledge of populations who actively use environmental goods in the Pacific Islands. These regional boundary organizations make these decisions about inclusion and exclusion through nontransparent processes, such as the selection of particular sciences for management strategies, the recommendations made to decision makers, and the streamlining of funders to approved scientific endeavors. One interviewee described the limitations of local knowledge as, "people know all the high-level jargon, but understanding the basic underlying issues is a challenge ... there are 
serious knowledge gaps." In order to mitigate for these perceived limitations, interviewees from regional organizations discussed how they would 'steer' funders toward proposals that use "replicable data." These decisions are typically not open to democratic accountability measures, and the decisions may not be representative of the needs and desires of local populations. This is not to say that other forms of knowledge, such as indigenous or practical understandings of the natural world, are left unconsidered, nor that these proposals with replicable data are necessarily in conflict with these ways of knowing. However, the participants from regional organizations in the Pacific Islands emphasized the challenges in capturing, recording, and scaling these knowledge sources, and, at times, used these justifications to exclude alternative conceptions of the world from many of their final decisions.

At the 2015 PIF Leaders' Meeting, the Pacific Islands Forum Leaders Declaration on Climate Change Action was created through deliberations among Pacific Island leaders, regional organization leaders, and leaders of colonial powers. Table 3 shows a selection of the demands made in the PIF declaration. Those phrases that highlight the global technical narrative are in bold. 
Table 3: Narrative analysis of the Pacific Islands Forum Leaders Declaration on Climate Change Action.

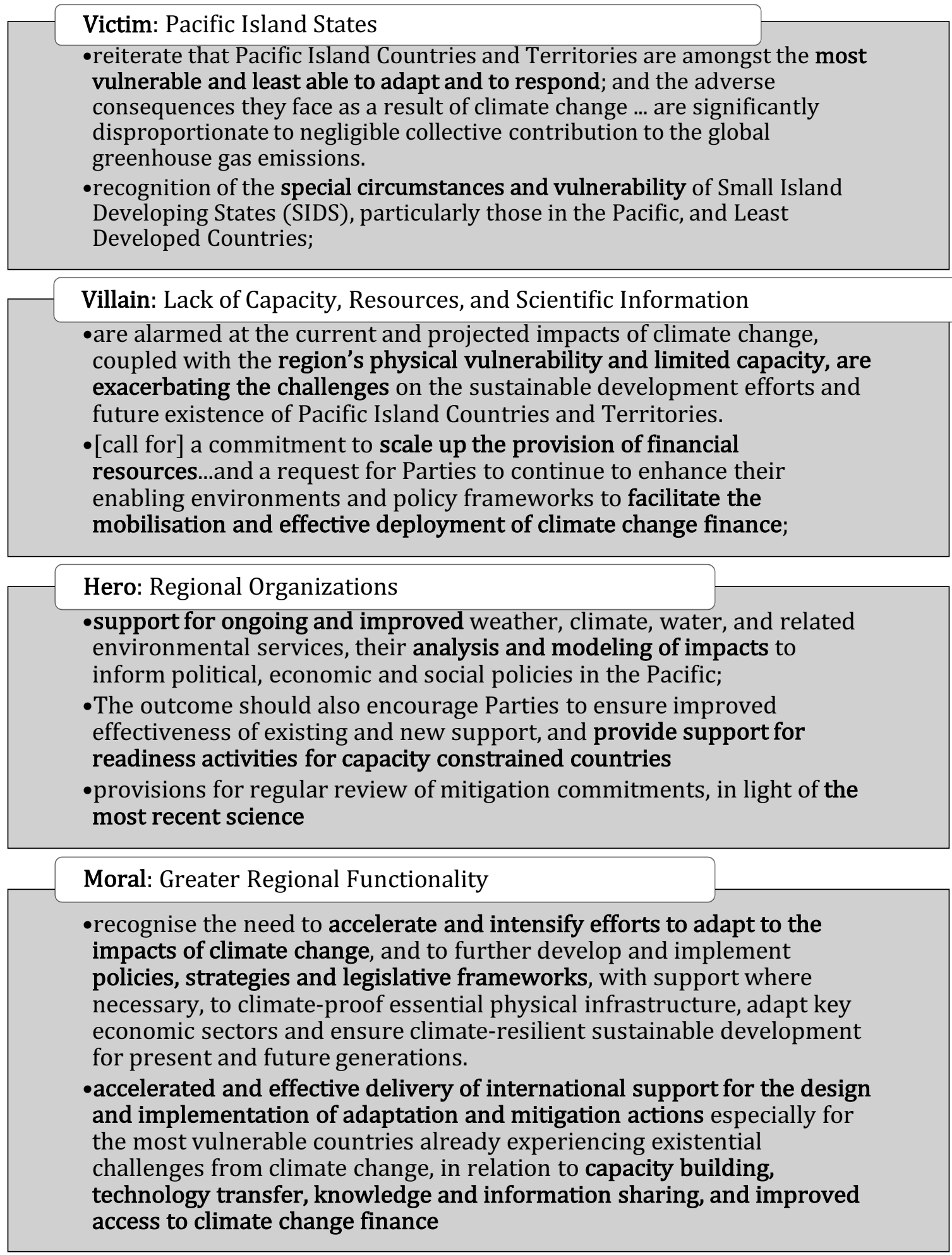


The PIF Summit declaration focused heavily on the global technical narrative reflected in interview statements and archives. The vulnerability of the Pacific Islands was emphasized, establishing their victimhood to the villain of low governance capacity and environmental instability. While the PIF narrativenetwork would acknowledge that prominent greenhouse gas emitters case the environmental instability, systemic issues are downplayed in this declaration. The regional organizations underscored their role as the hero in this narrative by providing authoritative science to inform decision-making. The policy moral, then, demands that regional organizations increase their functionality to accelerate and intensify effective adaptation and mitigation actions through technology, science, and finance. Through this, the global technical narrative that privileges the global over the local is reflected in the PIF Declaration on Climate Action.

While not as heavily emphasized, it is important to note that impacts on marginalized populations were also considered. The PIF Summit declaration discussed the "recognition of the disproportionate impact of climate change on women, youth, the elderly, disabled, indigenous peoples and other vulnerable and marginalised groups" and the "acknowledgment of the crucial role women will play in a global solution to climate change." However, the PIF Declaration on Climate Action focused primarily on increased capacity for scientific knowledge and governance, along with heightened functionality of regional organizations. This is in contrast to the PIDF Summit narrative. 


\section{Pacific Islands Development Forum Summit Narrative}

Those organizations that are highly involved in the PIDF network employ what I refer to as a local power narrative, or a storyline that puts local communities at the forefront of decision-making on climate activities. In this narrative, Pacific Island states are the victims of environmental and social disaster-similar to other regional organizations' narrative-and yet they have the power to adapt both their environmental and social strategies to achieve change. They see colonial powers, through funding and positions of power in other regional environmental organizations' decision-making structures, as being just as much the villain as their environmental vulnerability, due to colonial powers' ability to take the decision-making authority out of the hands of Pacific Island peoples. Instead, the local power narrative advocates for the Pacific Island peoples' engagement in their own decision-making to act as the hero. This left the participants of the PIDF Summit with a policy moral of local inclusion in decision-making and governance. This establishes a process for the Pacific Island peoples to regain power in determining their own environmental futures. This is not to say that the PIDF Summit narrative dismisses the role of global decision-making around climate change, such as would be present at COP21. Rather, it calls for more voices to take part in the on-the-ground decision-making that would empower local communities to take part in their own climate futures.

Through this narrative, interviewees and PIDF participants were interested in highlighting their own power. They emphasized the importance of shifting 
perceptions of their status from "Small Island States" to "Large Ocean States," discussing the "hammer" of regulation that they could bring down on illegal fishing and poor use of their ocean's Exclusive Economic Zones. They desired to be "subjects, not objects" of climate change discussions, and resisted being "regulated to the sidelines," as they felt they had been in previous decisionmaking experiences. As the Republic of the Marshall Islands Foreign Minister Tony de Brum stated:

This year has been an apocalyptic year for the Pacific, and climate change is the culprit. From Nangka to Dolphin to Maysak, our region is starting to feel like a war zone. People have died, homes have been destroyed, and economies left in ruins. But while our boat has been rocked, our resolve to weather the storm and turn the tide has grown stronger. As I have said before, while some like to dismiss us as small island nations, we are in fact large ocean nations. ... The world must know that the Pacific Islands are leaders, and not simply bystanders to the unsustainable path the world is currently headed on. Too often we let our big brothers in the Pacific family dictate our policies to us, rather than seeking to engage them in a discussion about what really matters to our shared region. Sometimes we need to be frank and fearless in telling them that enough is enough: you are talking about our survival here in a way you would not tolerate others doing to you. If Australia and New Zealand genuinely want to be considered Pacific powers then this means not only projecting their 
presence, but protecting ours. This must not be a debate over semanticsit is a debate for regional security and for our survival. This type of powerful language was used throughout the PIDF Summit, and in discussions with those who were highly involved in the PIDF Summit network.

PIDF's Suva Declaration on Climate Change, in contrast to the PIF declaration, was created through an open, participatory process. During the PIDF Summit prior to COP21, political contestation took place among states, nonstate actors, and private individuals to position the Pacific Islands on a variety of climate change issues. Not only was the strength of language debated-legally binding mandates and deep-decarbonization tactics-but also the level of representation the declaration exhibited was discussed. Civil society organizations representing youth, women, and more were given space to express their voices directly to Pacific Island leaders, and were able to advise on how the Pacific Islands should be positioned in upcoming COP21 negotiations. There was not total agreement about what should hold primary importance, allowing stances to be negotiated and discussed (otherwise known as plurivocity in the network; Lejano, Ingram, \& Ingram, 2013). The goal of the PIDF Summit was described as "providing the space to provide our voices to provide a collaborative solution." Table 4 shows a selection of the demands made in the PIDF declaration. In bold are the phrases that demonstrate the commitment to the local power narrative of the PIDF narrative-network. 
Table 4: Narrative analysis of PIDF's Suva Declaration on Climate Change.

Victim: Pacific Islands

-See and suffer from the adverse impacts of climate change, including but not limited to [list of environmental impacts], with scientific evidence clearly informing us these impacts will further intensify over time;

Villain: Ecological Vulnerability

-Are gravely distressed that climate change poses irreversible loss and damage to our people, societies, livelihoods, and natural environments; creating existential threats to our very survival and other violations of human rights to entire Pacific Small Island Developing States;

-Highlight that irreversible loss and damage caused by climate change goes beyond adaptation and is already a reality for PSIDS if there is inadequate mitigation action, and that climate change is already resulting in forced displacement of island populations and the loss of land and territorial integrity and further highlight that such loss and damage results in breaches of social and economic rights;

Hero: Pacific Island Peoples

-a new global dialogue on the implementation of an international moratorium on the development and expansion of fossil fuel extracting industries, particularly the construction of new coal mines, as an urgent step towards decarbonising the global economy;

-the development of Pacific based research and technology capacity as an essential foundation for innovation in our response to climate change;

Moral: Local Inclusion in Decision-Making

- Recognize that addressing gender based inequality and discrimination is essential for effective

-action on climate change

- Recognize the importance of engaging, as equal partners, civil society, women, youth and persons with disabilities, in all efforts towards building climate change resilience;

- capacity building on formal and non-formal education, knowledge management, with a particular emphasis on national languages and communication of climate change;

-support to enable the greater involvement of community, civil society (including women, youth and persons with disabilities) and the private sector, in our climate change responses and initiatives. 
The PIDF's Suva Declaration on Climate Change reflects the local power narrative, or the desire to put decision-making about local climate actions into the hands of local communities. While this narrative agrees that the Pacific Islands is the victim of environmental disaster, they are not painted as a powerless, vulnerable victim. In this narrative, the Pacific Islands are set in place to begin 'a new global dialog' that focuses on deep-decarbonization of the global economy and positions the Pacific Islands to be a leader in environmental innovation. This highlights the power of Pacific Island nations to make a change in their own climate futures. While this narrative also features the need for technological innovation and scientific knowledge, the focus is on these innovations coming from the Pacific, itself. Additionally, local voices are discussed as vital to climate governance, with a focus on equality of partnership of nonstate actors through making climate governance legible to local communities. This is made possible through making knowledge accessible via both formal and non-formal education, language translation, and others. In other words, the goal is not a central, authoritative science standing alone, but rather a distributed, contextual knowledge that can be bolstered through inclusion of local communities.

Returning again to Lejano, Ingram, and Ingram (2013) analysis of narrative-networks, the narrative in the PIDF Suva Declaration on Climate Change is attempting to bridge, integrate, translate, and generate knowledge to fill in the gaps of the dominant global technical knowledge narrative with discussions of local power. PIDF participants consistently discussed the break 
from colonial powers seeking to control their climate change agenda (otherwise known as alterity in the network, where actors present an alternative to the dominant narrative; Lejano, Ingram, \& Ingram, 2013). Fijian Prime Minister Bainimarama ${ }^{9}$ stated at the beginning of the PIDF Summit, "It is time for Australia to stop trying to undermine PIDF by urging regional leaders not to attend...Step back from the table and allow us to make our own decisions." Others rejected the "interference from outsiders" and "undue influences" of colonial powers, and decried the "ambition gap" exhibited by climate emitters such as the US, Australia, and New Zealand in not doing enough to save them from the effects of climate change. PIDF is thus poised to increase the level of inclusion of voices in climate governance in the Pacific Islands, as well as to incorporate a range of knowledge that includes local, contextual knowledge. This is not to deny the need for broader knowledge about climate issues, as scientific evidence and formal education is also valued, but rather to make space for gaps in the conventional narrative to be filled by local voices.

\section{Narrative Comparisons of PIF and PIDF Summit Declarations}

The contrast between the effects of the global technical narrative and the local power narrative is evident in both the participation of actors in decisionmaking in these summits, as well as the final statements of these documents. While the PIF Summit did not focus on the inclusion of nonstate actors in climate

\footnotetext{
${ }^{9}$ As discussed in Chapter 1, Prime Minister Bainimarama was installed following a 2006 military coup.
} 
governance, the PIDF Summit emphasized the equal partnership and high levels of involvement that marginalized groups should have in the climate governance process. Additionally, the PIDF declaration speaks of "violations of human rights" and "inequality and discrimination," terms that hold a much stronger connotation than the claim of the "disproportionate impact" on the Pacific Islands seen in PIF's declaration. By discussing human rights, inequality, and discrimination, those engaged with the PIDF declaration were able to connect the disproportionate impacts of climate change to larger, systemic challenges faced by marginalized populations. While interviews with PIF also brought up the villainization of the states that are sizeable greenhouse gas emitters, this was less evident in their final declaration, potentially due to the role of Australia and New Zealand in their negotiations. Finally, the discussion of "non-formal education" and the use of "national languages" in the PIDF declaration shows that civil society was active in working to ensure that these decision-making processes were open to all-a sentiment not carried by PIF's call for "capacity building, technology transfer, knowledge and information sharing, and improved access to climate change finance," that is indicative of the strength of the global technical narrative.

While these are relatively subtle differences, they have powerful implications for future environmental governance. PIF's declaration leaves the power for decision-making primarily in the hands of governmental and scientific elites within the region. Alternatively, by engaging civil society as equal partners 
in the battle against systemic challenges through the use of accessible information, the local power narrative of the PIDF declaration brings the authority for decision-making into the hands of Pacific Island peoples. The local power narrative is thus more capable of meeting the democratic needs for representation and accountability, while the global technocratic narrative employed by PIF and other regional environmental organizations is less capable of meeting these needs.

Interestingly, Pacific Island states utilize the narrative of both of these networks in the process of navigating transnational decision-making space. States employ their status as network bridges to strategically employ these narratives to meet their own ends. Again, while discussions of unity and family among Pacific Island nations was evident in the COP21 negotiations, this emphasis on unity can hide deep disagreements about climate change negotiation stances, the use of scientific or traditional knowledges and methodologies, and the role of particular voices, including civil society and colonial powers like Australia and New Zealand. The emergence of the PIDF Summit network demonstrates attempts by state and nonstate actors to provide a space by which to contest the dominant global technocratic narrative of PIF, colonial powers, and other regional intergovernmental organizations with their own local power narrative. However, the details of states' navigation of multiple narrative-networks in this case leaves more to be explored at a future date. 


\section{Implications for Climate Governance}

The narratives of the networks surrounding the PIF and PIDF Summits draw attention to the global and local dimensions of knowledge production and decision-making surrounding climate change. Struggles in the Pacific Islands within climate change diplomacy reflect larger questions about the role of states in shaping their own futures, especially as many of these states are reliant on traditional donor partners (external states) for project funding. Additionally, contestation between narrative-networks in the Pacific Islands is evident in the struggles over the authority to "know" the Pacific. The procedural closure of environmental decision-making through adherence to objectivity and generalizability can leave much of the political process to the side. The global technical narrative presents scientific research as benignly objective and correct, thus ignoring the situatedness and power inherent in knowledge production (Haraway, 1988; Lejano \& Ingram, 2009; Shapin \& Schaffer, 1985). One NGO worker that I spoke with discussed the lack of space for dialog surrounding environmental issues, arguing that any space that did emerge was usually policed by regional organizations. She encouraged me to remember that "engagement is not neutral .. . it's about power." This description is an overt reminder of the ways in which power can shape the spaces in which decisions are being made, particularly in international governance (Stone, 2008). Authority to speak in those spaces is directly related to who has power to share their voice. 
This procedural exclusion through the global technocratic narrative mirrors Barnett and Finnemore's (1999) discussion of the ways in which bureaucratization within international organizations maintains hidden power through classification, fixing of meanings, and diffusion of norms. The global technical narrative classifies authoritative science as a normative good, privileging 'objective' scientific knowledge over localized and practical knowledge sources that the Pacific Island peoples have identified as valued. In other words, the decisions about what is best for climate change action in the region are made outside of any public input and hidden within the bureaucratic structure, excluding much of the knowledges of Pacific Island peoples.

Alternatively, the local power narrative emerging through the network surrounding the PIDF Summit is evidence of resistance to the dominant global technical narrative. The PIDF Summit narrative-network pushed against the prevalence of colonial powers in decision-making in the PIF Summit (alterity), as well as the use of scientific information to dismiss the multiple ways of knowing including indigenous knowledge and contextualized, practical knowledge (encouraging plurivocity, instead), by setting up local Pacific Islanders as the hero. The local power narrative demonstrates efforts being made to contextualize knowledge in a place, as well as to put power in the hands of Pacific Islanders to transform their climate futures. By writing Pacific Islanders into the position of hero within the narrative, decision-making and governance is opened up to include multiple voices and knowledges. 


\section{Pacific Islands' Role in the Paris Agreement}

While the Paris Agreement is a product of long-term negotiations between UN states, Pacific Island nations played a significant role in formulating the final agreement through the High Ambition Coalition (Burleson, 2016). This is due to the pressure that Pacific Island representatives put on global emitters related to the loss of their atoll islands under high emission scenarios. However, it was not just the scientific conversation of the global technical narrative that brought about this change in targets, although that played a role in demonstrating the need for lower warming targets to save the atoll islands. Instead, the local power narrative was evident throughout negotiations as Pacific Island leaders emphasized their authoritative role in climate change governance. As Honorable Henry Puna, Prime Minister of the Cook Islands, stated during COP21:

Now that is leadership. Although we are victims to the effects of climate change, we are showing the rest of the polluting world that we are doing something to improve our situation not just for us but for the planet. We are not just environment victims, we are environment leaders.

Through this quote, and others like it, the leaders of the Pacific Islands demonstrated their commitment to the tenants of the local power narrative. This mirrored a transformation in COP narratives from challenges to opportunities, or 'shame and blame' to 'name and acclaim' (Ivanova, 2016). Pacific Islanders, while still demonstrating their understanding of victimhood in the climate narrative, also demonstrate that they understand their power through their moral 
leadership, and the ability to receive acclamation for their leadership. However, while the local power narrative held on to its authority in the COP21 negotiations, things shifted for COP23.

\section{COP23 and the Fijian Presidency}

In 2017 at COP23 in Bonn, Germany, Fiji became the first Small Island Developing State to hold the position of the presidency. COP23 was separated into two zones: the Bula Zone run by the Fijian delegates for government deliberation, and the Bonn Zone open to all sectors. This was a technical COP focused on the implementation of the COP21 agreement. In other words, instead of openly political negotiations, COP23 was characterized by negotiations on how carbon emissions should be measured, how they should be reported, and what accountability measures were in place, as well as bold moves by the private sector (particularly in the absence of the US's full participation).

While Fiji stood as an ardent advocate for the local power narrative during COP21 negotiations, this was less evident during their COP23 presidency. In the opening speech of COP23, Fijian Prime Minister Bainimarama stood beside the Pacific Island's collective commitment to $1.5^{\circ} \mathrm{C}$ warming and to "meet our commitments in full, not back away from them." However, while the lead-up to COP21 included such strong statements as "Those industrialised nations which are putting the welfare of their carbon polluting industries and their workers before our welfare and survival as Pacific Islanders," Prime Minister Bainimarama shifted to a more neutral tone during COP23 opening statements: 
We hope to infuse these negotiations with the Pacific Talanoa Spirit of understanding and respect. Because the only way for every nation to put itself first is to lock arms with all other nations and move forward together. ... We are all in the same canoe, which is why we have Drua-a Fijian ocean- going canoe-in the foyer. To remind us of our duty to fill its sail with a collective determination to achieve our mission.

The opening statement exhibited a universalism that was careful not to villainize industrialized states - as Prime Minister Bainimarama did during the lead up to COP21 - but rather to simply present greater cooperation as the hero. In this way, Fiji's narrative surrounding COP23 experienced bureaucratization (Barnett \& Finnemore, 1999) and depoliticization of climate change through it being a 'technical COP,' ignoring the contextual elements of knowledge production (Shapin \& Schaffer, 1985) and the local power narrative elements that were emphasized during COP21. This could also reflect Fiji's stance as a diplomatic leader to represent their role in the UN rather than represent the Pacific Island states, specifically. While I present only a brief investigation into this change, this period of diplomacy for the Pacific would benefit greatly from further study.

\section{Challenges in Future Governance}

While progress is being made to open up regional climate change diplomacy in the Pacific Islands to more democratic processes, there is still much to be done. Many of the employees of regional environmental organizations that I interviewed discussed how they felt that they wanted more public involvement in 
regional environmental decision-making, but that by doing so they risked problems of accidental exclusion or being in a situation in which they would not have the time or resources to implement programs. With the series of challenges that the Pacific Islands face, increased levels of inclusion and accountability can have serious tradeoffs in the efficiency of governance in the region. If time and effort is spent ensuring full public participation in decisions, many interviewees felt there would be limited time and resources left for achieving climate change adaptation and mitigation goals. However, while the global technical narrative, the use of boundary organizations, and the privileging of authoritative science may increase efficiency within the network, this efficiency comes at a cost that must be considered. Alternative understandings of the world and goals of environmental governance are dismissed through procedural mechanisms without the approval of the public. Without addressing the needs, knowledges, and capacities of local people, environmental governance efforts are likely to lose their effectiveness, credibility, and authority. The inclusion of nonstate actors, while producing challenges that must be addressed, can help to produce a more inclusive, representative, and accountable environmental governance. 


\section{Chapter 4: Discursive Strategies of Climate Governance Introduction}

Two years ago, we wrote: “The year 2014 was Earth's warmest in 134 years of records." Last year we wrote: "2015 was the warmest year ever recorded on Earth, and it was not even close." This year, we are running out of ways to say it. In 2016, surface temperatures on Earth were the warmest that they have been since modern recordkeeping began in 1880 . (NASA Earth Observatory, 2017)

As the earth experiences its hottest year on record for the third year in a row, the environmental vulnerabilities experienced by the Pacific Islands continue to escalate. Rising seas wear away low-lying atolls, threaten fresh water supplies, erode coastlines and coral reefs, increase the prevalence and strength of storms, and jeopardize food security both through agriculture and fishing (Keener, Marra, Finucane, Spooner, \& Smith, 2012). As the earth becomes hotter and hotter, the Pacific Islands are less able to adapt at the rate necessary to meet these growing environmental challenges. While Islanders have transformed their practices for thousands of years to deal with environmental shifts (Barnett \& Campbell, 2010), they no longer have the luxury of time to deal with changing conditions. In order to meet the needs of rapidly shifting environmental conditions, the Pacific Islands have been a target of large-scale research projects, resource-intensive environmental interventions funded by external states and agencies, and a general global interest. This makes the 
Pacific Islands a space of contention where local needs and global requirements are negotiated.

Due to the multi-scalar nature of climate change, Pacific Islands climate governance does not occur in a bubble, but rather is impacted by global efforts. During COP21 in 2015, states from around the globe took serious steps forward in acknowledging and acting upon the changing climate through the Paris Agreement. As with any global decision, however, there were multiple ways of understanding the problem and the solution. Within the Pacific, specifically, competing narratives prior to COP21 played themselves out surrounding local/global power within the climate change space (Denton, 2017). Different constructions of power, authority, and knowledge were advocated by various actors in attempt to secure legitimacy and resources.

This chapter looks to the post-COP21 governance space to see the way in which these local/global power relations are ensuing in regional efforts to adapt to and mitigate for climate change. First, I will explore the ideas of networks and discourse, and their relation to environmental governance efforts. Specifically using Bäckstrand and Lövbrand's (2006) three environmental discourses-green governmentality, ecological modernization, and civic environmentalism-I frame how discourses around environmental governance influence the direction of governance. Using social network analysis [SNA] of reports, project summaries, and research projects from the Pacific Climate Change Portal and interviews with climate change governance decision-makers and practitioners, I analyze the 
specific nature of local/global discourse around climate change governance in the Pacific. Finally, I position these discourses in relations of power, authority, and knowledge within the Pacific Islands climate change governance efforts.

\section{Discourse and Networks}

Networks are a useful way to explore the interactions of power, authority, and knowledge. Network theories assume that interactions between actorsindividuals or organizations - are grounded in the exchange of material and nonmaterial resources (Wasserman \& Faust, 1995). These resources could be finances, practical information, norms, standards, or understandings of the world. By exchanging resources in a relatively stable pattern, actors develop and maintain routine discourses. Discourse ${ }^{10}$ is understood here as "an ensemble of ideas, concepts and categories through which meaning is given to social and physical phenomena, and which is produced and reproduced through an identifiable set of practices" (Hajer \& Versteeg, 2005, p. 175). In other words, discourse is not only what actors say, it is also about the activities and institutions produced and upheld through their interactions with each other and the world around them. These practices can include governance operations, knowledge

\footnotetext{
${ }^{10}$ Following Howarth's (2000) division of theoretical frames, this approach to discourse is in contrast to the positivist, realist, or Marxist discourse approaches, due to the centrality of human meaning and understanding in explaining the social world. Instead, it builds on critical discourse analysis by emphasizing the contingent nature of these social constructions. This puts it within the poststructuralist frame, drawing in the broader field of practices that shape/are shaped by language. This is dealt with more in-depth in Chapter 2.
} 
production, decision-making procedures, and others. The narratives that were explored in the previous chapter can form some of the building blocks for discourses; however, discourse includes a broader and deeper history of the way things come to be spoken of in a particular way.

Networks can be seen as a space to perform and normalize power relations through regular discursive practices, or ways of speaking about, categorizing, normalizing, and standardizing the production of environmental and social systems. The power to shift environmental policy runs throughout the network, as actors seek to both frame the problem and structure the solution (Hajer, 1995; Litfin, 1994; Wesselink, Buchanan, Georgiadou, \& Turnhout, 2013). This power to shape the problem and the solution comes through the production of knowledge (Foucault, 1980), including information about processes and procedures (Barnett \& Finnemore, 1999), knowledge about the physical and social world (Miller, 2007), and the limits of what is considered acceptable (Finnemore \& Sikkink, 1998). These things can help to facilitate cooperation and shared understanding among network members, and at times the global polity (Andonova, Betsill, and Bulkeley, 2009); however, the privileging of particular knowledges can create spaces where some voices can be promoted at the expense of others (Agrawal, 2005).

Additionally, while many rational choice theorists work off the assumption that actors have a stable set of preferences that persist through time and can be fully understood by the researcher (e.g. Downs, 1957; Kahneman \& Tversky, 
1979; Marx \& Engels, 1978; Olson, 1965), studying the discourse within networks can assume that actors' preferences are formed through exchanges between network actors (Howarth, 2000; Lejano, Ingram, and Ingram, 2013). In other words, actors' viewpoints change as they interact and negotiate with other actors in the network. While similar standards, norms, and narratives become commonplace within networked relations (Grewal, 2008; Lejano, Ingram, \& Ingram, 2013), they are never final as they are always open for renegotiation (Butler, 1997; Laclau \& Mouffe, 1985). This takes the study of decision-making away from an objective, singular, totalizing - or all-encompassing-approach and toward an approach that allows for the dynamic nature of network exchanges. This is evident through the study of discourses of environmental governance.

\section{Discourses of Environmental Governance}

Governance here refers broadly to the designation of rules, standards, and norms according to which other actors make decisions (Bakker, 2010). In other words, governance is not limited to government, although the latter can play a crucial role in the former. Governance, instead, encompasses the breadth of institutions and ideologies that impact decision-making within a given society. ${ }^{11}$ In this dissertation, I do not look to "network governance" as a structure, distinct

${ }^{11}$ This understanding of governance addresses issues of power, unlike definitions where governance is seen as a process through which collective interests are defined and pursued (e.g. Pierre \& Peters, 2000). Instead of defining governance as actors working toward pre-defined, collective goals, this more general definition of governance allows the formation of goals to be questioned, as well. 
from governance in the form of hierarchies, markets, or communities (Pierre \& Peters, 2000). Instead, I view networks as a representation of relations throughout society that have a variety of purposes, of which governance is but one. Through this I avoid looking only to spaces designated as "networked governance" for networks, and instead I see the way that power is constructed in and through networks more broadly (Eilstrup-Sangiovanni, 2017; Grewal, 2008).

Governance of the environment is fraught with challenges as actors vie for power within existing and transforming political, financial, environmental, social, and technical systems (Grabowski, Denton, Rozance, Matsler, \& Kidd, 2017). The underlying foundation for these contestations is who has power in decisionmaking and practice, by what authority they have that power, and what knowledges are considered legitimate to create and uphold that authority (Barnett \& Campbell, 2010; Hulme, 2010; Jasanoff, 2004; Scott, 1998). These relations of power, authority, and knowledge both shape and are shaped by discourses that run in and through them (Agrawal, 2005; Hajer, 1995; Litfin, 1994).

\section{Bäckstrand and Lövbrand's Three Environmental Discourses}

Bäckstrand and Lövbrand (2006) have provided key insights into the ways in which environmental governance is spoken of and practiced, through three environmental discourses: green governmentality, ecological modernization, and civic environmentalism (Table 5). They present each of these discourses with a weak and strong version, described here. Green governmentality "epitomizes a 
global form of power tied to the modern administrative state, mega-science and big business" (Bäckstrand \& Lövbrand, 2006, p. 53-4). Following the work of Michel Foucault, this discourse entails the use of knowledge and expertise to regulate all aspects of human and nonhuman life through biopolitical ${ }^{12}$ fostering or management. This discourse is typified through the use of "eco-knowledges" (Luke, 1999, p. 104) that extend government control to the entire planet. As Bäckstrand and Lövbrand discuss, the weak version of this discourse is elitist and totalizing, while the strong version allows for humility and self-reflexivity in which scientific knowledge is made legible to the public.

The IPCC, for example, is a manifestation of the effects of the green governmentality discourse in that it surveils, accumulates global scientific knowledge, and sets standards for the climate (Bäckstrand \& Lövbrand, 2006). While for a long time it has set itself up as the ultimate authority on climate change, it has recently begun to become more self-reflexive in response to public criticism (Beck et al., 2014). Thus, IPCC's expression of the green governmentality discourse has shifted from a weaker to a stronger version by focusing on public trust in the form of representation, accountability, and political relevance, though more work is still necessary (ibid.).

Ecological modernization is focused on the "compatibility of economic growth and environmental protection, a liberal market order and sustainable

\footnotetext{
${ }^{12}$ Biopolitics, according to Foucault $(2003,2009,2010)$, is the state's use of scientific knowledge to classify, standardize, and normalize populations.
} 
development" (Bäckstrand \& Lövbrand, 2006, p. 52). While the green governmentality discourse focuses on scientific knowledge and governmental control of the globe, ecological modernization is concerned with economic approaches and interventions at a multitude of levels. The ecological modernization approach works to neutralize the contradictions and crises of capitalist development by emphasizing the availability of flexible, cost-effective, decentralized, and market-driven solutions to climate challenges that focus on 'win-win' scenarios (Hajer, 1995). According to Bäckstrand and Lövbrand, the weak form of ecological modernization is technocratic and neoliberal, while the strong or "reflexive" form allows for a bit more critique of dominant policy paradigms and encourages greater levels of "ecological democracy" (Barry, 1999, p. 113; Dryzek, 2000).

Forestry programs where developing countries are allowed to continue emitting by paying developed countries for carbon sinks are some preferred climate mitigation policy tools of the ecological modernization discourse (Bäckstrand \& Lövbrand, 2006). Reducing Emissions from Deforestation and Degradation $[R E D D]$ is a global example, where multi-scalar efforts allow developed countries to 'win' by mitigating their carbon emissions and developing countries to 'win' through poverty alleviation (Pagiola, Arcenas, \& Platais 2005). The weak ecological modernization discourse of the REDD program was challenged, however, due to technocratic decision-making that denied developing countries' access to the forestry products on which they were reliant, 
particularly in areas of tenuous land tenure practices (Ghazoul, Butler, MateoVega, \& Koh, 2010; Ziegler et al., 2012). Adaptations have been made to strengthen the program, including issues of good governance, equity, and the roles of indigenous peoples and forest-dependent communities, shifting the program to be called REDD+. REDD+ is an example of strong ecological modernization discourse at work, where market solutions are highlighted but democratic input is also valued.

Finally, civic environmentalism posits that "in order to build more effective environmental multilateralism, groups who are affected by environmental problems, or have a legitimate interest or stake, should have a voice in finding solutions" (Bäckstrand \& Lövbrand, 2006, p. 55). Civic environmentalism is primarily concerned with contesting the predominance of government- and market-driven problem/solution constructions. Still, Bäckstrand and Lövbrand determine that this discourse at times aligns with the strong forms of green governmentality and ecological modernization through its "reform-oriented" iteration that emphasizes the participation of civil society organizations and the democratization of decision-making. It also has a radical iteration that draws on the anarchist work of Antonio Gramsci to advocate for a restructuring of global environmental governance to a more just and eco-centric world order.

Civic environmentalism is exemplified by indigenous movements across the globe. The shift to a more inclusive REDD+ discussed above was based on the pressure put on by organized indigenous groups using the weak civic 
environmentalism discourse to increase participation in the existing REDD institution. Strong civic environmentalism, however, seeks to upend existing power structures - such as sovereignty, capitalism, and patriarchy-through a radical ecology perspective reflected in the 'Indigenous Peoples' Seattle Declaration," presented at the 1999 Seattle WTO protests.

As Bäckstrand and Lövbrand describe their work, "Discourses as 'knowledge regimes' brings us squarely to the role of science. In expert-driven global environmental change research, scientific knowledge, techniques, practices, and institutions enable the production and maintenance of discourses" (2006, p. 52). Therefore, each of these discourses is embedded in relations of power, authority, and knowledge. Green governmentality privileges large-scale monitoring, tracking, and scientific knowledge production. Ecological modernization utilizes evidence-based cost-benefit analyses, certifications, and standards. Civic environmentalism is primarily associated with context and the democratization of knowledge to include local understandings.

\section{Local/Global Elements of Environmental Discourse}

The structure of environmental discourse used by Bäckstrand and Lövbrand engages with the local/global contestations in climate change governance seen in the negotiations leading up to COP21 (Denton, 2017; Table 5). Green governmentality presents a global view, where elite scientific constructions of the social and environmental context are privileged. As Hulme argues, "Knowledge about multi-scalar processes and globally-aggregated 
outcomes that is insensitive to the peculiarities of place and context opens the way for unitary globalized explanations and predictions of environmental change. Masquerading as universal truths, these assert themselves as the unassailable view from everywhere" (2010, p. 559, italics added). Thus, the "view from everywhere" rhetoric of the green governmentality discourse mirrors the global technical narrative of climate change diplomacy in the Pacific (Denton, 2017). Civic environmentalism, on the other end of the spectrum, prioritizes place and context through local prioritization. Under this discourse, knowledge is tied to the space in which it was created (Haraway, 1988), and mirrors the local power narrative of climate change diplomacy in the Pacific (Denton, 2017). Ecological modernization discourse, alternatively, exists at multiple levels and thus contains both local and global elements. Under weak ecological modernization discourse, technocratic solutions require more of a global gaze, while the strong version requires broader participation.

Table 5: Chart of environmental discourses in relation to local/global strategies. Adapted from Bäckstrand and Lövbrand (2006).

\begin{tabular}{|c|c|c|c|c|c|}
\hline \multicolumn{2}{|l}{ Global Gaze } & \multicolumn{2}{r|}{ Local Prioritization } \\
\hline Green Governmentality & \multicolumn{2}{|c|}{ Ecological Modernization } & \multicolumn{2}{c}{ Civic Environmentalism } \\
\hline Weak & Strong & Weak & Strong & Weak & Strong \\
\hline Elite & $\begin{array}{c}\text { Self- } \\
\text { reflexive }\end{array}$ & Technocratic & Democratic & Reforming & Radical \\
\hline
\end{tabular}

While the discourses presented by Bäckstrand and Lövbrand differ substantially in practice, their practices are also interrelated. The private sector requires long-term regulatory frameworks to secure their investments, so as the 
private sector uses weak ecological modernization discourse it often requires the support of a weak green governmentality discourse from the public sector (Bäckstrand \& Lövbrand, 2006). Additionally, while strong civic environmentalism many times is presented as an alternative to green governmentality and ecological modernization, weak civic environmentalism aligns with strong ecological modernization in its emphasis on the involvement of civil society organizations.

\section{Implications of the Discourses for Climate Change Governance}

Each of these discourses-green governmentality, ecological modernization, and civic environmentalism - can bring about particular consequences within climate change governance practices. Green governmentality, while providing key insight into the global transformations of climate change and necessary actions from sovereign states, can also produce challenging power relations within climate change governance. As Agrawal (2005) has discussed in his investigation of the environmentality ${ }^{13}$ of conservation practices in Indian forests, "Once precise, statistical, generalizing arguments are invoked in the service of polity, it is difficult to counter them with vague, descriptive, anecdotal evidence. It is in this characteristic of statistical representations ... that their colonizing effects are to be found" (Agrawal, 2005,

\footnotetext{
${ }^{13}$ Agrawal uses environmentality as a play on "environment" and "governmentality," and provides a similar discursive frame as green governmentality here.
} 
p. 35). The use of models, statistics, and forecasts can have the effect of foregoing political conversation around what can and should be valued, while producing a one-size-fits-all solution. The strong version of green governmentality can help to broaden participation into these decisions, but many times brings in the public after primary decisions about knowledge and governance have already been made.

Ecological modernization can also have the effect of depoliticizing decision-making through focusing on streamlining, mainstreaming, and efficiency. While these efforts can produce cost-savings and imply a 'win-win' approach to decision-making in a space focused on sustainable development, it can also create a "problem closure" or defining solutions for a set of welldeveloped problems through apolitical measures (Hajer, 1995, p. 22). In other words, by portraying a 'win-win' approach, it makes it more challenging for those who do not see themselves as winning or who question the values being highlighted in the 'win' to put forward an alternative view that will be considered. The strong version of ecological modernization can allow for input from the broader civil society space, but still presents the time for participation as after the agenda has been set.

Civic environmentalism, in its weak form, can shift the levels of participation from input to agenda-setting. While this can assist the development of quality and effective outcomes in line with local needs, it is a costlier way of working in terms of time and other resources. It can reduce the efficiency and 
expediency of needed climate action. Strong civic environmentalism presents challenges to the existing system that can bring about broad social change. While achieving justice and equity targets that would be otherwise inconceivable, this form of civic environmentalism contests all other discourses, making it challenging to achieve change within the needed timeframe, the existing system, and in concert with appropriate partners.

It is also important to note that even in the strong versions of green governmentality and ecological modernization and in all forms of civic environmentalism, there are still power relations that create uneven spaces. As Schattschneider stated, "All forms of political organization have a bias in favor of the exploitation of some kinds of conflict and the suppression of others because organization is the mobilization of bias. Some issues are organized into politics while others are organized out" (1960, p. 71). A careful exploration of the mobilization of bias is necessary to better understand whose voice is being heard in a governance arrangement that fosters any of these discourses. In other words, while it may be tempting to venerate the inclusivity of civic environmentalism, or strong green governmentality and ecological modernization for that matter, a critical approach is key to demonstrating where issues are "organized out." This will be taken up more thoroughly in the next chapter.

These discourses can be seen in all manner of global environmental governance efforts. Green governmentality is prevalent in efforts to measure, normalize, and control levels of species biodiversity (Denton, forthcoming). 
Ecological modernization is utilized in arguments that present environmental pollution as merely a product of economic inefficiencies (Hajer, 1997). Civic environmentalism is prevalent as an element of environmental justice campaigns across the world. While these discourses take on a variety of forms and subject matters, they are particularly apparent in the Pacific Islands' climate change efforts. The next section describes my mode of investigation to look into these discourses in the Pacific Islands - a combination of social network analysis and qualitative methods.

\section{Social Network Analysis Methods}

In Pacific Islands climate change governance, states, NGOs, IGOs, IOs, private enterprises, and knowledge producing institutions at the local, national, regional, and global level are all working to meet environmental challenges. These organizations form connections through interactions with varying degrees of formality-e.g. designated networks of actors devoted to a particular cause, partnerships for projects and research efforts, and informal interactions among acquaintances. While SNA cannot capture all aspects of all relationships, it is a useful tool in understanding the form and structure of interactions among a large number of actors, thus making it a useful tool for understanding this broad range of multi-scalar organizations.

The Pacific Climate Change Portal [PCCP] was used as the source of data for this analysis. The PCCP is a central information location online that has gathered over 1,400 articles, reports, event participation lists, and more, relating 
to climate change governance in the Pacific Islands. The PCCP was instigated and is maintained by the Secretariat of the Pacific Regional Environmental Programme [SPREP]. The PCCP is not a complete source of all climate change programming in the region. It is also colored by SPREP leadership as SPREP has a vested interest in ensuring that its projects and reports, and those of its collaborator organizations, make their way into the portal, while other organizations may not see that type of documentation as vitally important. However, PCCP is the best collection of data on climate change programming in the Pacific Islands to date. The data was evaluated to identify when any two organizations: ${ }^{14}$

- worked together on a project,

- shared financial or other resources for a project,

- shared scientific or local knowledge for a project ${ }^{15}$,

- produced a scientific or policy paper together, or

- attended an event together.

Websites, grey papers (technical reports, programmatic information, etc.), newspapers, blogs, environmental reports, and financial statements were used to determine when these resource exchanges occurred. This limited the analysis to formal exchanges, missing the important yet hidden informal exchanges that occur regularly in the network, which is why the SNA was supported by interviews.

\footnotetext{
${ }^{14}$ Data was limited to the past 10 years [2006-2016] prior to analysis due to the availability of data for that period.

${ }^{15}$ As with the other measures listed here, this is limited to sharing that is evidenced in papers provided about projects.
} 
For the SNA, I focused on exploring the relative power positions of various organizations in the network. This served three distinct functions. First, it allowed me to select organizations that held greater or lesser power positions within the network as interview participants to ensure that multiple perspectives were considered in the findings. Additionally, the power positions were visualized in a map that was used as an interview tool to support participants' discussion of the power of other organizations in the network-either affirming or rejecting their status in the visualization (Appendix B). Finally, it allowed me to place the interview findings in context according to how embedded in the network participants' organizations appeared through the SNA, and what they thought of other organizations in greater or lesser power positions. In other words, it let me put the interviews in context according to how they viewed organizations at similar and different power positions.

For the SNA visualization, I looked at measures of how central organizations were to the network-in-degree, out-degree, and betweenness centrality - to determine the organizations that held more or less powerful positions. As Eilstrup-Sangiovanni explains, "network centralization does not concentrate formal authority in a single location, nor does it vest authority in a single actor that is empowered to define or enforce collective rules" (2017, p. 692). Instead, centralization is an informal and fluid measure of power. In-degree centrality refers to the number of incoming links a node has, which in this case demonstrates that they received financing, co-led a project, or simply 
participated. Out-degree centrality refers to the number of outgoing links a node has, which in this case demonstrates that they gave out funding or were a coleader in a project. Betweenness centrality, on the other hand, measures the number of times a node is located on the shortest path between two other nodes. This is a measure of how central the organization is to the network as a whole. In-degree and out-degree centrality captures the power to influence projects through financing, leadership, or participation, while betweenness centrality captures influence over flows of knowledge, information, and resources in the network as a whole. After applying an average of these measures, I divided organizations into the core, semi-periphery, and periphery of the network. In other words, I distinguished between those organizations with many connections in all types of centrality (core), those with a moderate number of connections (semi-periphery), and those with only a few connections to others (periphery).

\section{Interview Methods}

While the SNA can provide some insight into the structure of relationships between organizations working on climate change in the Pacific, it does little to provide feedback on why they have that power, if that power is considered legitimate by network participants, and what sources of knowledge they use to create and uphold that power. In other words, while SNA can give some insight as to where power might be located in the network, it is not definitive on that power nor does it demonstrate the authority or knowledge employed by 
organizations in relative power positions. Thus, I conducted interviews in order to provide insight into these elements of climate change governance.

Interviews for this portion of the dissertation took place in March and April of 2017, a little over a year after COP21 in December, 2015. Participants for these interviews came from Fiji, Samoa, the Cook Islands, Australia, and the Hawai'i Islands of the United States. Organizations were selected using a convenience sample from the categories of core, semi-periphery, and periphery (see description above) and distributed across various sectors-Pacific Island and external states, domestic and international NGOs, and IGOs. In this dissertation, I assumed that centrality and organizational type would impact perceptions of the authority and knowledge used by other members in the network (and that perceptions impact the creation and maintenance of ties), thus making it important to capture multiple types of organizations at various centralities. The individuals selected from these organizations generally had extensive knowledge of the organization's transnational environmental efforts and collaboration with other organizations, but their exact title may vary from organization to organization, e.g. Climate Change Advisor, Climate Services Director, Project Coordinator, etc.

The interviews covered topics related to power, authority, and knowledge within climate change governance in the Pacific. A copy of the interview guide is located in Appendix C. The interviews were semi-structured and centered around the visualization produced through SNA (see Appendix B), where I asked for 
participants' perspectives on what power, authority, and knowledge were brought by both central and peripheral organizations. I interviewed 30 individuals representing 21 organizations/government departments primarily in one-on-one settings, with 5 interviews taking place in groups of 2-3. The interviews ranged from 30 minutes to 3 hours (organizations and interview times are listed in Appendix D). Sixteen interviews were recorded and transcribed, and 5 were limited to notes only for a variety of reasons, including limitations of the meeting space and participant desires to not be recorded. The interviews were supplemented with reports, news articles, and studies to contextualize the interviews.

The interviews were transcribed, and then coded using thematic analysis (Braun \& Clark, 2012). This uses six steps: (1) becoming familiar with the data, (2) generating initial codes, (3) searching for themes, (4) reviewing themes, (5) defining and naming themes, and (6) producing the report. As opposed to a rich description of the entire data set, this dissertation focused on detailed accounts of particular aspects of the interviews and documents associated with power, authority, and knowledge. Thematic areas included agenda-setting, capacity opportunities and challenges, knowledge use, and collaboration strategies, all separated according to their existing and idealized forms as presented by participants.

These findings from the thematic analysis of interviews with Pacific Island practitioners were situated among broader understandings of climate change 
governance at the transnational and global scale using critical discourse analysis. As Howarth describes, discourse analysis places "investigated practices and logics in larger historical and social contexts, so that they may acquire a different significance and provide the basis for a possible critique and transformation of existing practices and social meanings" (2000, p. 129). In other words, this type of analysis deals with more than what was said by interviewees, but goes further to examine how those ways of speaking came to be.

Similar Chapter 3's division between the network that used the local power narrative and the network that used the global technical narrative, the interviewees' expression of the themes had a local and global expression. However, unlike the previous chapter, not all of the participants adhered to the either/or of global technical or local power approaches. Instead, there was a third category of participants that advocated for global agenda-setting and local implementation. This led me to the work of Bäckstrand and Lövbrand (2006), described above. The global technical narrative of the previous chapter was similar to the green governmentality discourse, while the civic environmental discourse captured much of the tenets of the local power narrative. The ecological modernization discourse aligned closely with the participants who fell somewhat in the middle with global agenda-setting and local implementation. While Bäckstrand and Lövbrand provide a useful set of discourses to utilize for this discussion, the fit is not perfect. Thus, in each section of the results below, I also provide challenges to the discourse discussed, allowing for a more nuanced 
engagement with the discourses that mirrors the flexible nature of discourses, in general.

\section{Results}

While participants put forward complex and varying views of climate change governance in the Pacific, distinctions in goals and strategies of governance showed similar patterns as in the discourses of green governmentality, ecological modernization, and civic environmentalism in both their strong and weak forms (Bäckstrand \& Lövbrand, 2006). This section examines climate change governance in the Pacific in light of this categorization of discourses. I present the ways in which organizations expressed these discourses, along with where the discourses experienced challenges. While the interviews provided the foundation for this discussion, the SNA findings are also used when participants are discussed as being central, semi-peripheral, or peripheral to the network. While I anticipated a greater degree of distinction between the discourses used at each of these levels, there was a loose pattern that is useful for demonstrating the degree to which a particular discourse is embedded in the network.

\section{Global Governance of Science and Control}

Green governmentality discourse was prevalent throughout many of the more central organizations in the network (see Fig. 3). Primarily composed of IGOs and states, these agencies were concerned with building and maintaining a "view from everywhere" (Hulme, 2010, p. 559) through the modern administrative 
state. Measurement, analysis, and technical information were primary features of the discussion, as well as looking to organize decision-making through the use of expertise. Scientific knowledge was seen as an important missing element to achieving these goals within the Pacific Islands. As one participant discussed the knowledge situation in the Pacific:

It's gotta be said, we are still talking about a relatively small number of skilled professional in the Pacific, and as I just said, they will probably always be probably dependent on Western nations not only for funding, but also for capability. I mean [large organizations working outside the Pacific Islands] have got access to credible computing infrastructure that some Pacific Islanders could only dream of, and that's just the harsh reality.

Capacity challenges were framed as a lack of scientific knowledge and technological capabilities that could be corrected through greater access to resources devoted to monitoring, experiments, models, and surveys. Due to the high cost of these endeavors, these agencies tended to speak of competition over mandates, resources, and (occasionally) ownership of information. 
Figure 3: Pacific Island climate change network core.

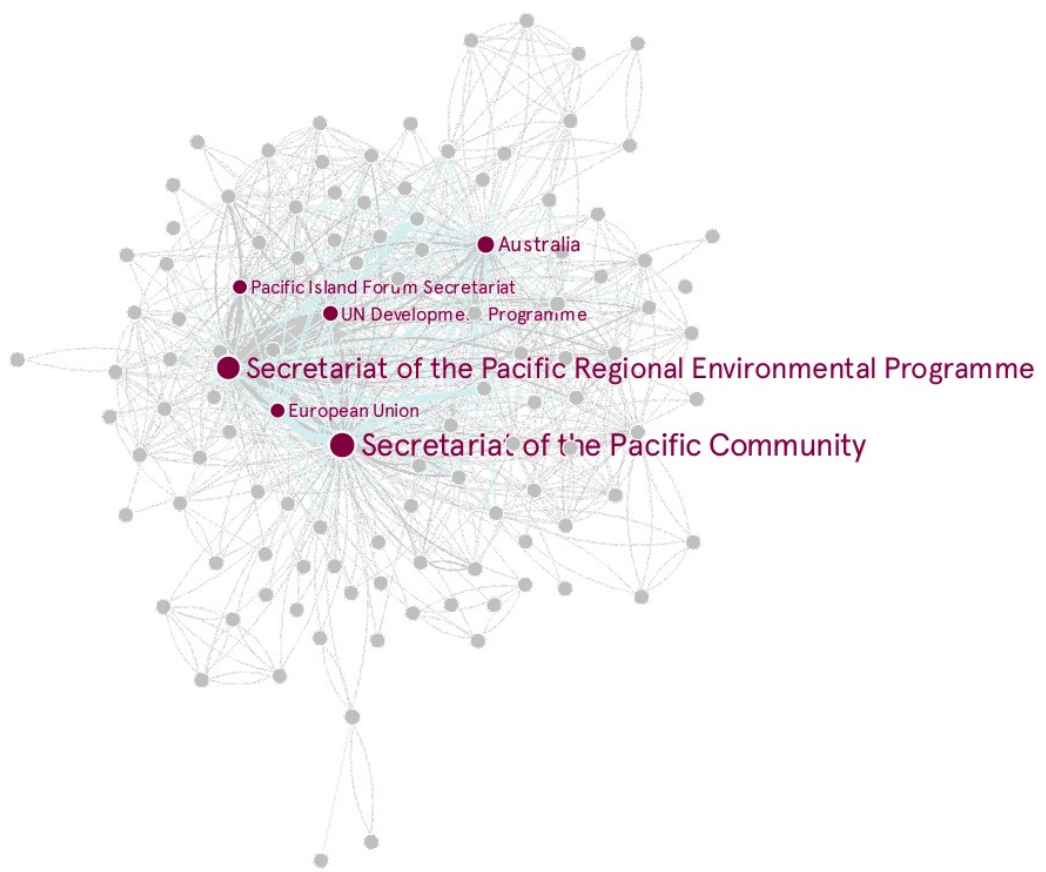

Additionally, the green governmentality discourse is characterized by the use of technical expertise to delimit options within climate change governance discussions. One organization spoke of the findings of technical analysis as "the only solution." Others felt that opening up decisions to political discussion complicated what could be a streamlined decision processes. As one participant stated:

So, we sat down and came up with this ... a list was developed and without saying it, decided it should be this island. Just absolutely this one. \#laughs\# It took the government almost a year to decide on that island. In this quote, the course of action is normatively intertwined with the output of a technical process. While sovereignty is a key element of green governmentality in the Pacific Islands, this desire to optimize technical expertise in decision- 
making practices is embedded in the discourse. While monitoring, experiments, models, and surveys can be complex in and of themselves, the use of technical solutions simplifies decision-making by delimiting options that are available for discussion to those highlighted by experts.

These elements of green governmentality tend to foster a solution to climate change governance in which the participants' own organizations are highly valued. All but one central organization with whom I spoke primarily used the green governmentality discourse and had a technical/scientific component that is needed to overcome the capacity challenges described in the discourse. While weak green governmentality has previously been used to produce and uphold the legitimacy of these organizations, there has recently been pressure to make the practices of these organizations more democratically responsive. Thus, participants shifted between weak and strong iterations of green governmentality, as they struggled between the need to make knowledge accessible to the public to allow for accountability and self-reflexivity, and a clean, elite understanding of the world. As one interviewee described some data he had been working on for public consumption:

It's not as scientifically accurate as we would like but it does get the message across and the loss in scientific integrity, if you want to call it that, is acceptable ... somewhat acceptable. And we realize that we're just not gonna breeze in information that's $100 \%$ scientifically acceptable to the media and to the public. Compromises have to be made both ways, I 
guess. And that's interesting because there's been a big shift in that direction in the last few years. When I began in climatology it was all about getting information that was $100 \%$ scientifically accurate, we did not care what it looked like. And quite often, we spent a horrendous amount of time showing your clients how to interpret our product. But that's quickly changing. It's going the other way, and it's forcing us to think about the way we deliver information, and that's resulted in communication specialists being employed at significant numbers at the bureau of meteorology. So, we've gotten to a point now where we can't release anything to the public unless it's been through a communications expert. Which is challenging, but we see the need for it. We like to work with them.

Multiple participants with whom I spoke echoed this ongoing struggle within the green governmentality discourse. On the one hand, scientific rigor provides the most important solution options to growing global challenges. On the other, the communication and distribution of knowledge to the larger population is seen as a valuable new frontier for climate change governance. Most participants spoke of knowledge communication as an exciting opportunity to be relevant to decision-makers and the public, but there was also some hesitation in regards to the potential loss of accuracy, efficiency, and opportunity for technical information to be ignored. 


\section{Challenges to the green governmentality discourse.}

Technology plays a key role in green governmentality by providing the ability to surveil, gather and examine large amounts of data, and run simulations of potential control efforts. While traditional donors including the US, Australia, New Zealand, France, Germany, and others have provided access to advanced technologies, the fragmented nature of project-based development in the region has limited the capabilities of Pacific Islands states to streamline their data inputs to achieve control. As one individual who had worked both within Pacific Island states and externally described the situation:

you may have New Zealand select a particular brand of automatic weather station and install it in multiple countries. Then you have another donor that says "No, I prefer to go with instrumentation that comes from my country." So, you've got a bit of a mismatch ... which creates complications in reference to having to train people at the national MET (Meteorological) services. National MET services having to service different sort of equipment. And I thought to myself, "You know, perhaps you could have an agency like SPREP sort of saying, like setting the rules to some extent or providing guidance with reference to how aid might be provided in the Pacific." You would be careful, because you can't say to a donor, "Yes we'd be happy to take money from you and we will tell you what, or we'll give you a list of something we want from you but we won't 
necessarily accept something from your country." You know what I mean.

It's a complicated space. Very complicated space.

This "complicated space" challenges the authority of Pacific Island state agencies in their efforts to control the knowledge space in their own countries. Capacity challenges can already be overwhelming for SIDS and LDCs due to their small populations and economies. One interviewee pointed out the challenges states face in just paying their employees from month to month. However, these capacity challenges are vastly exacerbated by state agents having to learn multiple technologies, reporting mechanisms, etc., in efforts to meet donor requirements.

This lack of control over the technological space is only one piece of a broader challenge surrounding state control in the Pacific. Many participants expressed their feelings that outside donors (primarily, but not limited to, colonial states) were leading much of the agenda of the region. As one participant argued:

Interviewee: The problem with the countries is they keep receiving the money, they are not in a position to just stand up and tell them, "Guys, listen, this is the way we should do it," because they feel like by doing that, you upset the government, and therefore you will not get the money that you want to get. But the reality is on the ground, despite the many fundings for climate change coming through the region, you hardly see any tangible output or outcome. 
Interviewer: Why do you think that is?

Interviewee: It's dictated by the donor. Projects are being implemented according to their terms and conditions.

Therefore, under this power relationship where external states can dictate much of the policy agenda, as well as the technologies of environmental measurement, Pacific Island states struggle to place themselves in positions of power within the green governmentality discourse. ${ }^{16}$ Thus, while central IGOs and external states utilize green governmentality to justify their financial and resource investments into scientific programming, they are forced to broaden their discourse to maintain legitimacy. One way in which they do this is by also including aspects of other discourses, including ecological modernization.

\section{Mixed Governance of Sustainable Development and the 'Win-Win'}

The ecological modernization discourse was primarily utilized by participants from organizations in the semi-periphery of the network (Fig. 4) that were engaged in local/regional implementation of agendas set in regional/global networks. One central organization with whom I spoke used the ecological modernization discourse primarily, while other central organizations used it sparingly in conjunction with the green governmentality discourse. The ecological modernization discourse is expressed in the Pacific primarily through efforts to

\footnotetext{
${ }^{16}$ While this still holds true, Pacific Island states have begun exerting their influence more assertively recently. This topic will be taken up in more detail in Chapter 5.
} 
mainstream climate change into all sectors, especially sustainable development and disaster risk reduction. The regional governance surrounding climate change in the Pacific has shifted from the Pacific Islands Framework for Action on Climate Change [PIFACC] (2006-2015) to the Framework for Resilient Development in the Pacific [FRDP] (2017-2030). FRDP sees climate change as more of a variable impacting development than the independent concept evident in PIFACC. As the executive summary describes the framework:

The FRDP advocates for the adoption of integrated approaches, whenever possible, for coping with and managing climate change and disaster risks, in order to make more efficient use of resources, to rationalise multiple sources of funding which address similar needs, and for more effective mainstreaming of risks into development planning and budgets. (FRDP, 2016, p. 2)

FRDP is meant to streamline funding mechanisms and activities, increase efficiency and effectiveness toward the goals laid out in the document, and mainstream governance mechanisms for risk, broadly defined. Resilient, sustainable development practices are the principle goal of the practices put forward by the framework. 
Figure 4: Pacific Island climate change network semi-periphery.

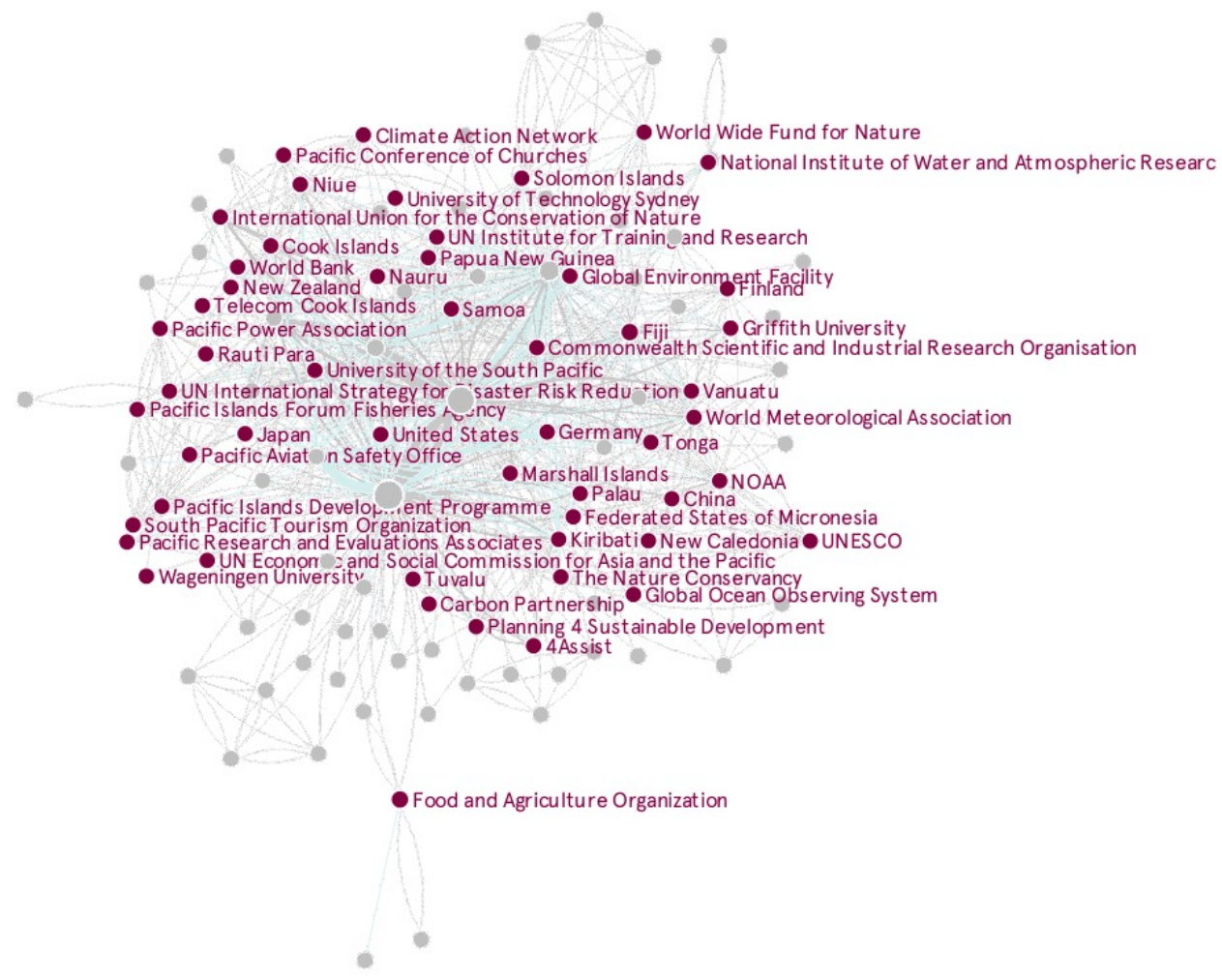

The goal of the ecological modernization approach of the FRDP is to ensure that piecemeal planning and governance is replaced by a more centralized mechanism for development decision-making. As one individual pointed out:

You can have all climate change project funded, doing nice things, cutting ribbons, but in the end of the day you get development going on that is not resilient to disasters. So, you are just gonna keep building disasters, basically, unless these things are incorporated into the regular development decision-making processes. So, that is why we stepped outside of the box and tried to get inside regular development. 
In light of this view, the relegation of climate change to one of a list of variables is seen as justified for the sake of making sure that resilient, sustainable development stays a priority. Participants espousing ecological modernization use equivalencies - climate change is really the same as disasters, which all impact development, which can actually be sustainable development - to mainstream climate change funding and action. Under this understanding, competition between organizations and government sectors is unnecessary and instead there can be a 'win-win,' where resilience to climate-influenced disasters is met while the region continues to engage in rapid aid-based development.

The ecological modernization discourse was primarily concerned with the need to improve reporting to regional and global entities, to meet funding requirements, and to integrate risk into existing governance mechanisms. Thus, participants using the ecological modernization discourse were concerned primarily with the lack of capacity needed to meet external requirements. These capacity needs are described by one participant:

So, how these stakeholders can use, integrate this risk template, or use this risk template when they implement projects; and secondly, how they assess funds or grants to implement these projects ... And also, there's one other capacity building of this community groups or committee groups to use the government templates to access funds because government also has funding for projects that comes into their office. 
Participants like this one regularly discussed the challenges countries and communities faced when attempting to implement donor-led projects, access financing, and meet external evaluation requirements. While this has some similarities to the green governmentality discourse in regards to reporting, here bureaucratic expertise is considered more of an immediate need than scientific expertise. The two can, however, be intertwined, as donors require both bureaucratic and scientific inputs. As one participant described the process: when countries are trying to apply for GCF or Adaptation Fund or what have you, there's lots of things that they need to provide-cost benefit analysis, gender analysis, economic and social safety guards, EIA, and stuff. Some countries have the capacity to do that, others don't. So, we ... help with those types of crucial studies needed to get over the line for funding.

In this way, technocratic reporting mechanisms cause the separation between the green governmentality discourse and ecological modernization discourse to become blurred in efforts to meet donor requirements.

Ecological modernization in the Pacific includes a range of local/global scales in order to implement the strategies laid out in the FRDP. As one organization described the governance setup:

they have to align because it all leads from the global frameworks to the regional frameworks and then align it to the framework at the national level. That's the logic of how it should work. Then it goes down to the line 
ministries and relevant areas and then down to the community level where they pilot. Whether it is a climate change adaptation project, a coastal adaptation project, some disaster risk reduction, some of the resilience work, some agricultural work, and then to the technical areas.

In other words, the agenda is set at the global level, which provides a framework for regional and national actions, which then trickles down to the community level. Most participants that used the weak version of ecological modernization saw local/global strategies and decision-making processes as working in concert across multiple scales, primarily through a top-down flow. As one participant described the situation, “I don’t think there should be any reason for tensions, because the strategies are determined by the national representatives that sit on these regional discussions." Those using a strong version of ecological modernization, alternatively, emphasized the need for greater community participation and input. However, community engagement was primarily limited to project implementation, not agenda-setting.

\section{Challenges to the ecological modernization discourse.}

Ecological modernization is the underlying logic behind many projects in the region. Approximately $86 \%$ of the US $\$ 748$ million of bilateral and multilateral funds given to the Pacific Islands for climate change in 2010-2014 was in the form of project support, and around $42 \%$ was devoted to enabling environments, or "activities to mainstream climate change into sector policies, planning and management (including in the energy, forestry and water sectors)" (Atteridge \& 
Canales, 2017, p. 17). This is compared to approximately $1 \%$ directed toward general budget support and $9 \%$ devoted exclusively to research (ibid.). As funding is directed toward development and mainstreaming activities within the Pacific Islands, the ecological modernization discourse, with its emphasis on economic solutions, is highlighted. This produces a situation in which many of the central organizations that primarily utilize green governmentality to legitimize their own work also discuss projects in terms of ecological modernization for funding reasons. As previously discussed, this 'discourse mixing' comes primarily by arguing for the need for operational capacity to implement scientific findings.

There is still a formidable amount of resistance, however, to the ecological modernization discourse. In the initial discussions on the FRDP, some decisionmakers argued that a technocratic focus on development and disaster hid the political arguments surrounding climate change. For instance, the FRDP limits the abilities of the Pacific Islands to engage heavily with the shame-and-blame tactics that have categorized some of Pacific Island climate change diplomatic efforts (Denton, 2017) due to the 'win-win' approach between development and climate issues that is reliant on consensus. Some participants, therefore, felt that the FRDP was inadequate in addressing the more contentious, global issues of climate change, such as GHG emissions by developed countries.

Additionally, organizations using the ecological modernization discourse, again, are primarily implementing agencies in the region that are responding to global conventions and networks. This creates an inside/outside tension where, 
in meeting global requirements and channeling outside funding, organizations must carve out a space for themselves on the ground. One participant described the situation like this:

From our perspective, [it] is that ability to convene, to facilitate and to be seen as a neutral player, because of our global status. Absolutely we are engaging the region, but we are not of the region, per se ... We may only have a couple of junior local staff headed by Pacific Islanders and the bulk of our staff is a few expatriates like me, but that's who we are in this region. So, I think we fit into a space there and that shows through our ability to bring together Pacific Island leaders and decision makers through our leadership programs and through the summits that we have held. Highlighting the organization's capabilities as "neutral facilitators" that is a direct part of ecological modernization, the participant pointed out the need to open up facilitation to allow regional involvement:

We ask what other countries want to do, and I guess that's the big thing. It's gotta be less about us coming in with 'here's our great regional framework or global theme' and much more about the countries saying, 'We've already got our priorities set, we know what we want to do, and we just want to help.' I guess that's the creative tension it should be.

This feeling of being "not of the region, per se" was shared by many organizations who engaged with ecological modernization, but it was also tied with a desire to address regional issues in ways that put more power back in the 
hands of regional players. With these challenges, both green governmentality and ecological modernization have incorporated some elements of civic environmentalism.

\section{Local Governance of Traditional Knowledge and Participation}

Civic environmentalism is prevalent throughout the organizations at the periphery of the network who also tend to work more locally within the Pacific Islands (Fig. 5). This discourse fosters local constructions of climate challenges and solutions that utilize the capacity of Pacific Islanders. This capacity can include traditional knowledges, community governance structure, and the importance of proximity to climate change impacts for the ability to understand and develop solutions. Instead of fostering a "view from everywhere" (Hulme, 2010, p. 559), participants utilizing the civic environmentalism discourse were concerned with integrating climate and disaster risk management into the local context with actions already being taken by communities:

They already know how to do their work, but we are just adding on what they already know. We are not bringing something new but we are just adding on to what they already know, in terms of the work that they are doing. And then for them to know the importance of integration or importance of climate change, disaster risk how it a main ... it's a main thing that we are looking at in the best way right now in terms of what we are fighting for, what we've been facing. 
As opposed to the work of ecological modernization to mainstream climate change and disaster into government planning and development, the goal with civic environmentalism is to directly support communities' existing efforts. There is a sense that communities are already working to make positive changes surrounding the environmental ramifications of a shifting climate, and that their work should be supported by outside organizations. Their capacity is highlighted, while acknowledging that more can be done to integrate their knowledge into governance practices and support their existing efforts.

Figure 5: Pacific Island climate change network periphery.

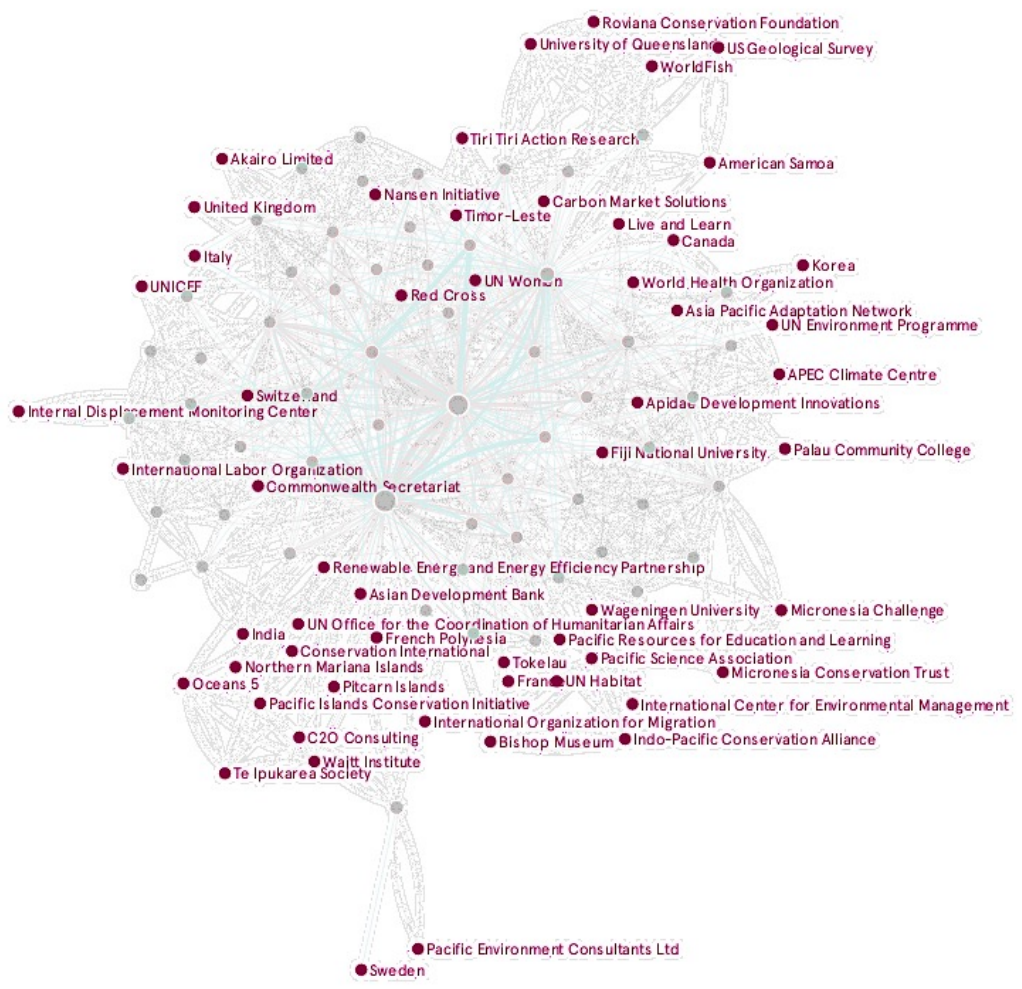

Instead of a centralized decision-making model, civic environmentalism promotes participation by the broader community. The participants emphasized 
that local capacity and knowledge are valuable and should be taken into consideration during decision-making. As one participant noted:

It has to be more holistic and it has to be driven by what the community wants to learn about, what's important to them and not just pay lip service, but actually do it properly.

Additionally, one participant focused on building a bottom-up approach:

So, our role is to build this model up because the existing model is topdown. That means we build the bottom-up approach so that the community can influence the policy by understanding what are the issues affecting them and what is the priority to them.

As opposed to a weak engagement model that might be used to draw community members in after the agenda is set, civic environmentalism argues for community participation in agenda-setting and policy-making from the beginning. Thus, community knowledge is valued and highlighted, but it is not venerated. The need to integrate scientific knowledge is seen as a critical element of governance. As one participant stated, "We are adding onto their current traditional knowledge that they have, and try and marry that to the scientific knowledge of climate change and disaster risk." The need for both types of knowledge to act in concert is a key element of the use of civic environmentalism in the Pacific Islands.

When the organizations put forward a weak version of the civic environmentalism discourse, they tended to be impact-oriented, looking to the 
way that projects could be reformed to be more useful to their participants. These conversations were particularly pitted against the project challenges brought about through organizations using the weak ecological modernization discourse:

I know like [a specific central organization], oh my god, their monitoring and evaluation frameworks and stuff like that, they are very rigid, they are very detailed, and all that stuff. And then it's like, well, then what. Once you get past that, past ticking your boxes, and past crossing your Ts and dotting your l's, then what are you left with? What is the big impact? ... Doing something is not achieving something or having results or having impact for those people that need it most. And until that happens it's same of the same thing over and over again. Unfortunately.

Thus, the weak version of the discourse was concerned with the efficacy of projects to meet the needs of local community members, and the way that previous projects had failed to meet that goal. As it is a reform-oriented approach, most advocated for a tweak of the existing system into a more inclusive version the fostered respect for local knowledge. While some Pacific Islanders did engage with a strong version of the civic environmentalism discourse that was radically anti-development and democratic, the sample of those using radical civic environmentalism was too small to fully develop insights into its use. 


\section{Challenges to the civic environmentalism discourse.}

While presented as an alternative to the more dominant green governmentality and ecological modernization discourses, the reformist civic environmentalism primarily utilized in the Pacific Islands is intertwined with the status quo. Development pathways where funding is distributed from countries in the Global North to the developing countries of the Pacific is discussed only in terms of broader inclusion rather than changing the mold. One particularly straightforward interviewee stated:

Interviewee: The problem is [major Pacific organizations] still depend on outside funding. So, they wanna impress the donor more than achieve tangible outcomes on the ground. It's keeping the donor happy though is the priority so that they can keep getting more funds.

Interviewer: Which donors are the cranky ones?

Interviewee: Almost all of them. \#laugh\# They have been doing nothing.

Development funding is not intended on bringing about tangible change, it's about the country's interest. And that's the problem. The best approach will be to listen to the recipient, but unfortunately, that's not happening. They dictate how it's delivered, in what way, in what form, and that's the reality we just have to live with. Although many reports are coming through that it's not working, this modality, and yet nobody listen to it. So, you start wondering whether, are they are really yielding tangible outcomes or it's just something to fulfill their interest, to keep you in their pocket. 
While this shows considerable distaste with the current state of funding models, civic environmentalism in the region did not present a tangible alternative. More, this participant just wanted to bolster the capacity of the region to deal with these challenges, and wanted some avenues of support to lend themselves to that end. This participant additionally stated:

For example, now we are in the process of developing a course on multilateral reporting and that's a great deal for the countries. They are all struggling with all this reporting on climate out of the different conventions. Now we have the Sustainable Development Goals. So, countries are so overwhelmed with little capacity. Most of the time they rely on foreign consultants coming to do their reporting for them, but they say it's about time we build our capacity in the region.

Thus, while there is strong resistance to the form of the donor-recipient model, the participants utilizing civic environmentalism struggle to put forward an alternative that is substantively different from the basic operational capacitybuilding tactics of ecological modernization.

Additionally, while there is a lot of hope in that community involvement has seen a rise among project requirements, many peripheral organizations that utilize the civic environmentalism discourse are skeptical, at best, as to the impact on communities' lives. One participant stated:

I think consultation is actually really important, if done effectively, it can actually lead to better outcomes ... l've seen those consultations happen 
and I'm judging from an outsider's perspective and I'm just thinking like this just sounds ... it doesn't sound genuine. I'm left thinking, "What now?" I've been left thinking that, and I wonder as a community member if you're like, "Oh this is just what we'll have to do to get our next bit of funding for the project," rather than actually feeling they really matter in that discussion. I don't know, I can't speak on behalf of communities' experiences, but it'd be very interesting to go and ask them. And they will definitely say, "We're thankful to our donors." And yes, you are for your money, but do you really feel your needs are being met and the project is structured the way you want and monitored the way you want, and all these things that can actually give the community a voice? It's very difficult.

There was an apparent struggle among many participants who felt as if developments within the status quo might be hopeful, but did not go nearly far enough in their current form. In other words, while civic environmentalism is growing in strength, somewhat, it still felt to many as a peripheral discourse that was perfunctory rather than impactful.

\section{Three Environmental Discourses in Conversation}

In the space of Pacific Island climate change governance, these three discourses - green governmentality, ecological modernization, and civic environmentalism in both their strong and weak forms - appealed to different constructions of power, authority, and knowledge (Table 6). Green 
governmentality, in both its strong and weak forms, appealed to expert authority and scientific knowledge to produce and uphold its power. The expertise was grounded in the ability to produce global types of scientific knowledge. Power was located in knowledge institutions and the administrative state for the weak form of the discourse, while the strong form moved power slightly out to the public through knowledge communication.

Additionally, ecological modernization was focused on the rational-legal authority (Barnett \& Finnemore, 1999) embedded in an operational knowledge of development. This authority is "invested in legalities, procedures, and rules" through bureaucratization in the classification, fixing of meanings, and diffusion of norms (Barnett \& Finnemore, 1999, p. 707). In other words, this authority came through the operational elements of development-the frameworks, standards, and conventions to follow - in global, regional, and local funding and project requirements. Under a weak, technocratic version of the discourse, development partners that fund and set the criteria for development practices had power, along with those implementing government agencies, NGOs, and IGOs that carried out the projects on the ground. For the strong, more democratic version of ecological modernization, civil society organizations were brought in as a structured public participation mechanism for implementation.

Finally, civic environmentalism appealed to practical authority and contextual knowledge in both its strong and weak forms. According to Abers and Keck, "Practical authority is a kind of power in which the capabilities to solve 
problems and recognition by others allows an actor to make decisions that others follow" (2013, p. 7). This type of authority occurs with regular, successful engagement in the network, sustained by knowledge of the local context. The desired location of power in the weak form was in institutionalized civil society, while the strong form called for a more complete decentralization that denies the predominance of development. 
Table 6: Power, authority, and knowledge in environmental discourses.

\begin{tabular}{|c|c|c|c|c|c|}
\hline 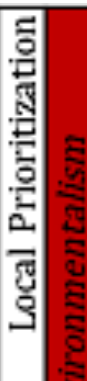 & & 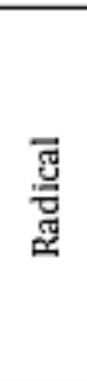 & 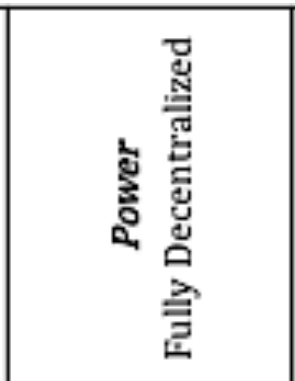 & 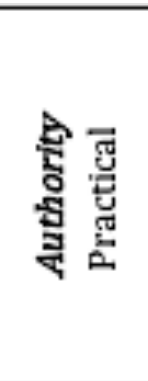 & 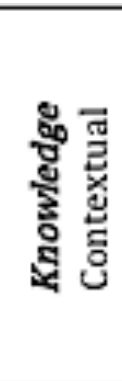 \\
\hline & 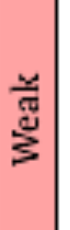 & 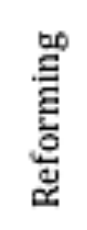 & 密总 & 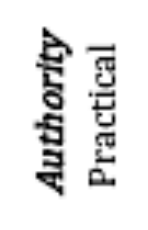 & 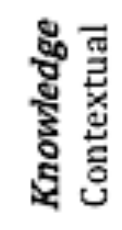 \\
\hline & $\begin{array}{l}\text { 焗 } \\
\text { 总 }\end{array}$ & 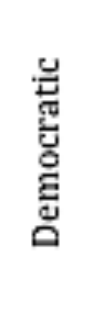 & 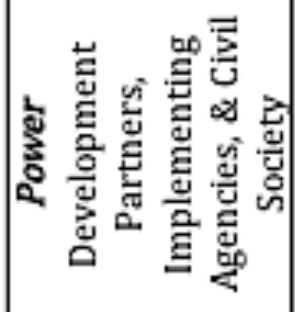 & 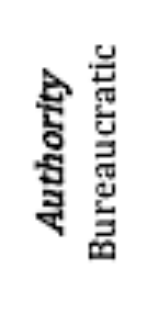 & 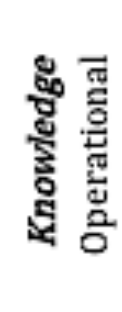 \\
\hline & 弟 & 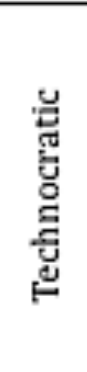 & 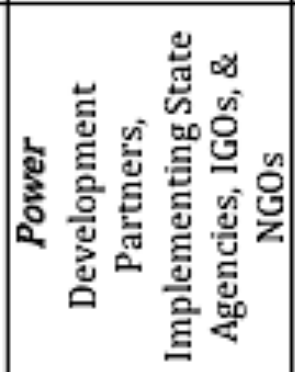 & 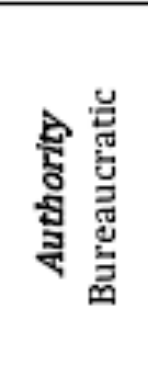 & 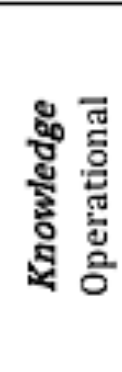 \\
\hline & 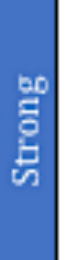 & 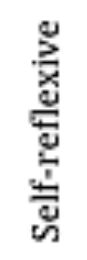 & 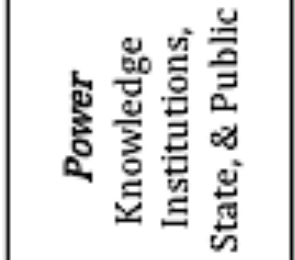 & 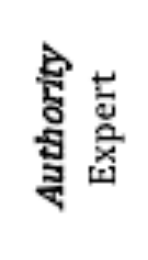 & 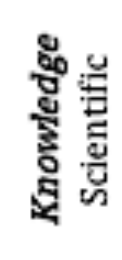 \\
\hline 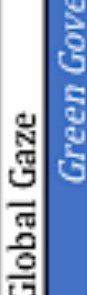 & 照 & 㽞 & 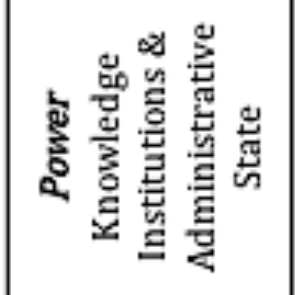 & 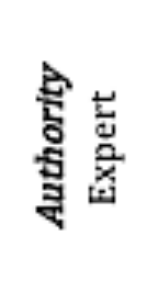 & 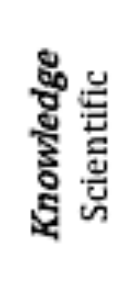 \\
\hline
\end{tabular}


While they are presented here as being distinct, there was overlap in the participants' discussions of climate change in the Pacific (Fig. 6). Central organizations that primarily engaged with green governmentality also utilized elements of ecological modernization by discussing the need to support operational capacity to implement their scientific findings. Correspondingly, the central and semi-peripheral organizations that used ecological modernization also appealed to scientific knowledge as it was needed to obtain funding. Civic environmentalism made its way into green governmentality and ecological modernization in similar ways-green governmentality focused on the increased communication of science, while ecological modernization emphasized the need for local inclusion for project implementation. Civic environmentalism took on elements of green governmentality by including the need for scientific knowledge in decision-making and ecological modernization by also discussing local involvement in development project implementation. 
Figure 6: The relationship between green governmentality, ecological modernization, and civic environmental discourses.

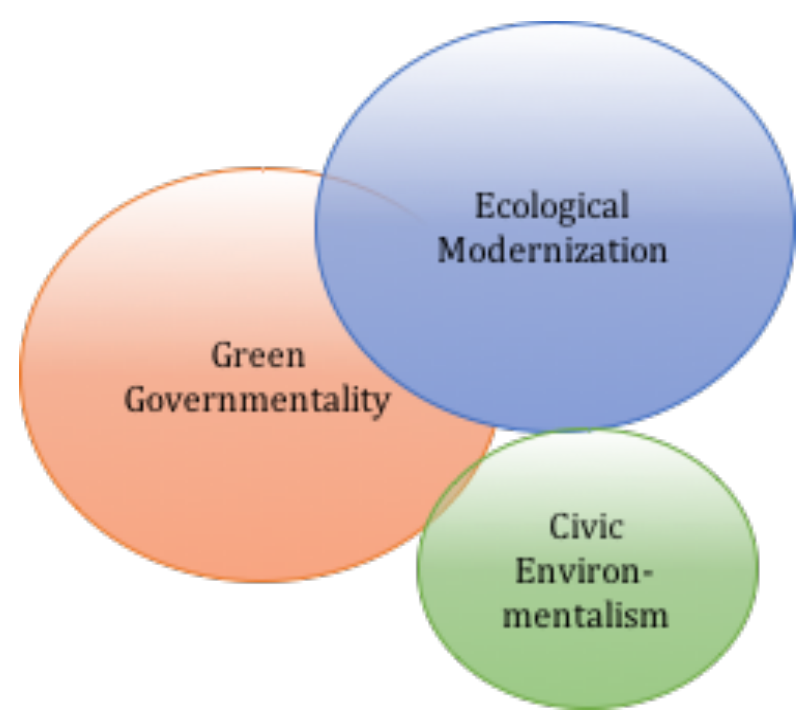

While there is some overlap amongst participants using each of the three discourses, the degree of integration varied. Green governmentality and ecological modernization upheld each other through regular and sustained engagement between organizations that fostered shared discursive constructions. Due to the fact that civic environmentalism is utilized primarily by organizations toward the periphery of the network, it has experienced a more limited uptake by other central and semi-peripheral organizations. In fact, the integration of civic environmentalism into green governmentality and ecological modernization is a relatively new phenomenon, according to participants. As one participant from a central organization described the shift:

we are hoping we would set up a whole new engagement with the NGOs to align with their work, and the NGOS typically don't ... one of the reasons that we haven't worked with them is because we're climate 
scientists and we do climate science. They most do climate adaptation, disaster risk management, and so forth with their work. And we sort of just said, "Oh, well, they'll get the science along with everybody, and they'll do something with it." Now we're realizing that if we work more closely with them right from the onset $\ldots$ because they've got connections and credibility with stakeholders that we can't even begin to dream about, and we want those same people to have a better understanding of the science is saying about the climate and climate change in particular. It seems logical now that we would start talking to NGOs to help work with them to actually try to get our message across to the subnational scale. This is like the provincial governments, local community, and so forth. So, we haven't done much in the past but we would definitely see NGOs as an emerging sort of stakeholder for us as science providers.

While still strongly identifying with the scientific knowledge production elements of green governmentality, this participant demonstrated the recent shift of more central organizations toward acknowledging the need for broader inclusion in decision-making and governance. While still limited, it is considered a growing field of discussion and practice in the Pacific.

Part of the reason for this shift could be a degree of disappointment with the impacts of top-down governance. Participants from central organizations were aware of the feelings of disgruntlement held by communities over the top- 
down governance efforts that had previously been the norm. As one participant stated:

We got some communities now and we say we are here from [central organization], and they are like, "That's impressive." But not anymore, no one cares anymore. It's, "You are here to waste our time some more. You are here to talk about your big fancy sweet potatoes that can withstand salty soils and water-logged soils, but at the end of the three-year period you are gone, and we never hear from you again." So, I think people in the community have been quite adversely affected by projects.

This sense of short, one-off projects was shared by other peripheral organizations, as well. One participant from a peripheral organization put it this way:

Because there are a lot of piloting, piloting of models and projects. After that, that's it. Another funding comes, let's pilot it again. And when you go to the community, then there's, "Oh, we're here to do a baseline survey on ..." "Oh! We are over-surveyed. Where's all the information that was collected? The same information that you wanted the Ministry of Health, or the local NGO, or the government came and collected it. Where's that information? So, you guys aren't coordinating." And I think one of the lessons we've learned is that we're too focused on piloting, piloting, piloting. And I think some of the funding coming in are too regional so you could have $90 \%$ of the funding stuck at the regional and national level. 
The focus was on building the resilience of community, but they only get $10 \%$ of that funding, which is just loose change. So that means you don't really have that impact.

This acute understanding of the challenges in current governance structures and mechanisms could be bolstering the uptake of democratization of knowledge and agenda-setting in governance priorities, either through stronger green governmentality and ecological modernization discourses or through more civic environmentalism in the network. In other words, the vocal assertion of disenfranchisement by communities could be pushing organization to localize their practices. Additionally, the success of the local power narrative in COP21 negotiations (Denton, 2017) could be seen as producing and produced by this local shift in governance priorities. This idea will be taken up more fully in the next chapter. 


\section{Chapter 5: Climate Empire \\ Introduction}

A participant shared with me an interesting perspective on the challenges of power within the Pacific. First, he drew a picture of a Fijian in traditional attire. He said, "See, they are half-naked." He then drew a missionary in a suit and tie, and he said, "See, here they come in, and they are very clothed." He then drew another suited figure, and stated, "So, the Fijians followed the way of the missionary, they dressed up, and they wore their suits." He then vaguely drew another figure.

And now, we have all these people in the movies and around. And they are half-naked again! And what do Fijians do? They have started to be half-naked. So, these people from the outside, they have influence. And if they take away climate change, then don't you think things will go back to the way they were before?

This participant discussed the dramatic transformations surrounding the global emphasis on climate change on Pacific Island society, finance, and the environment, itself. He expressed a deep concern that at some point climate change would no longer capture the global imagination, and the Pacific Islands would be left with the repercussions.

Governance of the climate has reshaped global pathways of power in numerous ways. Practitioners and decision-makers are networking together on issues of climate change at local and global levels in ways that shape both the 
global and the local spaces in remarkable ways. The networks I have visualized so far in this dissertation have been presented as static, representing a crosssection of spaces and ideas at a particular point in time. However, the networks that these static visualizations represent are, in reality, constantly shifting and reacting to the spaces in which they exist. They shift and change as organizations vie for power in the form of funding, control over rules and standards, and influence in decision-making spaces (Grewal, 2008; Hadden, 2015). While the histories of these networks influence their trajectory (similar to path dependence (Pierson, 2000)), the networks are not fixed. As Miller and Edwards have argued, "global environmental governance...functions by means of new, complex, hybrid forms of knowledge and power still being forged-and therefore still fragile, negotiable, and worthy of our most careful and creative attention" (2004, p. 6).

This chapter works to better understand the structure and fluidity of global environmental governance in the Pacific Islands. First, I conceptualize the impact of what I call Climate Empire on the social and environmental realities of the Pacific Islands. Climate Empire builds on the work of Michael Hardt and Antonio Negri (2000) along with a reconsideration taken on briefly by Clark Miller (2004) to explore the way in which the global systems of information and communication are restructuring the way the earth is governed. I then look specifically at Climate Empire within the Pacific Islands, paying particular attention to the way in which Climate Empire has been built through the legitimation of global knowledge, 
funding practices, and regionalism. Additionally, I explore the implications of Climate Empire for the way in which nature is constructed and governed within the Pacific Islands. Finally, I look to the relationship between local and global elements of climate knowledge and its impact on the production of Climate Empire.

\section{Empire}

The concept of empire has been used by scholars of anthropology, literature, history, and political science through a variety of lenses and settings throughout the years. ${ }^{17}$ While showing the ways in which empire has been used across the disciplines, Pitt's (2010) extensive review of the concept of empire demonstrates its wide-ranging uses and definitional challenges, yet emphasizes the social stratification and the inherent inequalities embedded in empire. Doyle, alternatively, provides a usefully straightforward definition: "Empires are relationships of political control imposed by some political societies over the effective sovereignty of other political societies" (1986, p. 19).

While empires have a long history-Persian, Turkish, Mongolian, and others-much of the recent work in empire has dealt specifically with the historically imperial powers of European countries and the more recent American

\footnotetext{
${ }^{17}$ While I use the concept of Empire loosely here to discuss global climate regimes, it is important to note that historic empires have brought about violence and death, to which the challenges of Climate Empire do not even come close to comparing. I hope to honor the history of those that have died at the hands of agents of empires, while exploring a subtle way in which these logics and mechanics of control share similarities with the climate regime.
} 
expansions (Pitts, 2010). European empire and liberalism are in many ways "mutually constitutive" (Armitage 2004a, p. 602, as cited in Pitts, 2010), where the tenets of self-government, economic growth and stability, and moral individualism are incorporated into exported forms of Western modernity. While cultural divides and differing ideas for governance brought substantial challenges to Western expansionism, in many ways, compliance with empire was brought about through non-Western elites' professionalization and internalization of universalist values (Bull \& Watson, 1984). This final understanding of the role of elites in building and maintaining an empire provides a sort of bridge to understanding the way in which empire is explored in this dissertation.

While states play a vital role in the governance of the globe, Hardt and Negri (2000) present a different, less state-centric understanding of Empire in their work by the same name. Hardt and Negri argue that the sovereignty of states has declined post-World War II, and its place has been taken by the governmentality, or logic of rule, that they call Empire. "Our basic hypothesis is that sovereignty has taken a new form, composed of a series of national and supranational organisms united under a single logic of rule. This new global form of sovereignty is what we call Empire" (ibid., p. xii). These 'organisms' go beyond traditional spaces of authority to include multinational corporations and supranational organizations (e.g. the International Monetary Fund, World Bank, United Nations, the G8, etc.) that police economic production and set themselves above space, time, and the social order. In other words, they move fluidly 
throughout global territories, presenting an ahistorical and apolitical approach to governing.

Less than a state or set of states imposing their will, this understanding of Empire functions as an "imperial machine" shaping and pushing networks of information and communication. Empire works in and through a master narrative of universality and inclusivity that, following Foucault's biopower (2003, 2009, 2010), ${ }^{18}$ is interested in populations rather than people. In other words, instead of policing individual bodies and actions, it deals with efforts to classify, standardize, and normalize whole populations. "Power, as it produces, organizes; as it organizes, it speaks and expresses itself as authority. Language, as it communicates, produces commodities but moreover creates subjectivities, puts them in relation, and orders them" (Hardt \& Negri, 2000, p. 33). Empire is less concerned with the impact of traditional forms of sovereign authority, and more with the forms of language, knowledge, and categorization that influence the internal realities of people across the globe.

One of the primary ways that the production of Empire is made possible, according to Hardt and Negri, is through informatization, or the transfer of the economy from the disciplinary factory to knowledge, communication, and affective services. Through this transfer, an information economy has emerged that is reliant on networks of cooperation and communication imbedded in

${ }^{18}$ Foucault's biopower, however, does differ substantially. See Dean (2003) for a critique of Hardt and Negri's usage. 
systems of immaterial labor. The global networks that construct the information economy form a decentered and deterritorialized apparatus of rule that runs throughout all spaces of production. This stands in stark contrast to the material forms of labor and production highlighted in Karl Marx's work (1978), thus requiring new forms of administration.

While this network works in and through all spaces of production, Hardt and Negri also argue, "[t]he decentralization and global dispersal of productive processes and sites, which is characteristic of the postmodernization or informatization of the economy, provokes a corresponding centralization of the control over production" through a virtual panopticon of monitoring and regulation (2000, p. 297). In other words, in response to the dispersal of spaces of production, Empire exerts a corresponding centralization of efforts to police these networks. It is through this constant expansion and contraction that Empire creates its own crises. However, due to the inevitability of micro-conflicts in the networks that form Empire, Hardt and Negri refer instead to "corruption" (ibid., p. 202), which they see as more representative of the continual state of disruption than a central crisis.

While Empire could be understood as a bleak prognosis, Hardt and Negri also emphasize that the networks of information and communication made to service Empire also function to create a new political constituency, the "multitude." The multitude's collective power is made possible through the new global pathways shaped by the sovereign. In other words, the connectivity that is 
necessary for Empire's rule also means that constituents can form relationships with one another and create new forms of democratic rule. Their power extends democratic possibilities through and beyond traditional state boundaries to encircle the globe.

\section{Colonial Histories and Empire}

While Hardt and Negri devote little time to discussing Empire's relation to colonialism, the use of the Pacific Islands as a case study in this dissertation makes this a particularly compelling relationship. Colonial rule existed with a single point of domination and resistance: the administrative state as the arm of imperial power in the colonies (Storey, 1997). This space was governed in part through the alternating forces of coercion and threat of revolt. Alternatively, the power within Empire is deterritorialized, scattered across multiple spaces.

Instead of letting pressure build to where coercion is required, Empire is able to keep coercion at a minimum by virtue of its deterritorialized and decentered nature.

An interesting analogy for these different forms of crises would be in the differences between tomato sauce and broth when boiling. The viscosity of tomato sauce means that, even with only moderate heat, large bubbles tend to form and erupt. It is thus necessary to constantly stir the sauce in order to pop the bubbles before they get to the surface. If left alone, boiling tomato sauce makes a mess. Similarly, the tension created in the tight form of control with the colonial state meant that, without constant attention, the pressure built in 
resistance was quite large and caused eruptions that required coercion to contain. Thus, the crises of colonialism were acute. Alternatively, with similar heat, boiling broth creates smaller bubbles. These smaller bubbles can let out air a little at a time, making it less likely the bubbles will ever build large enough to, at the point of eruption, make a mess. The governmentality of Empire creates an unending number of spaces at which pressure can build and be released without the need for (as much) coercion. Thus, the corruption of Empire is less damaging to its overall structure. This is, admittedly, a bit simplified. Colonial governments have long relied on science and technology within their colonies to shore up their power in ways that have similarities to the efforts put forward by Empire (Anderson, 2006). However, this differentiation will be discussed in more detail when discussing the Pacific Islands as a case study.

\section{Furthering Empire}

The critiques to Hardt and Negri are noteworthy (Passavant \& Dean, 2004; Sprague, 2011). First, their limited attention to the continued role of the state limits their applicability to modern day forms of governance (Sprague, 2011). Although some argue that governance is now "post-sovereign" (Karkkainen, 2004), this may be an overstatement. The transformation of sovereignty in an age of global relations is not solely a state-constraining force, it is also enabling (Weiss, 2005). New relations of 'entwinement' with other global power networks at transnational and supranational levels that can actually reinforce, while admittedly transforming, the role of domestic institutions in 
upholding global power relations. As Jessop (2004) argues, deterritorialization is not causing states to cede sovereignty, but rather it is encouraging them to increase their efforts toward metagovernance: redesigning markets, constitutional change and juridical re-regulation of organizational forms and objectives, organizing conditions for self-organization, and collibration, or using the tension between two social groups to achieve policy aims. "What we are witnessing is the rescaling of the complexities of governance, rather than the rescaling of the sovereign state or the emergence of just one more arena in which national states pursue national interests" (Jessop, 2004, p. 67). Understanding state sovereignty in this way, while a conceptual break from Hardt and Negri, can help to better frame issues at play within international governance, particularly within postcolonial spaces like the Pacific Islands.

When looking to the Global South, Empire faces further challenges. Hardt and Negri's attestation of the "smoothness" and "immanence" of Empire not applicable under the fractured and incomplete nature of governance in the Global South (Dunn, 2004). Specifically, Empire relies on the groundwork of modern sovereignty - where "the nation sustains the sovereign by claiming to precede it" (Hardt \& Negri, 2000, p. 101) - to build their new postmodern sovereign in Empire. In other words, Empire as post-sovereign is borne out of a stable and somewhat universal understanding of the sovereignty of the nation-state. The challenge is that, with the colonial histories of many developing nations, modern sovereignty was never fully established such that it must 'give way' to a post- 
modern sovereignty (see Dunn (2004) regarding Africa). Thus, it is important to avoid the pitfalls of a Eurocentric Empire by allowing for a "multiple and shifting construction of sovereignty" (Dunn, 2004, p. 146) that takes seriously the histories of spaces and does not succumb to a totalizing "smooth" postsovereignty.

With these critiques in mind, I seek in this dissertation to build on the concept of Empire, rather than take it as presented. One particularly useful perspective by which to further the concept of Empire comes from Clark Miller. In taking Hardt and Negri's work beyond the realm of economic production, Miller argues that their work could be improved by paying attention to the science and technology that creates and upholds the rules of the machine. He states:

Contra Hardt and Negri, if Empire exists, its power relies in the construction of new systems for classifying, standardizing, organizing, and ordering knowledge and people on a worldwide basis. These systems - at once scientific, technological, social, and political-link together the inhabitants of far flung networks, structuring the production and reproduction of identities, values, and bodies (Bowker \& Star, 1999). This was the fundamental insight of Foucault's work on the normalizing, disciplinary technologies of the prison and the sanitarium and the experts who designed their practices and architecture (see, e.g., Foucault, 1973). Thus, as we seek to understand the constitutional foundations of global governance, we must not turn to the United Nations General Assembly- 
or even the Security Council-but rather to the Specialized Agencies, and to the growing array of public and private, formal and informal institutions of scientific, technical, and technological production and harmonization that lie outside the UN. It is in these institutions that Empire's regulatory and normative armature is being forged. (Miller, 2004, p. 81)

This understanding of Empire allows for a deeper analysis into the knowledges at play in producing and reproducing Empire. He argues that this global order resides in:

first, the growing tendency of people all over the world to frame policy problems in specifically global terms; and, second, the casting of actions in specifically technical terms as a strategy for bypassing traditional concerns with sovereignty in the world system. (ibid., p. 82) In seeking to understand the globalism at the heart of this Empire, Miller looks less at material flows (Keohane \& Nye, 2001) and more to role of building a global imaginary (e.g. orientalism (Said, 1978) and the making of the nation (Anderson, 2006)). This global imaginary makes knowledge of the earth feasible by organizing systems to produce and reproduce the globe (Miller \& Edwards, 2001). Technical assistance is the practice of power that bolsters the authority of these global governance institutions.

Miller's attention to the full range of systems at work in the Empirescientific, technological, social, and political-along with his emphasis on the practices of power can make the concept of Empire more useful for analyzing the 
current system of governance. This expansion allows for greater nuance than the "smooth" and "global" Empire, and takes seriously the fragmentation that occurs in the reproduction of Empire in multiple spaces. In other words, by taking seriously the rules of the imperial machine, it becomes easier to see the way in which those rules shift, change, and are differently interpreted in multiple spaces. This is particularly evident within the global systems of climate change governance.

\section{Climate Empire}

In this section, I explore the processes occurring globally and within the Pacific Islands regarding climate change governance under the concept of Climate Empire. Climate Empire is the network of knowledge and communicative services that imagine, build, and administer the globe. This includes the scientific, technological, social, and political systems that make the climate legible and governable. Following Miller, Climate Empire includes the "public and private, formal and informal institutions of scientific, technical, and technological production and harmonization" (2004, p. 81) that produce the technical and bureaucratic knowledge and procedures meant to control anthropogenic climate change.

These networks of communicative and knowledge-producing institutions are not free-flowing, but rather are grounded by the "regulatory and normative armature" (Miller, 2004, p. 81) of global climate change governance. The regulatory armature is found in the ability of institutions to deem what is and is 
not deemed authoritative knowledge for work in the Climate Empire. The master narrative of universality and inclusivity within Empire produces a normative drive toward biopolitical control over the earth and its inhabitants. State sovereignty is, thus, transformed by the governmentality of Climate Empire.

In this understanding, power is less about the disciplinary or juridical power of governments over constituents. Instead, power "is deployed and exercised through a net-like organization" (Foucault, 1980, p. 98), where the entire network of climate change practitioners and decision-makers is wrapped up in the circulation of power. This does not assume that Climate Empire is a post-sovereign space, nor that it is smooth. Rather, it is a space of both domination and renegotiation among multiple actors.

In the same way as Empire is the "non-place" of power in relations of production (Hardt \& Negri, 2000, p. 190), Climate Empire encompasses the whole globe as its 'territory.' Climate Empire has set itself as a policing force above space, time, and the social order. The climate itself is constructed as a global and globalizing force (Jasanoff \& Martello, 2004; Miller \& Edwards, 2001), thus providing space for Climate Empire to cross sovereign boundaries through a deterritorialized and decentered apparatus of rule. In other words, because climactic changes are unable to be studied and solved on a state-by-state basis, global networks of climate knowledge and communication are necessary to meet the challenge of climate change, as presented by Climate Empire. 
Climate Empire gains authority by exploiting an apolitical discourse, as the purveyors of instrumental solutions to global, technical problems (Demeritt, 2001). In other words, the authority of Climate Empire is fostered by the expectation that decisions should defer to scientific expertise and bureaucratic structures. Scientific, technological, social, and political systems form the "engineering rules" of the imperial machine that is Climate Empire. In other words, the scientific view of the earth, the technologies we use to measure it, the social ways in which we relate to it and one another, and the political systems by which we seek to govern it all work to produce and reproduce the Climate Empire.

Efforts to know the earth rely on a global imaginary that is created and upheld through networks of climate communication. In order to police the climate multitude, Climate Empire's panopticon comes through authoritative science (Bocking, 2004), and its ability to monitor, evaluate, and regulate knowledge production according to the standards of unanimous, quantitative, generalized, and conducted according to scientific process. As Bocking has described, "The authority of science ... is not simply self-evident; it is a phenomenon embedded within environmental politics, constructed and asserted whenever participants in environmental politics require it to support their positions" (ibid., p. 10). It is upheld through administrative rationalism, or the process of "seeking, with the guidance of technical expertise, rational and efficient solutions to the problems of society, translating the authority of science into political power" (ibid., p. 21). 
Climate Empire thus polices what is considered authoritative knowledge. It does this by using administrative rationalism to not only require authoritative science for its own activities, but also to legitimize the use of authoritative science as the final say in decision-making in its subjects' eyes. As Agrawal has pointed out, "[M]odern forms of power and regulation achieve their full effects not by forcing people toward state-mandated goals but by turning them into accomplices" (2005, p. 217). Forms of climate knowledge are thus taken up by people as they seek to meet global requirements for resources and eventually become internalized as legitimate ways of knowing the earth.

This is not to say that the Climate Empire is somehow outside or distinct from the productive machine of the Empire. In fact, governance of the earth is tightly interwoven with the professionalization, economization, and overall neoliberalization of productive systems throughout the earth (Bakker, 2010; Castree, 2008). Specifically viewing climate change diplomacy and governance as functioning under a Climate Empire, however, can provide a different perspective on the ways in which the imperial machine of Empire governs the globe.

\section{Local and Global Construction of Climate Empire}

Globally, climate information flows through networks that are primarily dominated by a relatively closed group of white, male climate change scientists and practitioners from industrialized nations (Barnett \& Campbell, 2010). This allows for relative ease within these spaces to police the types of knowledge 
considered legitimate and maintain the authority of Climate Empire (an exception being the "climate deniers" that many times come from these same spaces). However, knowledge cannot stay at this global level and be useful for overcoming climate change challenges. While Climate Empire can be seen purely in global terms, the local and global actually work together in producing and reproducing the Climate Empire. This is primarily accomplished through the relocalization of information that is a necessary component of climate knowledge. As described by Miller:

Technical assistance works as a two-way street. Data collection networks developed by these institutions provide detailed information for increasingly sophisticated models of global systems and processes. At the same time, these networks help relocalize global knowledge in a variety of ways: (1) translating and extrapolating the outputs of global models into locally relevant information; (2) transmitting and transplanting this locally relevant information from sites of production to sites of consumption; and (3) helping recipients interpret and make sense of information in relation to local or national policy. (2004, p. 83)

The relocalization of knowledge, then, occurs as the outputs of global technical models are reintegrated into the spaces from which their inputs came (Fig. 7). The relocalization of knowledge reconstructs local categories and representations by working to meet global requirements. The local also plays an 
important role in reshaping these spaces, as knowledge is gathered through data collection networks and incorporated into global models. ${ }^{19}$

Figure 7: Diagram illustrating the knowledge transfer within Climate Empire.

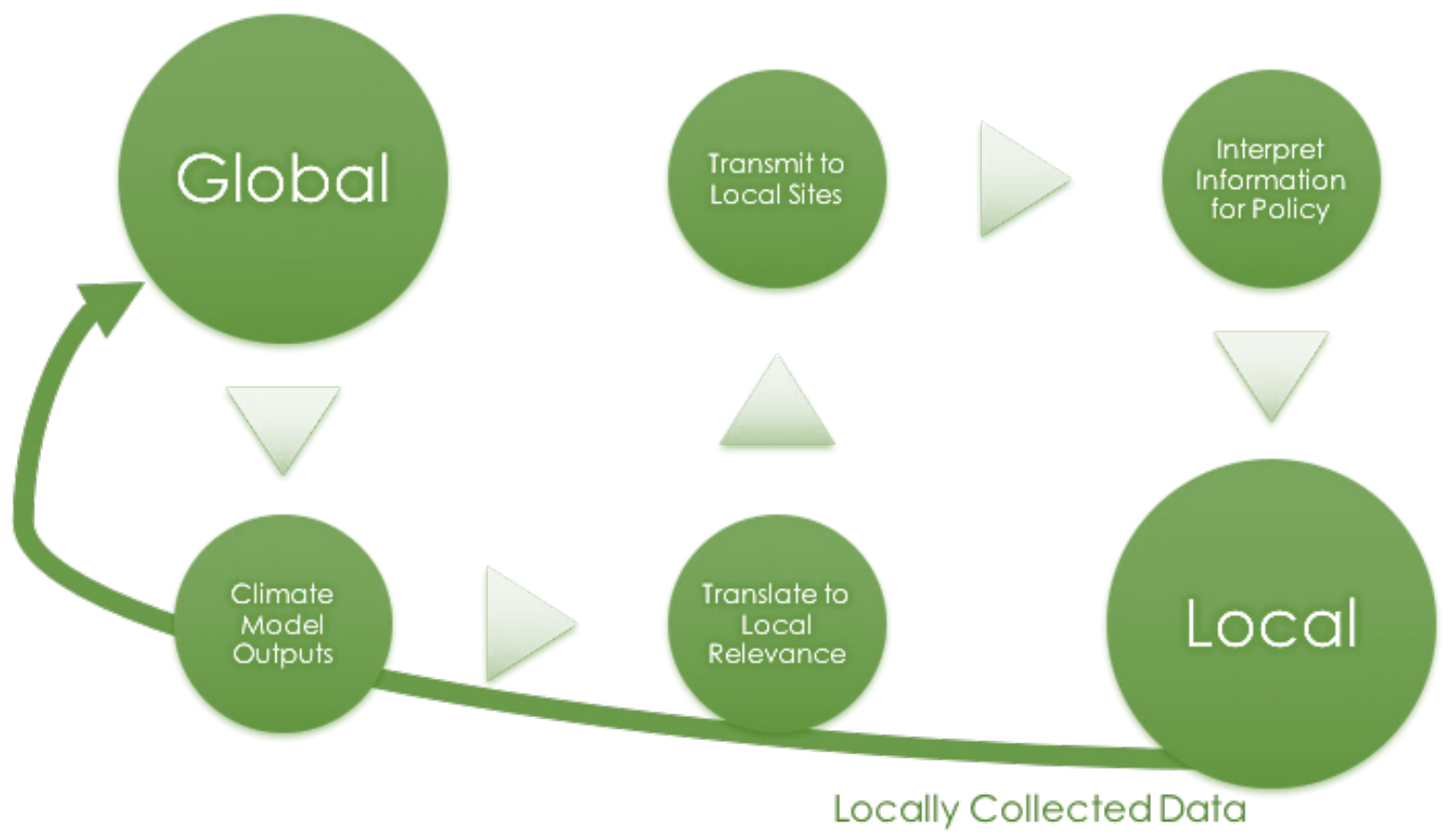

Thus, the local and global are not pitted against each other at ends of the spectrum, but rather are co-constituted as data is locally collected, globally analyzed, and relocalized within polices and projects. As Hardt and Negri describe it, "In many characterizations the problem rests on a false dichotomy between the global and the local, assuming that the global entails homogenization and undifferentiated identity whereas the local preserves heterogeneity and difference" (2000, p. 44). They call instead for a more nuanced

\footnotetext{
${ }^{19}$ Miller's work deals with the transformation of the global by the local limitedly, but this topic is taken up more in the "Relocalization of Knowledge and Reshaping the Climate Empire" section of this chapter.
} 
understanding of the relation between the two. This chapter seeks to do just that. While the previous chapters of this dissertation have presented local and global as positioned on opposite ends of the spectrum, this chapter works to reconsider the creation of both the local and the global under a network of relations. The next section is concerned with the way in which Climate Empire is structured within the Pacific Islands. I will then look to the way in which relocalizing knowledge impacts Climate Empire in ways that have been heretofore underexplored.

\section{Building the Pacific Island Climate Empire}

The colonial legacies of the Pacific Islands are still palpable within governance in the region. An emphasis on vulnerability, lack of capacity, and powerlessness is evident in the speech and practices of actors, particularly those external to the region. Climate change governance in the region is ripe with "assumptions about scale (large global forces literally and metaphorically drowning small islands); power (social-ecological drivers of vulnerability which overwhelm weak local systems); and knowledge (models and indexes are a sine qua non for decision making)" (Barnett \& Campbell, 2010; p. 2). While these views are challenged by some (a topic taken up later in this chapter), they directly impact what is understood as possible and desirable in the region.

These views of power, authority, and knowledge are mirrored in the global elements of the narratives and discourses in Chapters 3 and 4 of this dissertation. In Chapter 3, the villain of the global technical narrative was lack of 
capacity, resources, and scientific information. As discussed in Chapter 4, organizations that used the green governmentality discourse framed capacity challenges as a lack of scientific knowledge and technical capabilities, while organizations that used ecological modernization discourse were concerned with the lack of bureaucratic capacity necessary to meet external donor funding requirements. While focused on slightly different operational elements of climate change governance, these ways of speaking all share the view that legitimate decision-making occurs through the use of scientific and bureaucratic knowledge, and that a lack of those particular types of capacity is the foundation of the problem in the Pacific.

These ways of speaking about and governing climate change have, over time, built Climate Empire. Climate Empire in the Pacific Islands has come about through three main processes. First, informatization of the climate has ensured that the scientific and technical expertise remains at the forefront of decisionmaking. Second, financing for climate change governance has cemented colonial legacies and ensured that Western logics of rule remain pertinent to Pacific Island decision-making. Finally, regionalism within the Pacific Islands has fostered a focal point for these logics of rule, fortifying the networks of knowledge and communication, while also deepening the policing capabilities for Climate Empire. Each of these areas are taken up below. 


\section{Informatization}

Informatization, again, is the process behind the production of the information economy through knowledge, communication, and affective services. Within Pacific Island Climate Empire, knowledge networks work to gather local climate information, deliver it to global information processing spaces, and relocalize it. In these spaces, scientific and technocratic understandings of the climate and its inhabitants are required in order to ensure efficiency across the dispersed transnational and global spaces in which the nodes of the network are situated. In other words, due to the multi-scalar and distributed production of climate knowledge - both regionally within the Pacific Islands and globallyauthoritative science is privileged for its ease of translation and scalability.

By forming climate change governance around these models and indexes that accompany authoritative science, efforts to boost scientific, bureaucratic, and technical capacity have been pushed to the forefront of governance, while the adaptive capacity of community interventions has been largely ignored (Barnett \& Campbell, 2010). This has left many of the central Pacific Island climate practitioners privileging bureaucratic and scientific knowledges over local constructions of climate vulnerability in order to meet the capacity constraints produced by informatization.

Additionally, global requirements have pushed governance in the region to form in particular ways due to the ill-adaptive ways of informatization. As one participant stated: 
[UNFCCC] demand[s] countries to put in place frameworks, national and regional frameworks on climate change, national adaptation plans on climate change, national policies on climate change. So that that's an outside-driven problem. So, when countries follow those instructions, they silo climate change as a sector, which in fact is not a sector.

In other words, UNFCCC's drive for clear bureaucratic structures pushes countries to consider climate change as external to the other issues and challenges being faced as a region. This silo-ing effect of outside influence was criticized by many of the participants with whom I spoke. Many participants stated that an integrated approach was the only way they could see climate change issues actually being addressed. However, the high levels of expertise required by the informatization of climate change in the Pacific stood as a formidable barrier to greater levels of integration.

\section{Financing}

Climate Empire in the Pacific Islands is, in many ways, built by the flows of resources in the region. While the discursive practices upholding the scientific and bureaucratic authority do considerable work to legitimize the Climate Empire, they gain much of their power through financial backing. The transformative impact of global financing on governance in the region was discussed by many participants, particularly within government agencies, but also in regional organizations more broadly. One participant described the impact of GCF's globally regulated funding as follows: 
there was a GCF project approved Vanuatu that is like 40 million USD for the MET office. I've worked with the MET office, and it's like there's probably 5 people in the climate section. I just can't imagine how that's gonna distort the MET office compared to other government departments. How that's gonna exacerbate the differences between ... well anyway, I guess this is all part and parcel of the climate change space.

This individual also stated:

In relation to the funding, again, what I'm interested in is some of these projects are so ... they almost reinforce the silo-ing of climate change ministries and create empire-building within the countries themselves, within the climate change ministries.

Funneling unprecedented quantities of money into government departments bolsters the ability of Climate Empire to shape Pacific Islands governance according to its own image.

In the Pacific Islands, global and regional organizations discuss the need for states to be at the forefront of decision-making. In practice, however, states' interests are many times dictated by the requirements of funding. Traditional donor partners-including post-colonial states-along with global bodies such as the UN agencies, the Global Environment Facility [GEF], and others, provide much of the funding for the region through a variety of bilateral, multilateral, and regional funding mechanisms (Atteridge \& Canales, 2017). While donors' activities vary considerably, many funding requirements tax the capabilities and 
capacities of Pacific Islanders in ways that can limit access. One participant described a project in this way:

Fiji was the first one to get approved, the Green Climate Fund project. So, overall that was a $\$ 200$ million project that the Green Climate Fund was gonna put in 40 million, because it's in phases and the first phase cost 40 million. We did some calculation with the others whose work contributed to this, and we reckoned it was 2 million for all the things that went down [cost benefit analysis, gender analysis, economic and social safety guards, environmental impact assessment, etc.]. 2 million in from 200 million up, not bad. But nobody in the region has 2 million lying around to do that in the first place.

In other words, while there was a formidable amount of funding on the table, GCF required \$2 million of upfront investment in research to access the funds that they may or may not receive in the end, a considerable barrier for many Pacific Island countries. Participants regularly discussed this type of issue. The series of bureaucratic, scientific, and technical boxes needing to be checked off in order to receive financing took up valuable time and energy, while ensuring that Western logics of rule remain pertinent to Pacific Island decision-making.

The bureaucratic, scientific, and technical conditions to be met for financing sediments the imperial power of Climate Empire. Funders from external to the region gain dominance over decision-making spaces by holding the keys necessary to access resources. They determine the rules of the game, ensuring 
their requirements are met through administrative functions and the production and policing of authoritative knowledge. While there are conversations about changing these forms of funding (as one participant stated, "This absolute appetite for rethinking [the donor-recipient] relationship in the Pacific."), there remains a power imbalance between funder requirements and the ability of Pacific Island states to determine their own climate futures. This is reinforced through efforts toward regionalism.

\section{Regionalism}

Much of the informatization and financing within the Pacific Islands occurs through regional governance efforts, particularly through CROP agencies. As many states are small, regional agencies concentrate the capacity of the region by drawing top Pacific Island and international talent into their organizations. Repeating again from the introduction of this dissertation, CROP agencies were described by one participant as a "decolonization process that warped into technical assistance." This relationship to the colonial histories of the Pacific Islands impacts the current governance efforts. While CROP agencies are mandated to receive instructions from states, the colonial legacies within CROP agencies is evident in the partial or full participation of states such as Australia, New Zealand, and others. This is not to say that outside states control these decision-making spaces, but rather they make for complicated and, at times, contentious relationships. 
CROP agencies gain much of their regional power by being a funnel for climate financing in the region. The bureaucratic structures that form the rules for finances within the Pacific put pressure on the limited bureaucratic capacities of organizations, thus privileging the CROP agencies' ability to pool the region's resources. For instance, the process to become an Accredited Entity for Green Climate Fund [GCF] funding is challenging, expensive in terms of time and resources, and yet it is necessary to access the billions in global financing available through GCF. SPREP was the first regional entity able to commit the time and resources to achieve this accreditation. This put this CROP agency in a unique position to determine what projects would and would not receive this financing.

Colonial legacies and control over finances have also placed CROP agencies in the position to lead the data collection networks (Miller, 2004) that serve to push locally gathered information into global climate models. This is accomplished through technical assistance programs that work to increase the capacity of states and local knowledge producers. The technical assistance provided by CROP agencies to connect the global and the local plays a large role in policing knowledge. As discussed in Chapter 3, CROP agencies many times serve as 'boundary organizations' in the Pacific. They play this role by lending or taking away authority from different ways of knowing. This is not to say that they work at the boundary of the network, but rather that they form a boundary between different portions of the network. CROP agencies hold central positions 
within the Pacific Islands climate change network (Chapter 4), but also serve significant brokerage functions in the network. For instance, SPREP and SPC, two of the CROP agencies most focused on climate change, have gatekeeper ${ }^{20}$ scores approximately 3.5 times larger than any other organization in the network. The brokerage scores allow regional entities to form a boundary between the local community information and strategies and the global donor bodies that allows them to be a gatekeeper for the type of knowledge that is deemed acceptable.

CROP agencies could thus be understood as agents of Climate Empire, functioning at a regional level to institutionalize the global technical logic of rule. Through bureaucratic and technical expertise, CROP agencies reinforce the requirements for particular types of knowledge and capacity that have authority in global intergovernmental organizations and post-colonial states. This type of decision-making can impact the sovereignty of states through subtle means. As one participant described the role of CROP agencies:

a lot of outcome documents and communiqués are written by the agencies for themselves, it seems. Just to justify their ongoing work, rather than a proper discussion and debate on a hard decision that needs to be made,

${ }^{20}$ Gatekeeper scores are determined by the number of instances of $B \rightarrow A \rightarrow A$, where $A$ and $B$ are separate groups in the network and the middle position is the broker. For instance, Australia $\rightarrow$ SPREP $\rightarrow$ 
and what that means for the countries to make that decision. That kind of

conversation. It seems to be about just agencies justifying their existence. The decision-making within the region, thus, tends to more heavily reside in the activities of these agencies, rather than the countries' informed decisions.

What makes this procedural control interesting in light of Climate Empire is the ability to both extend the network and centralize control. Regionalization makes for easier policing of the logics of rule at work within Climate Empire, as CROP agencies can work as a focal point for multiple projects in multiple locales simultaneously. The brokerage scores discussed earlier in this section demonstrate their role in finance, where they channel funding from global actors to local projects. Their connection to global financial flows, along with their work on the ground, allows them to monitor the local representations of climate change projects, thus extending the Climate Empire's panopticon to multiple levels. These elements of the Climate Empire impact both the social and environmental realities of climate change governance in the Pacific Islands.

\section{Climate Empire and Nature in the Pacific Islands}

The discussion of immaterial labor formed through knowledge networks in Climate Empire can leave behind the material realities relevant to production (Sprague, 2011), particularly when considering production of the environment. Another way in which this investigation of Climate Empire can shift away from Hardt and Negri's Empire is through a careful consideration of the material elements of constructing and governing the climate. 
One example of this material relationship with nature comes in the form of pigs. Pigs pay an interesting role in the social and environmental histories of the Pacific. Products of migration as early as the fourth century A.D., pigs have played an integral role in the survival of Polynesians. The pua'a (Polynesian pig), was small, free-roaming, and relatively domesticated. As Maly, Pang, and Burrows discuss:

Clearly, domesticated pua'a carried strong cultural value in traditional Hawai'i. Aside from being an important possession and food source, an oral tradition describes the adventures of Kamapua'a (the pig child), a powerful demi-god who ranged over the islands and into the sea. Even the name of the traditional land management system, ahupua'a, refers directly to the pua'a and highlights the animal's importance among the variety of resources that were collected and offered during the annual mahakiki tributes. $(2013$, p.2)

However, the modern pig shares little with the pua'a beloved by fourth century Polynesians. The modern pig is a product of European immigration and is much larger and feral, gradually moving further away from humans and into "pristine upland forests" (ibid.). Conservation efforts have recently explored options to remove these feral pigs from the land due to their non-native status along with the environmental challenges they pose (East Maui Watershed Partnership, n.d.). This is made even more relevant as climate change impacts the forests' ability to recover from disturbances like the pig. 
One individual I spoke with, however, shared a different view. Luau feasts that include kālua pigs cooked in an imu, or underground oven, are a critical part of native Hawai'ian social connectivity. They provide a space to get together and share abundance, and have served a variety of purposes throughout the Polynesian history on the islands. During the collapse of the sugar cane industry, native Hawai'ians were hit with high levels of unemployment, a particularly vulnerable position with limited employment options. However, this period also saw an increase in luaus, made possible by hunting the feral pigs around the islands. The pigs thus offered an opportunity for the community to feed itself, check in and reconnect, and make sure that everyone was getting the support they needed to get through this challenging period. Additionally, the pig represented the connectivity of the community - it had to be passed around to be slaughtered, butchered, cooked, then passed out to the community. It served a role as both the catalyst for the network and a practice of the network at the same time.

While this story is specific to the US Hawai'ian islands, the sentiment was shared by others I spoke with throughout the Pacific Islands. The individual who shared this story was concerned with the inextricability of the social and environmental networks. He discussed how any environmental management actions had to be placed within their social contexts in order to capture potential unintended consequences. 
As environmental concerns are subjugated to scientific and bureaucratic expertise, nature becomes an 'other' (Scott, 1998) to be oriented in service of the Climate Empire. In other words, instead of understanding nonhuman nature as a player in governance networks through its activities and efforts for survival (Latour, 2005; Lejano, Ingram, \& Ingram, 2013), Climate Empire makes nature into an object that can be "terraform[ed]," where "nature is approached as a terrestrial infrastructure subject to state protection, management and domination" (Bäckstrand \& Lövbrand, 2006, p. 55). The construction of nature as separate and controllable as opposed to integrated and fluid creates challenges for climate change governance. While Climate Empire works to create a "terraform" project, exerting control through governmentality onto social and environmental systems, local constructions of nature in the Pacific Islands introduce fluidity, adaptability, and responsiveness to governance of these systems. These competing discourses and their resulting practices can have tangible impacts on social and environmental governance. This misalignment is evident as knowledge is locally collected, globally analyzed, and relocalized in the Pacific Islands under Climate Empire.

\section{Relocalization of Knowledge and Reshaping the Climate Empire}

Following Judith Butler's (1997) work, Agrawal argues, "although it is fair to suggest that development discourses colonize subjects, surely they do not colonize all subjects" (2005, p. 225). This is also true of Climate Empire's efforts within the Pacific Islands. Local and regional organizations in the Pacific Islands 
have made efforts to reframe power, opening up the climate change space to include local strategies for governance (see Chapters 3 and 4 of this dissertation). The split in the narrative of climate diplomacy mirrors a larger trend of localization within environmental governance (Agrawal, 2005). Environmental loss to recuperation, appropriation to resistance, these stories of a new environmental governance mirror the post-colonial trend in discourse among developing nations from domination to freedom and subjugation to power. They are stories of liberation from the rigidity of the colonial master to the agency of the 'local,' in whatever form that takes. However, the Pacific Islands' localism still struggles against the discourses of powerlessness embedded in colonial legacies, focus on technical and bureaucratic capacities, and reliance on external funding.

While Climate Empire works in and through global strategies to produce and uphold their technical bureaucratic and scientific authorities, these global spaces are pushed into contact with these local challenges through data collection networks and efforts to relocalize knowledge. Data collection networks gather local information in order to globally analyze it. The relocalization of knowledge occurs within Climate Empire as climate information is communicated throughout the network. Again, this is done through:

(1) translating and extrapolating the outputs of global models into locally relevant information; (2) transmitting and transplanting this locally relevant information from sites of production to sites of consumption; and (3) 
helping recipients interpret and make sense of information in relation to local or national policy. (Miller, 2004, p. 83)

In the Pacific Islands, information on sea level rise, weather patterns, ocean temperatures, marine species, etc., is meticulously gathered through data collection networks, like the Global Climate Observing System (GCOS). GCOS was established in 1992 in order to standardize and routinize climate observations (Salinger et al., 2002). The Pacific Islands' GCOS (PI-GCOS) gathers climate information in-situ (more detailed than satellite data), and works through a formal system for delivering that information to GCOS. Global organizations like the World Meteorological Organisation and Intergovernmental Oceanographic Commission are working directly with organizations like SPREP and SPC to build the PI-GCOS data collection network. The information is then analyzed at a global level according to statistically predictive climate models in hopes of uncovering the true and correctable patterns of the globe. This globallymodeled data is then relocalized into Pacific Islands climate policy. The first objective presented for the PI-GCOS is, "To continually advocate the importance of GCOS observing systems to policy applications on the part of national governments and other interested users (e.g. social, cultural and economic implications)" (ibid., p. 7). Therefore, the relocalization is complete as PI-GCOS interprets global climate information for national policy.

The relocalization of knowledge produces crises as local and global ways of knowing come face to face. As local and global understandings of climate 
change in the Pacific Islands come into contact, resistance against the global constructions of environmental governance is discernable. Particularly in my interviews with participants from organizations at the periphery of the network, the local/global disconnect was evident. As one individual stated:

How people from outside governments pretend that they know everything in that region. They say, "we have the solutions to your problem." When you see most people talking about the solutions in the Pacific are the ones from outside. So, sometimes I just wonder, these are crazy people!

The idea that an external actor-even an external actor with access to technical knowledge and resources-could know the Pacific Islands well enough to speak for them and offer definitive solutions was deemed laughable by many participants. Communities can also feel confused or overwhelmed by the climate work occurring in the region. As one participant stated:

I just think the way it's structured right now makes it difficult for communities to know whether their money is coming from the SPC, SPREP, the UN ... I don't get the sense that they really know that. I heard one of the communities say, "Well, we always know when we have to talk about the project because we see the UN truck, and that's how the community knows." Fair enough.

These challenges can cause disconnect in the ability of Climate Empire to work in these localized spaces. 
While many times the local constructions of climate change can come in contrast with global constructions, they are all still focused on a similar goal-to alleviate the burden of challenges brought about by climate change. However, the complex nature of climate change in the Pacific Islands makes this even more of a challenge than in other places. As one individual I spoke with described her work:

one community we went to said, 'we need more knives.' And they were talking about climate change, and we were like, 'what?' And then we realized it's because they associate money coming from big institutions, and then we're there, so they are like, 'we should ask for knives so we can use this for fishing, agriculture or whatever.' So, for them, this is a holistic way of looking at the issues. It's not like they're worried about sea-level risk. The way we break down issues, I don't think it's the same at all because 'this is my life, this is my experience, so it doesn't really matter what it affects...whether the soil is eroding or whether the sea-level is rising. No matter is happening, this is how I experience this problem in my life.'

In this case, local participants may question the relevance to climate change to their lives at all. In fact, the focus on climate change may be seen as deferring resources away from more immediate needs - knives - such that the imperial imposition of Climate Empire is apparent. These levels of detachment between global climate change and local realities-ranging from disconnected decision- 
making to imperial imposition-presents a challenge as agencies work to connect the global and local for the production and reproduction of the Climate Empire.

It is in this space that CROP agencies become vitally important for the production and reproduction of Climate Empire. CROP agencies function as boundary organizations in order to mitigate the corruption formed from local resistance. These boundary organizations mediate and facilitate the coproduction of knowledge (Cash et al., 2006) in ways that may stifle, delegitimize, and displace certain forms of knowledge (Lejano \& Ingram, 2009) in order to streamline knowledge processes. Boundary organizations, thus, work to police Climate Empire by managing corruption in multiple spaces of data collection networks and relocalization processes. This ensures that there is not a single point of resistance, but multiple spaces of contestation. Returning again to the analogy earlier in this chapter, while the "tomato sauce" of colonial forms of rule required continuous attention, Climate Empire works in and through the "broth" of regional governance by creating multiple points of pressure and pressure alleviation. This can also be demonstrated through network structure, as is done below (Fig. 8). Again, this is not a perfect analogy. Colonial powers many times worked through regional elites (Bull \& Watson, 1984) in ways that may mirror the Climate Empire network approach. However, this is meant to exemplify a broader shift in organizational power structures of control. 
Figure 8: Network visualizations of differing relations of power under colonial and Empire rule.
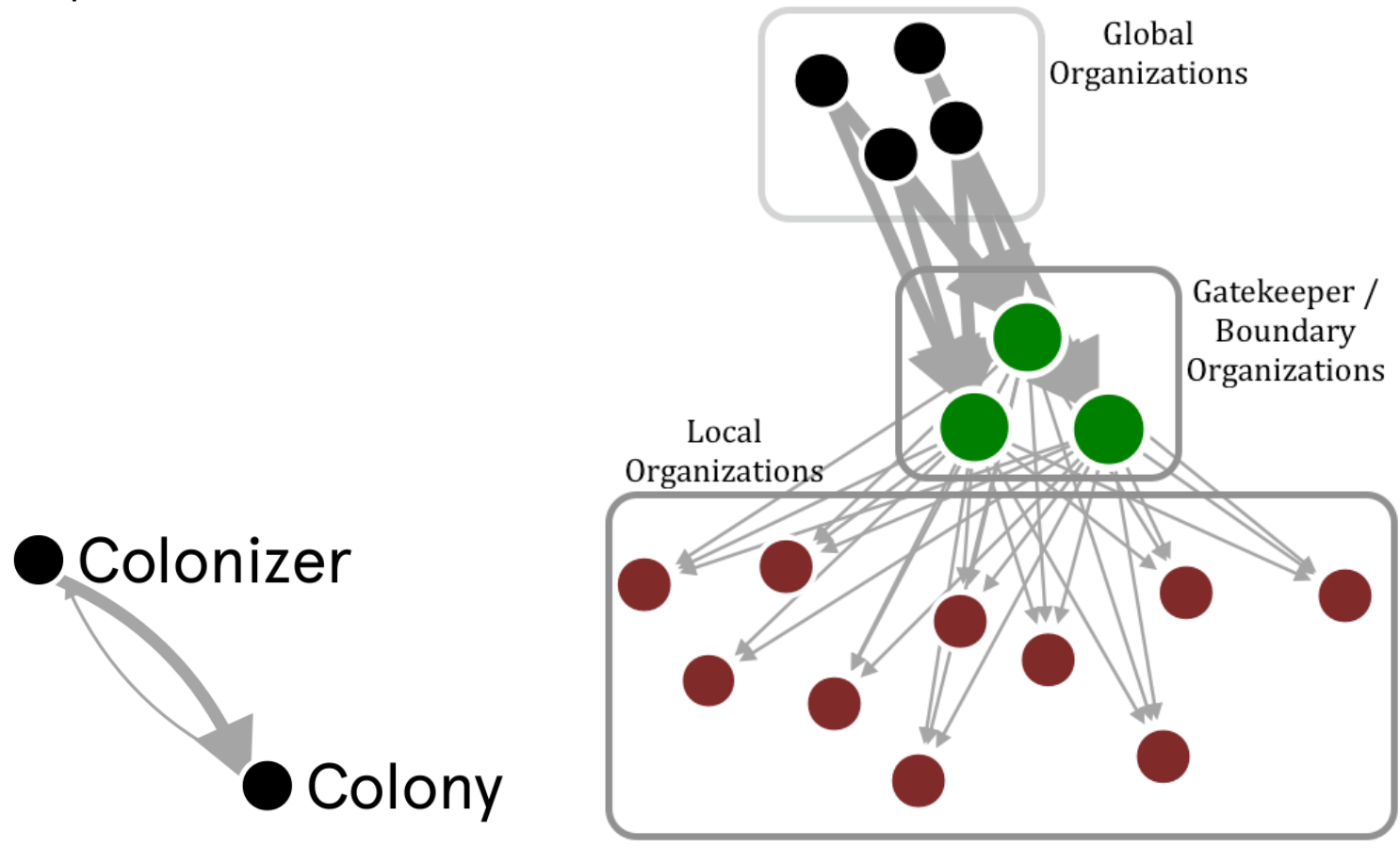

While this could be analyzed under a unidirectional pattern of boundary organizations conforming the local to the global requirements-fitting with the traditional understanding of Empire - it is also important to consider the ways in which these boundary organizations recalibrate global spaces to adapt to the demands of the "multitude." Relocalization of knowledge requires that global spaces are capable of creating locally relevant information out of the global climate models, while transmitting that information to sites of consumption where it can be transformed into policies and practices. While the influence of colonial legacies and financing in the Pacific Islands ensures that those local spaces are transformed in ways that can accept the global climate information, the continued 
resistance of local spaces has caused reverberations that run throughout the Climate Empire, all the way up to the global level.

Global projects are responding to these reverberations of resistance by including varying degrees of local involvement in their projects. The REDD program has become REDD+, now including good governance, equity, and the roles of indigenous peoples and forest-dependent communities. The Convention for Biological Diversity is working to increase the "full and effective participation of indigenous and local communities," guided through an advisory committee (Convention for Biological Diversity, no date, para. 1). The UN Climate Secretariat has recently added the local communities and indigenous peoples platform to inform decision-making (UNFCCC, 2017). This is not to say that these programs have completely or even effectively brought local issues into their decision-making, but rather that local resistance has encouraged shifts in their programs.

One participant spoke of a project in the Pacific that addresses some of these issues. Under pressure from states and local entities, agencies have begun to invest in both the collection of local proverbs and the use of scientific methodologies to adapt those local proverbs to the current state of the climate. In other words, agencies are collecting these proverbs, verifying proverbs scientifically, and then creating new proverbs that are relevant to changing conditions. Interestingly, agencies have not stopped there. While the global elements of climate change are still considered vitally important to understanding 
and acting upon the challenges ahead, experiences of climate change vary across scales and spaces. A fisherman on the Fijian coastline will experience dramatically different effects than a hunter in the Fijian hills. This type of detailed scale is not currently possible with the climate models available. However, agencies have begun to consider using the local proverbs to change the way in which climate change is understood and studied to include the small-scale shifts in local patterns.

While new, pilot-based, and lightly funded by Australian aid, this project makes an interesting step. Pressure within the region has caused external partners - like Australia - to fund projects that highlight local knowledge and strategies in ways that may have previously been seen as somewhat illegitimate under the global, technical solutions of Climate Empire. Again, the goal of this project is to incorporate local knowledge into existing scientific models and strategies. Therefore, these types of projects could alternatively be seen as furthering the biopolitical (Foucault, 2003, 2009, 2010) control over local populations. In projects like these, the panopticon of Climate Empire extends further down into the local spaces, measuring, quantifying, and standardizing experiences at all levels. Enlisting local participants in legitimizing the authority of foreign rule occurred throughout the successful empires of the past (Storey, 1997), and is now repeated within Climate Empire. By using authoritative science to validate and update local knowledge, it also extends the normalizing impact of 
Climate Empire. It is in this tension, space of corruption, and series of contradictions that Climate Empire remains ripe for future exploration.

\section{Conclusion}

Using Climate Empire as a concept by which to explore the power, authority, and knowledge within climate change governance in the Pacific Islands can ensure that the complexity inherent in the network of local/global spaces is properly considered. Grounded in the technical and scientific approaches to climate change diplomacy and governance, Climate Empire gains authority by utilizing apolitical discourse, bringing instrumental solutions to global, technical problems. The informatization of climate change governance that fosters these technical approaches, the use of financing to secure the use of Western logics of rule, and the regionalization efforts that provide avenues for monitoring and policing all work together to form the Climate Empire in the Pacific Islands. The relocalization of knowledge, while providing depth for the reach of Climate Empire, also provides space for local resistance to make space to transform the globe. 


\section{Chapter 6: Conclusion: Findings and Recommendations Introduction}

In a recent study of Tuvalu's landmass, researchers found that, as adaptive ecosystems, the islands of Tuvalu had actually grown over the last four decades (Kench, Ford, \& Owen, 2018). These findings produced a wide range of reactions among recipients: hope among islanders, vindication among climate deniers, or anger and frustration among Pacific Island climate negotiators, depending on the recipient's position (Friedman, 2018). In 2016, the Guardian released a story entitled, "Five Pacific islands lost to rising seas as climate change hits" (Anon., 2016). Immediately after, the publication released a correction requested by the study's authors, "Headlines 'exaggerated' climate link to sinking of Pacific islands" (Mathiesen, 2016). These instances highlight the fact that debates over knowledge within climate change diplomacy and governance within the Pacific Islands are rarely that simple. The power and authority produced by and productive of climate change knowledge means that contestation is at the heart of the decision-making. One of the ways in which these contests play out is through the ways of speaking about climate change diplomacy and governance-the narratives that ground the stories of policy and the discourses that frame climate change in historical contexts.

This dissertation explored the way that these issues of power, authority, and knowledge are constructed and circulated through networks of climate change practitioners and decision-makers in the Pacific Islands. Utilizing social 
network analysis, narrative, and discourse approaches, I focused on issues of communication and collaboration in efforts to govern the globe-locally, regionally, and globally. In this conclusion, I will provide a summary of the dissertation, draw broad themes that run throughout the dissertation, and gather together the recommendations for governance that were described by participants.

\section{Summary}

In Chapter 2 of this dissertation, I explored the theories that could help to explain the ways in which power, authority, and knowledge run throughout transnational environmental governance networks in the Pacific Islands. First, transnational governance was positioned as a multi-actor space that includes non-state actors. Power was presented as productive, relational, distributed throughout society, and expressed through the text and practices of discourses. Power/knowledge-or the ways in which this productive, relational, and societal discursive power is heavily embedded in regimes of knowledge and ways of understanding the world-was used to orient the role of knowledge production in formulating power relations. Networks were presented as a useful tool for organizing the dynamics of power, authority, and knowledge within the multiactor space. Finally, I organized power, authority, and knowledge according to traditional, bureaucratic, scientific, and practical relations.

In Chapter 3, I discussed the diplomatic efforts of the Pacific Islands in the lead-up to COP21, particularly the declarations presented at the Pacific Island 
Forum [PIF] Summit and Pacific Islands Development Forum [PIDF] Summit. These declarations were explored from a narrative-network approach, where both the organizational representation and narrative construction differed between the two groups. The PIF Summit included a limited representation of states and IGOs, producing what I referred to as a global technical narrative that emphasizes the scientific and bureaucratic solutions to climate problems. Alternatively, the PIDF Summit had broader participation that included more states and wide variety of domestic and international NGOs, producing what I referred to as a local power narrative that advocated local decision-making and information. The global technical narrative was presented as efficient, but had some challenges for representation of alternative ways of knowing. Alternatively, the local power narrative can open up knowledge and decision-making, but can also be costly in terms of time and resources.

For Chapter 4, I used Bäckstrand and Lövbrand's (2006) three environmental discourses-green governmentality, ecological modernization, and civic environmentalism - to further explore the use of discourse in producing and reaffirming the local/global contestations over the power, authority, and knowledge of Pacific Island climate change governance efforts. Green governmentality emphasized scientific expertise, global knowledge, and decisionmaking concentrated in the administrative state and knowledge producing institutions. Efforts were being made to broaden these decision-making spaces through the use of science communication. Ecological modernization applied the 
rational-legal authority embedded in an operational knowledge of development. Authoritative decision-making under this discourse was either concentrated in donor partners and implementing agencies, or distributed to civil society depending on the strength of the discourse. Finally, civic environmentalism functioned under practical authority, focusing on contextual knowledge and social inclusion. Civil society was brought into development processes under the reformist version of the discourse, while the radical version that denies the primacy of development was limitedly discussed. There was some overlap between the central organizations that employed the green governmentality discourse and the moderately central organizations that used the ecological modernization discourse. The civic environmentalism was used slightly by other groups, but mostly was used at the periphery of the network.

Finally, expanding on Hart and Negri's (2000) work in Empire, Chapter 5 looked at climate change diplomacy and governance under the concept of Climate Empire - the network of scientific, technological, social, and political systems that produce knowledge and communicative services to make the climate legible and governable. Climate Empire is formed as informatization (the production of the information economy through knowledge, communication, and affective services) privileges scientific and technical expertise, financing has ensured that Western logics of rule remain pertinent, and regionalism has fostered a focal point for these logics of rule. Importantly, the local and global elements of climate change diplomacy and governance are connected in the 
relocalization (Miller, 2004) processes inherent in global knowledge. In climate change spaces, data is locally collected, globally analyzed, and relocalized within polices and projects. This interaction between the local and global spaces means that both are impacted in significant ways.

\section{Drawing the Strands Together}

While the dissertation follows a number of threads within diplomacy and governance in Pacific Island climate change networks, there are a few themes that run throughout the dissertation. Chapters 3 and 4 both deal extensively with the local and global elements of climate change diplomacy and governance in the Pacific Islands (Tables 6 and 7). Global constructions of climate change were found in diplomatic spaces through the global technical narrative, while in governance spaces it was found in the green governmentality and ecological modernization discourses. While these ways of speaking and acting are described in previous chapters as distinct, they also hold strong similarities as they privilege the role of global technical information in decision-making and practice. The local power narrative of the discussion on diplomacy and civic environmentalism discourse of the discussion on governance both share many key elements of local construction. In these ways of speaking and acting, local understandings of climate change and its impacts have power and should be considered within decision-making. 
Table 6: Discourses of Pacific Island climate governance.

\begin{tabular}{|c|c|c|c|c|c|}
\hline 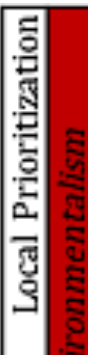 & $\begin{array}{l}\text { 哭 } \\
\text { 总 }\end{array}$ & 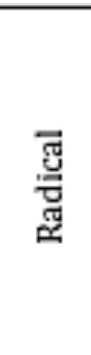 & 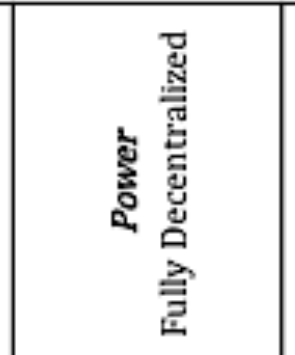 & 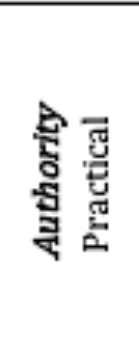 & 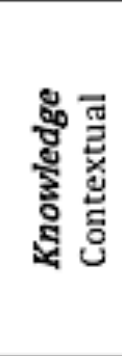 \\
\hline & 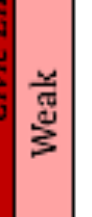 & 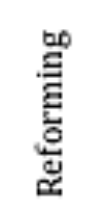 & 屁总 & 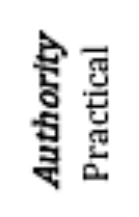 & 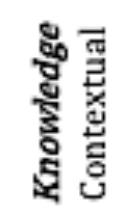 \\
\hline & 总 & 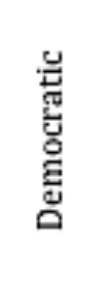 & 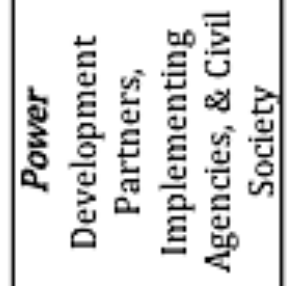 & 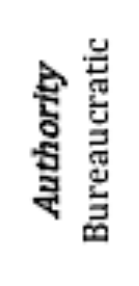 & 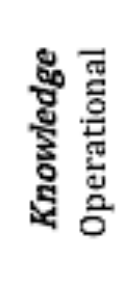 \\
\hline & 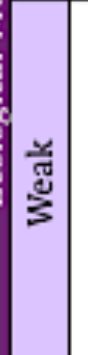 & 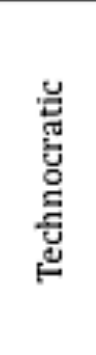 & 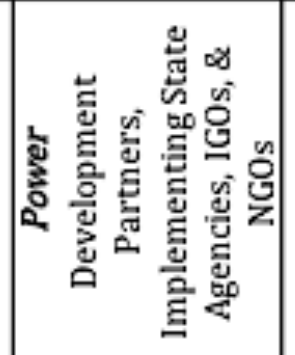 & 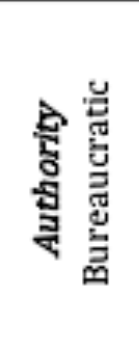 & 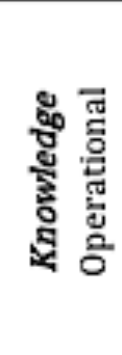 \\
\hline & $\mid$ & 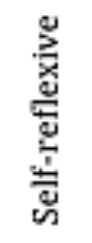 & 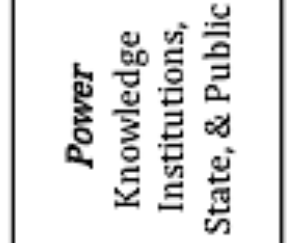 & 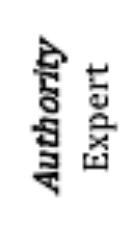 & 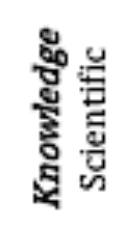 \\
\hline 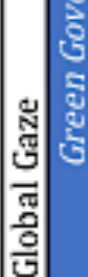 & 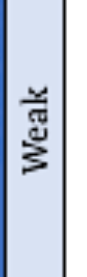 & 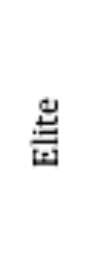 & 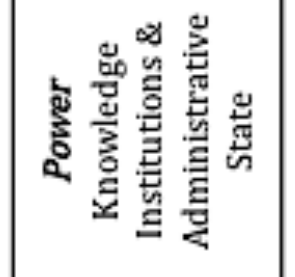 & 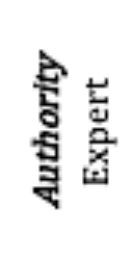 & 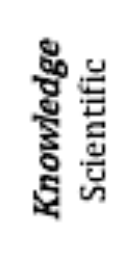 \\
\hline
\end{tabular}


Table 7: Narratives of Pacific Island climate diplomacy.

\begin{tabular}{|l|l|}
\hline \multicolumn{1}{|c|}{ Global Technical Narrative } & \multicolumn{1}{c|}{ Local Power Narrative } \\
\hline Victim: PICs & Victim: PICs \\
Villain: Lack of Capacity, Resources, & Villain: Ecological Vulnerability due to \\
and Scientific Information & Emitters \\
Hero: Regional Organizations & Hero: Pacific Island Peoples \\
Policy Moral: Greater Regional & Policy Moral: Local Inclusion in \\
Functionality & Decision-Making \\
\hline
\end{tabular}

These discourses align in such a way that they provide a local/global break in the power, authority, and knowledge considered in strategies in the Pacific Islands. The global way of understanding power, authority, and knowledge in the Pacific Islands is focused on expert and bureaucratic authority through the privileging of scientific and operational knowledge (Fig. 9). Through the requirements that these types of authority and knowledge place on organizations working toward diplomacy or governance, power is found in organizations that have large quantities of technical capacity at their disposal. In other words, in order to gain power and authority according to global requirements, capacity for technical knowledge and expertise is required. These ways of knowing the earth also have particular strategies for governing it, specifically terraform projects that view the earth as separate from the social world and controllable. Thus, the climate is approached with particular attention paid to the ways in which it can be approached globally and technically, and controlled. 
Figure 9: Outline of the global discourse within climate change governance and diplomacy in the Pacific Islands.

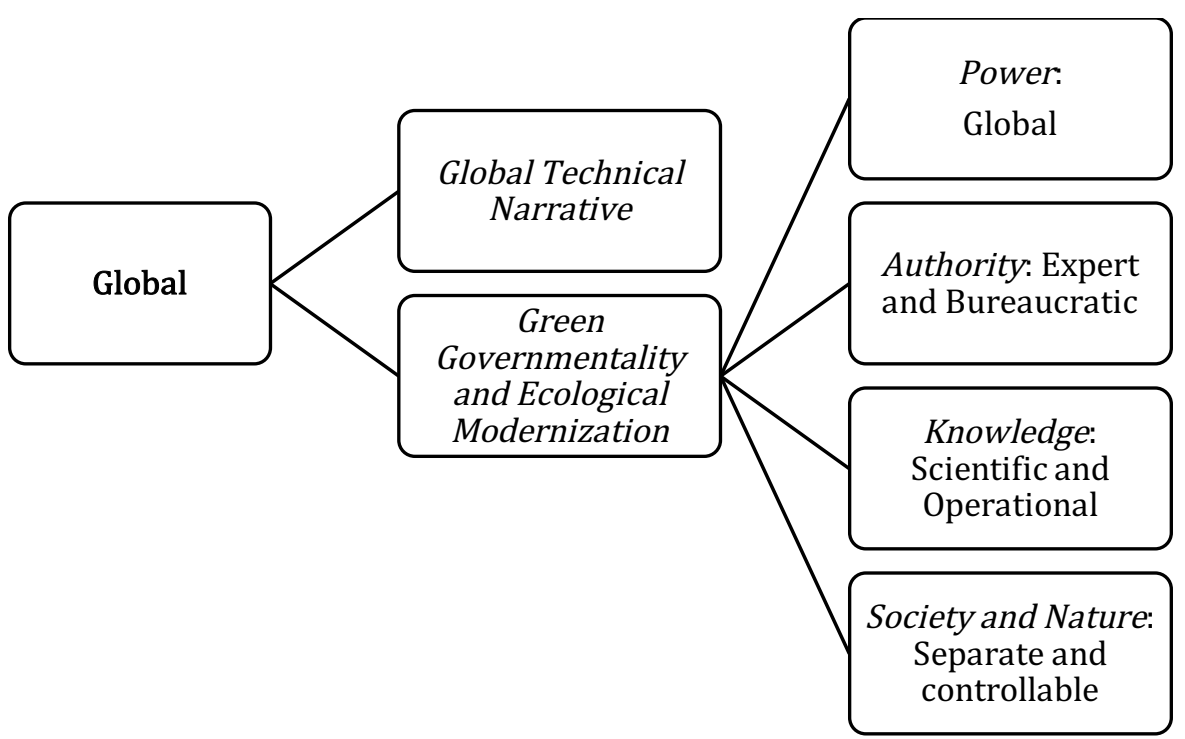

Local strategies for speaking and acting upon climate change governance and diplomacy privilege practical authority and contextual knowledge (Fig. 10). This reframes capacity challenges under the ability to know the local environment and to make decisions at that level. In local strategies for governance and diplomacy, nature is unable to be terraformed and controlled. Instead, it is integrated with the social world and it is fluid. Nature is, thus, a player in governance networks through its activities and efforts for survival (Latour, 1995; Lejano, Ingram, \& Ingram, 2013). This understanding privileges local, adaptive efforts to be enacted alongside global strategies. 
Figure 10: Outline of the local discourse within climate change governance and diplomacy in the Pacific Islands.

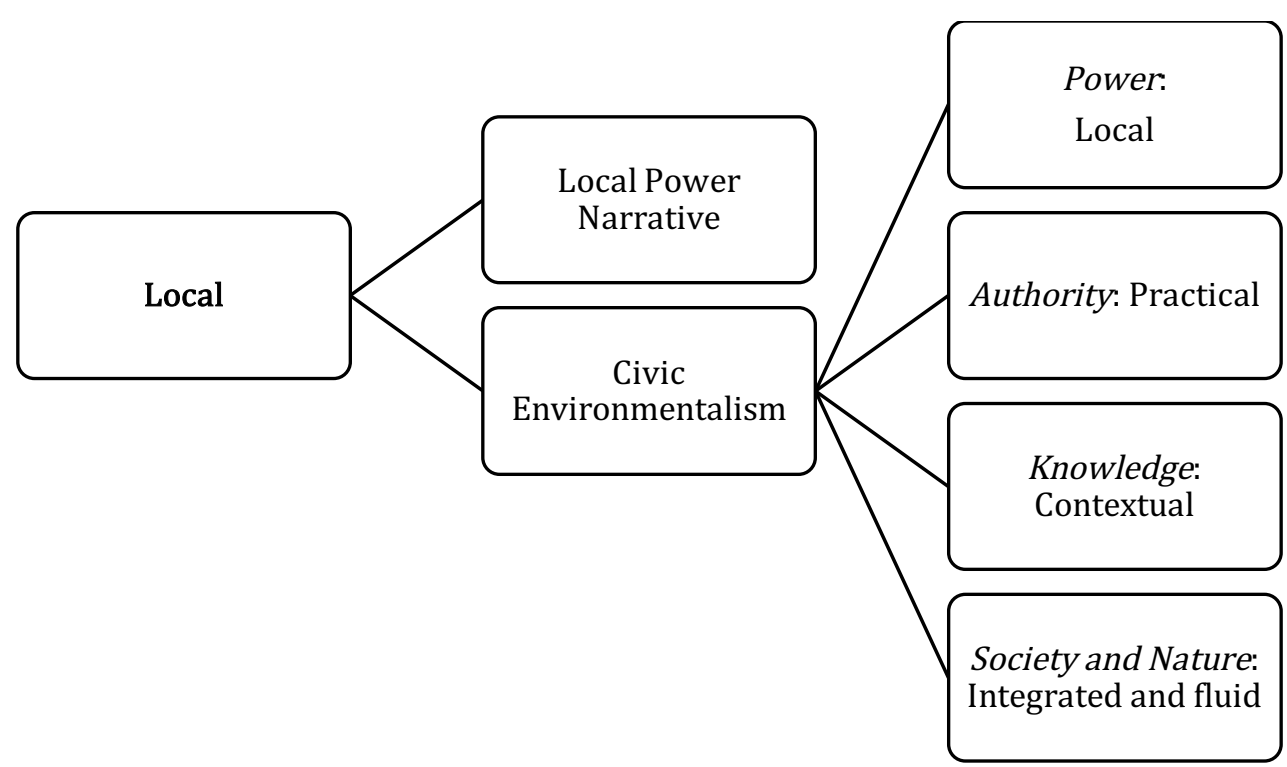

While these local and global strategies are in many ways distinct, they are brought together under the formation of Climate Empire. Climate Empire works in and through global strategies to produce and uphold their technical bureaucratic and scientific authorities; however, these global spaces are also reconnected with the spaces of local resistance through data collection networks and efforts to relocalize knowledge. This connection means that both the local and the global are impacted through the production and reproduction of the Climate Empire. While the use of local strategies in global projects has increased in recent years, this could have varying impacts on the circulation of power in these spaces. For instance, projects that incorporate local knowledge can make for better decisionmaking in local spaces, or they could extend panopticon of Climate Empire further down into the local, measuring, quantifying, and standardizing 
experiences at all levels. It is in this place of expansion and resistance that work remains left to be done.

\section{What Now?}

There were a few themes that I heard from the majority of Pacific Island participants about what could be done to improve the system of climate change governance and diplomacy. First, it is important that the burden of climate change is distributed according to historic roles in causing climate change. This includes the full range of strategies, particularly in regards to diplomatic leadership in emissions reductions, domestic mitigation strategies, and easy to access, sufficient, and sustainable financing for countries facing the brunt of climate challenges. The US has been and continues to be one of the largest emitters of GHGs in the world, yet President Trump recently rescinded US support of the Paris Agreement. Additionally, the transition in the US has caused trepidation within Pacific Island countries that rely on the funding. As one participant explained:

Donors don't like long term investments. I guess it's understandable, the kind of flux that we have in terms of change. Just this morning I heard USAID budget might be slashed in the next year, and USAID has only just come back in the region like two years ago with a huge amount of money. They wanted to align to climate change. So, on Trump's end, he's cutting all that out. I have some friends who applied for these USAID posts, and 
they're going to go for an interview, but they're probably not going to take it seriously, because they don't think he'll last too long. \#laughs\# While lighthearted, this quote one example of how participants felt that their projects could easily be put in limbo based on the political shifts of other countries. Australia, for instance, had shifted focus while I was there from "climate change" to "climate variability" due to the political pressure. This adjustment in vocabulary changes the timescales on which their MET services focus, shifting emphasis and funding from long-term endeavors. These efforts among climate emitters to reduce their involvement and shift responsibility vastly exacerbates the already challenging task among Pacific Islands to adapt to climate change.

While it may require committed global action to overcome the challenges of climate change, the second issue pertains to the role of global powers in Pacific Island affairs. It is vitally important for the Pacific Islands to receive financing and technical assistance in adaptation and mitigation strategies. That being said, there are ways of doing this that concentrate power in the hands of external actors and those that work to rely on local actors to set the agenda. It is not enough that local actors are brought to the table to work on projects dictated by external actors. Instead, the practical knowledge and experience of local actors must help drive the agenda in the first place. This is important not only for issues of justice, but also for efficacy. For example, Govan (2009) and Sievanen, 
Gruby, and Campbell (2013), among others, have demonstrated the ways in which local involvement can bolster the impacts of governance in the region. Along the lines of efficacy, a third issue that came up multiple times in the interviews is longevity of projects. Pilot projects, short-term interventions, surveys, etc., were discussed as being the mode of operations of many funders. This forced the already understaffed organizations and agencies to juggle multiple projects at a time with multiple funders, interventions, and reporting strategies. As one participant described the pressure that puts on practitioners:

All these things are an inverted pyramid that lands on one particular person's head on the ground. That person has to have the pyramid stuck on his head and goes down to the community level to try and translate all those results from all those projects and all those technical interventions to make it work at the ground level. It's hard. ... So, all these fancy people like myself that might say, "Yeah, you need to drop a good work plan, and these are the things we think you need to do." But at the end of the day, that poor sap's gotta go out and figure out how to do it on his or her own. This pressure on practitioners - particularly those within government agencieshas exacerbated existing capacity challenges within the region. Unsurprisingly, a "brain drain" was also discussed as educated and trained individuals leave positions in search of better pay and less stressful environments. This happens some with the concentration of capacity in regional agencies, but also as Pacific Islanders move to Australia, New Zealand, the US, and others. Thus, a number 
of participants with whom I spoke emphasized the need for long-term interventions that are properly funded, particularly in regards to organizational capacity and support.

While these interventions are significant, as it is said, it is important not to throw the baby out with the bathwater. These chapters have critically discussed the challenges at play with local, regional, and global governance in the region, but there is a lot of good at work, as well. Many of the region's funders, decisionmakers, and practitioners are aware of the challenges discussed in this dissertation, and some even made progress toward mending power imbalances between my 2015 and 2017 trips through funding requirement changes and project shifts. As I spoke about in chapter 6, recent projects have worked to integrate local knowledge into climate models in ways that could mutually benefit local and global strategies. While acknowledging room for improvement, most participants spoke to a few key projects that they saw really making strides toward what they wanted to see in climate change governance and diplomacy. Perhaps most importantly, many of the individuals with whom I spoke held passion, hope, and motivation for a better world that was contagious.

Acknowledging and appreciating where network actors at all levels can agree (or come close to agreeing) that things are working well can help guide future efforts for governance and diplomacy.

Again, these suggestions were generated through the conversations I was able to have with Pacific Island climate change practitioners and decision- 
makers, which brings me to the final suggestion. Empowerment is a key element of governance and diplomacy that is more challenging in these postcolonial locales. Space to have open, collaborative communication that recognizes and addresses issues of power is vital. 


\section{References}

Abbot, K. W., \& Snidal, D. (2000). Hard and soft law in international governance. International Organization, 54(3), 421-456.

http://doi.org/10.1162/002081800551280

Abers, R. N., \& Keck, M. E. (2013). Practical authority: Agency and institutional change in Brazilian water politics. Oxford: Oxford University Press.

Adler, E., \& Haas, P. M. (1992). Conclusion: Epistemic communities, world order, and the creation of a reflective research program. International Organization, 46(1), 367. http://doi.org/10.1017/S0020818300001533

Agrawal, A. (2005). Environmentality: Technologies of government and the making of subjects. Durham, NC: Duke University Press.

Agrawal, A., \& Gibson, C. C. (1999). Enchantment and disenchantment: The role of community in natural resource conservation. World Development, 27(4), 629-649. http://doi.org/10.1016/S0305-750X(98)00161-2

Allen, M. R., Barros, V. R., Broome, J., Cramer, W., Christ, R., Church, J. A., ... Dubash, N. K. (2014). IPCC fifth assessment synthesis report: Climate change 2014 synthesis report. Retrieved from https://www.ipcc.ch/pdf/assessment-report/ar5/syr/SYR_AR5_SPMcorr2.pdf

Anderson, B. (2006). Imagined communities: Reflections on the origin and spread of nationalism. New York: Verso Books. 
Andonova, L. B., Betsill, M. M., \& Bulkeley, H. (2009). Transnational climate governance. Global Environmental Politics, 9(2), 52-73.

http://doi.org/10.1162/glep.2009.9.2.52

Atteridge, A., \& Canales, N. (2017). Climate finance in the Pacific: An overview of flows to the region's Small Island Developing States, 74. Retrieved from www.sei-international.org

Bachrach, P., \& Baratz, M. S. (1962). Two faces of power. American Political Science Review, 56(4), 947-952.

Bäckstrand, K., \& Lövbrand, E. (2006). Planting trees to mitigate climate change: Contested discourses of ecological modernization, green governmentality and civic environmentalism. Global Environmental Politics, 6(1), 50-75. http://doi.org/10.1162/glep.2006.6.1.50

Bakker, K. (2010). The limits of "neoliberal natures": Debating green neoliberalism. Progress in Human Geography, 34(6), 715-735. http://doi.org/10.1177/0309132510376849

Barnett, J., \& Campbell, J. (2010). Climate change and small island states: Power, knowledge, and the South Pacific. Earthscan.

Barnett, M. N., \& Finnemore, M. (1999). The politics, power, and pathologies of international organizations. International Organization, 53(4), 699-732. http://doi.org/10.1162/002081899551048 
Barnett, M., \& Duvall, R. (2005). Power in international politics. International Organization (Vol. 59). Portland State Library. http://doi.org/10.1017/S0020818305050010

Barnett, M., \& Finnemore, M. (2004). Rules for the world: International organizations in global politics. Cornell University Press.

Barry, B. (1999). Statism and nationalism: A cosmopolitan critique. In I. Shapiro \& L. Brilmayer (Eds.), Global Justice (pp. 12-66). New York: New York University Press.

Bartlett, C. Y., Maltali, T., Petro, G., \& Valentine, P. (2010). Policy implications of protected area discourse in the Pacific islands. Marine Policy, 34(1), 99-104. http://doi.org/10.1016/j.marpol.2009.04.021

Beck, S., Borie, M., Chilvers, J., Esguerra, A., Heubach, K., Hulme, M., ... Görg, C. (2014). Towards a reflexive turn in the governance of global environmental expertise the cases of the IPCC and the IPBES. Gaia, 23(2), 80-87. http://doi.org/10.14512/gaia.23.2.4

Biermann, F., \& Gupta, A. (2011). Accountability and legitimacy in earth system governance: A research framework. Ecological Economics, 70(11), 18561864. http://doi.org/10.1016/j.ecolecon.2011.04.008

Biermann, F., \& Pattberg, P. H. (2012). Global environmental governance reconsidered. MIT Press.

Bocking, S. (2004). Nature's experts: Science, politics, and the environment. New Brunswick, NJ: Rutgers University Press. 
Bodin, Ö., \& Prell, C. (2011). Social networks and natural resource management: Uncovering the social fabric of environmental governance. Cambridge, MA: Cambridge University Press.

Boström, M., \& Hallström, K. (2010). NGO power in global social and environmental standard-setting. Global Environmental Politics, 10(November), 3-4. Retrieved from http://www.mitpressjournals.org/doi/abs/10.1162/GLEP_a_00030

Braun, V., \& Clarke, V. (2012). Thematic analysis. In APA handbook of research methods in psychology, Vol 2: Research designs: Quantitative, qualitative, neuropsychological, and biological. (Vol. 2, pp. 57-71). Washington: American Psychological Association. http://doi.org/10.1037/13620-004

Bull, H., \& Watson, A. (1984). The expansion of international society. New York: Oxford University Press.

Burleson, E. (2016). Paris Agreement and consensus to address climate challenge. Insights, 20(8).

Butler, J. (2007). Excitable speech: A politics of the performative. Routledge. Carter, G. (2015). Establishing a Pacific voice in the climate change negotiations. In G. Fry \& S. Tarte (Eds.), The New Pacific Diplomacy (pp. 205-221). Canberra: Australian National University Press.

Cash, D. W., Adger, W. N., Berkes, F., Garden, P., Lebel, L., Olsson, P., ... Young, O. (2006). Scale and cross-scale dynamics: Governance and 
information in a multilevel world. Ecology and Society, 11(2), 8. http://doi.org/8

Cashore, B. (2002). Legitimacy and the privatization of environmental governance: How non-state market-driven (NSMD) governance systems gain rule-making authority. Governance, 15(4), 503-529. http://doi.org/10.1111/1468-0491.00199

Castree, N. (2010). Neoliberalism and the biophysical environment 1: What "neoliberalism" is, and what difference nature makes to it. Geography Compass, 4(12), 1725-1733. http://doi.org/10.1111/j.17498198.2010.00405.x

Convention for Biological Diversity. (n.d.). General information. Retrieved March 1, 2018, from https://www.cbd.int/traditional/general.shtml Cooper, A. F. (2008). Beyond one image fits all: Bono and the complexity of celebrity diplomacy. Global Governance, 14(3), 265-272.

Cooper, P. J., \& Vargas, C. M. (2004). Implementing sustainable development: From global policy to local action. Lanham, Maryland: Rowman \& Littlefield. Corbett, J., \& Connell, J. (2015). All the world is a stage: Global governance, human resources, and the "problem" of smallness. The Pacific Review, 28(3), 435-459. http://doi.org/10.1080/09512748.2015.1011214

Corlew, L. K., Keener, V., Finucane, M., Brewington, L., \& Nunn-Crichton, R. (2015). Using social network analysis to assess communications and develop networking tools among climate change professionals across the 
Pacific Islands region. Psychosocial Intervention, 24(3), 133-146.

http://doi.org/10.1016/j.psi.2015.07.004

Davies, J. S. (2012). Network governance theory: A Gramscian critique.

Environment and Planning A, 44(11), 2687-2704.

http://doi.org/10.1068/a4585

Dean, M. (2003). Empire and governmentality. Distinktion: Scandinavian Journal of Social Theory, 4(1), 111-122.

http://doi.org/10.1080/1600910X.2003.9672849

Demeritt, D. (2001). The construction of global warming and the politics of science. Annals of the Association of American Geographers, 91(2), 307337. http://doi.org/10.1111/0004-5608.00245

Denton, A. (2017). Voices for environmental action? Analyzing narrative in environmental governance networks in the Pacific Islands. Global Environmental Change, 43. http://doi.org/10.1016/j.gloenvcha.2017.01.006

Downs, A. (1957). An economic theory of democracy. New York: Harper \& Row.

Doyle, M. W. (1986). Liberalism and world politics. American Political Science Review, 80(4), 1151-1169.

Dryzek, J. S. (2000). Deliberative democracy and beyond: Liberals, critics, contestations. Oxford University Press on Demand.

Dunn, K. C. (2004). Africa's ambiguous relation to empire and Empire. In P. Passavant \& J. Dean (Eds.), Empire's new clothes: Reading Hardt and Negri (pp. 143-162). Routledge London. 
East Maui Watershed Partnership. (n.d.). Management. Retrieved from http://eastmauiwatershed.org/explore-the-watershed/management/

Eilstrup-Sangiovanni, M. (2016). Global governance networks. (J. N. Victor, A. H. Montgomery, \& M. Lubell, Eds.) (Vol. 1). Oxford University Press. http://doi.org/10.1093/oxfordhb/9780190228217.013.30

Engel-Di Mauro, S. (2014). Ecology, soils, and the Left: An ecosocial approach. Palgrave Macmillan.

Fairclough, N. (2014). Language and power (3rd ed.). London: Routledge.

Finnemore, M., \& Sikkink, K. (1998). International norm dynamics and political change. International Organization, 52(4), 887-917.

Foucault, M. (1988). Madness and civilization: A history of insanity in the age of reason. New York: Vintage.

Foucault, M. (2010). The birth of biopolitics: Lectures at the Coll\{è\}ge de France, 1978-1979. London: Macmillan Publishers.

Foucault, M. (1984). The history of sexuality. Volume one: An introduction. (R. Hurley, Ed.).

Foucault, M. (2003). Society must be defended: Lectures at the Coll\{è\}ge de France, 1975-1976. London: Macmillan Publishers.

Foucault, M. (1980). Power/knowledge: Selected interviews and other writings, 1972-1977. Pantheon.

Foucault, M. (2009). Security, territory, population: Lectures at the Coll\{è\}ge de France 1977--1978. London: Macmillan Publishers. 
Framework for Resilient Development in the Pacific (FRDP). (2016). An integrated approach to address climate change and disaster risk management.

Friedman, L. (2018). Tuvalu is growing (for now). New York Times.

Friedrichs, J. (2005). Global governance as the hegemonic project of transatlantic civil society. In M. Lederer \& P. S. Mueller (Eds.), Criticizing global governance (pp. 45-68). London: Palgrave Macmillan.

Fry, G. (1997). The south pacific "experiment": Reflections on the origins of regional identity. Journal of Pacific History, 32(2), 180-202.

http://doi.org/10.1080/00223349708572837

Ghazoul, J., Butler, R. A., Mateo-Vega, J., \& Koh, L. P. (2010). REDD: A reckoning of environment and development implications. Trends in Ecology \& Evolution, 25(7), 396-402.

Giddens, A. (1984). The constitution of society: Outline of the structuration theory. Cambridge: Polity Press.

Glasbergen, P. (Ed.). (1995). Managing environmental disputes: Network management as an alternative. Dordrecht, Netherlands: Kluwer Academic Publishers.

Glenn, J. (2008). Global governance and the democratic deficit: Stifling the voice of the South. Third World Quarterly, 29(2), 217-238. http://doi.org/10.1080/01436590701806798 
Goldsmith, S., \& Eggers, W. (2004). Governing by network. Washington, D.C.: Brookings Institution Press.

Govan, H. (2009). Achieving the potential of locally managed marine areas in the South Pacific. SPC Traditional Marine Resource Management and Knowledge Information Bulletin \#25, 25, 16-25. Retrieved from http://manejocomunitario.marvivablog.com/files/2010/08/Trad25_16_Govan. pdf

Grewal, D. S. (2008). Network power: The social dynamics of globalization. Yale University Press.

Gruby, R. L., \& Campbell, L. M. (2013). Scalar politics and the region: Strategies for transcending Pacific Island smallness on a global environmental governance stage. Environment and Planning A, 45, 2046-2063. http://doi.org/10.1068/a45420

Gulbrandsen, L. H., \& Andresen, S. (2004). NGO influence in the implementation of the Kyoto Protocol: Compliance, flexibility mechanisms, and sinks. Global Environmental Politics, 4(4), 54-75. http://doi.org/10.1162/glep.2004.4.4.54 Haas, P. M. (1989). Do regimes matter? Epistemic communities and Mediterranean pollution control. International Organization, 43(3), 377-403. http://doi.org/10.1017/S0020818300032975

Hadden, J. (2015). Networks in contention. Cambridge: Cambridge University Press. 
Hajer, M. A. (1995). The politics of environmental discourse: Ecological modernization and the policy process. Oxford: Clarendon Press.

Hajer, M., \& Versteeg, W. (2005). A decade of discourse analysis of environmental politics: Achievements, challenges, perspectives. Journal of Environmental Policy and Planning, 7(3), 175-184.

http://doi.org/10.1080/15239080500339646

Haraway, D. J. (1988). Situated knowledges: The science question in feminism and the privilege of partial perspective. Feminist Studies, 14(3), 575-599. http://doi.org/10.2307/3178066

Hardt, M., \& Negri, A. (2000). Empire. Cambridge, MA: Harvard University Press. Harré, R. (1975). Causal powers: A theory of natural necessity. Hobbes, T. (1651). Leviathan. Scolar Press.

Howarth, D. (2000). Discourse: Concepts in the social sciences. Buckingham: Open University Press.

Hull, R. B., \& Robertson, D. P. (2000). The language of nature matters: We need a more public ecology. In P. H. Gobster \& R. B. Hull (Eds.), Restoring nature: Perspective from the social sciences and humanities (pp. 97-118). Washington, D.C.: Island Press. http://doi.org/citeulike-article-id:2396549 Hulme, M. (2010). Problems with making and governing global kinds of knowledge. Global Environmental Change, 20(4), 558-564. http://doi.org/10.1016/j.gloenvcha.2010.07.005 
Ivanova, M. (2016). Good COP, Bad COP: Climate reality after Paris. Global Policy, 7(3), 411-419. http://doi.org/10.1111/1758-5899.12370

Jasanoff, S. (2005). Designs on nature: Science and democracy in Europe and the United States. Princeton University Press.

Jasanoff, S. (2004). States of knowledge: The co-production of science and the social order. New Brunswick, NJ: Routledge.

Jasanoff, S., \& Martello, M. L. (Eds.). (2004). Earthly politics: Local and global in environmental governance. Cambridge, MA: MIT Press.

Jessop, B. (2004). Multi-level governance and multi-level metagovernance. In I. Bache \& M. Flinders (Eds.), Multi-level governance. Oxford University Press.

Jinnah, S. (2010). Overlap management in the World Trade Organization: Secretariat influence on trade-environment politics. Global Environmental Politics, 10(2), 54-79.

Kahneman, D., \& Tversky, A. (1979). Prospect theory: An analysis of decision under risk. Econometrica, 47(2), 263-292.

Karkkainen, B. C. (2004). Post-sovereign environmental governance. Global Environmental Politics, 4(1), 72-96.

Keck, M. E., \& Sikkink, K. (1999). Transnational advocacy networks in international and regional politics. International Social Science Journal, 51, 89-101. http://doi.org/10.1111/1468-2451.00179

Keck, M., \& Sikkink, K. (1998). Activists beyond borders: Advocacy networks in international politics. Ithaca, NY: Cornell University Press. 
Keener, V., Marra, J., Finucane, M., Spooner, D., \& Smith, M. (Eds.). (2012). Climate change and Pacific Islands: Indicators and impacts: Report for the 2012 Pacific Islands Regional Climate Assessment. Island Press. Retrieved from https://ebookcentral-proquestcom.proxy.lib.pdx.edu/lib/psu/detail.action?doclD=3317627

Kench, P. S., Ford, M. R., \& Owen, S. D. (2018). Patterns of island change and persistence offer alternate adaptation pathways for atoll nations. Nature Communications, 9(1), 605. http://doi.org/10.1038/s41467-018-02954-1

Keohane, R. O. (1982). The demand for international regimes. International Organization, 36(2), 325-355. http://doi.org/10.1017/S002081830001897X

Keohane, R. O., \& Nye, J. (2001). Power and independence. Longman.

Kickert, W. J., Klijn, E. H., \& Koppenjan, J. F. . (1997). Managing complex networks: Strategies for the public sector. Thousand Oaks, CA: Sage Publications.

Krasner, S. D. (1999). Sovereignty: Organized hypocracy. Princeton, NJ: Princeton University Press.

Krause, K. (1991). Military statecraft: Power and influence in Soviet and American arms transfer relationships. International Studies Quarterly, 35(3), 313-336.

Laclau, E., \& Mouffe, C. (1985). Hegemony and socialist strategy: Towards a radical democratic politics. London: Verso. 
Latour, B. (2005). Reassembling the social: An introduction to actor-networktheory. Oxford University Press.

Lejano, R. P., \& Ingram, H. (2009). Collaborative networks and new ways of knowing. Environmental Science \& Policy, 12(6), 653-662. http://doi.org/10.1016/j.envsci.2008.09.005

Lejano, R., Ingram, M., \& Ingram, H. (2013). The power of narrative in environmental networks. Cambridge, MA: MIT Press.

Litfin, K. (1994). Ozone discourses: Science and politics in global environmental cooperation. New York: Columbia University Press.

Locke, J. (1689). Two treatises of government.

Lukes, S. (2005). Power: A radical view (2nd ed.). New York: Palgrave Macmillan.

Martello, M. L., \& Jasanoff, S. (2004). Introduction: Globalization and environmental governance. Earthly Politics: Local and Global in Environmental Governance, 1-29.

Marx, K., \& Engels, F. (1978). The Marx-Engels reader. (R. C. Tucker, Ed.). New York: Norton.

McAdam, D., McCarthy, J. D., \& Zald, M. N. (1996). Comparative perspectives on social movements: Political opportunities, mobilizing structures, and cultural framings. Cambridge University Press. 
McBeth, M. K., Jones, M. D., \& Shanahan, E. A. (2014). The narrative policy framework. In P. A. Sabatier \& C. M. Weible (Eds.), Theories of the Policy Process (pp. 225-266). Boulder, CO: Westview Press.

Mill, J. S. (1869). On liberty. London: Roberts $\{\&\}$ Green.

Miller, C. (2004). Resisting empire: Globalism, relocalization, and the politics of knowledge. In S. Jasanoff \& M. L. Martello (Eds.), Earthly politics: Local and global in environmental governance (pp. 81-102). MIT Press Cambridge, MA.

Miller, C. A. (2007). Democratization, international knowledge institutions, and global governance. Governance, 20(2), 325-357. http://doi.org/10.1111/j.1468-0491.2007.00359.x

Miller, C. A., \& Edwards, P. N. (2001). Changing the atmosphere: Expert knowledge and environmental governance. (C. A. Miller \& P. N. Edwards, Eds.). Cambridge: MIT Press.

Mitchell, R. B. (1998). Discourse and sovereignty: Interests, science, and morality in the regulation of whaling. Global Governance, 4(3), 275-293.

Mohan, G., \& Stokke, K. (2000). Participatory development and empowerment: The dangers of localism. Third World Quarterly, 21(2), 247-268.

Morgan, D. L. (2013). Integrating qualitative and quantitative methods: $A$ pragmatic approach. Thousand Oaks, CA: Sage publications. 
NASA Earth Observatory. (2017). Global temperature record broken for third consecutive year. Retrieved from http://earthobservatory.nasa.gov/IOTD/view.php?id=89469

Nye, J. S. (2008). Public diplomacy and soft power. The ANNALS of the American Academy of Political and Social Science, 616(1), 94-109. http://doi.org/10.1177/0002716207311699

O'Toole, L. J. (1997). Practical and agendas in public administradon. Public Administration Review, 57(1), 45-52.

Olson, M. (1965). The logic of collective action: Public goods and the theory of groups. Cambridge: Harvard University Press.

Ostrom, E. (2010). Beyond markets and states: Polycentric governance of complex economic systems. American Economic Review, 100(3), 641-672. http://doi.org/10.1257/aer.100.3.641

Pagiola, S., Arcenas, A., \& Platais, G. (2005). Can Payments for Environmental Services help reduce poverty? An exploration of the issues and the evidence to date from Latin America. World Development, 33(2 SPEC. ISS.), 237253. http://doi.org/10.1016/j.worlddev.2004.07.011

Passavant, P. A., \& Dean, J. (Eds.). (2004). Empire's new clothes: Reading Hardt and Negri. London: Routledge.

Peters, B. G. (1998). Managing horizontal government: The politics of coordination. Public Administration, 76, 295-311. 
Pierre, J., \& Peters, G. B. (2000). Governance, politics and the state. New York: St Martin's Press.

Pierson, P. (2000). Increasing returns, path dependence, and the study of politics. American Political Science Review, 94(2), 251-267.

Pietri, D. M., Stevenson, T. C., \& Christie, P. (2015). The Coral Triangle Initiative and regional exchanges: Strengthening capacity through a regional learning network. Global Environmental Change, 33(September), 165-176. http://doi.org/10.1016/j.gloenvcha.2015.05.005

Pitts, J. (2010). Political theory of empire and imperialism. Annual Review of Political Science, 13(1), 211-235. http://doi.org/10.1146/annurev.polisci.051508.214538

Porter, T. M. (1994). Making things quantitative. Science in Context, 7(3), 389407. http://doi.org/10.1017/S0269889700001757

Rawls, J. (1971). A theory of justice. Cambridge, MA: Harvard University Press. Robertson, R. (2012). Cooking the goose: Fiji's coup culture contextualised. Round Table, 101(6), 509-519. http://doi.org/10.1080/00358533.2012.749095

Rosenau, J. N. (2007). Governing the ungovernable: The challenge of a global disaggregation of authority. Regulation \& Governance, 1, 88-97. http://doi.org/10.1111/j.1748-5991.2007.00001.x

Rousseau, J.-J. (1762). The social contract. (M. Cranston, Ed.). 
Said, E. (1978). Orientalism: Western representations of the Orient. New York: Pantheon.

Salinger, J., Clarke, G., Collins, D., Diamond, H., Lefale, P., Ngari, A., ... Taiki, H. (2002). Pacific Island GCOS action plan, (March).

Schattschneider, E. E. (1960). The semi-sovereign people. New York: Holt, Rinehart and Winston.

Scholte, J. A. (2004). Civil society and democratically accountable global governance. Government and Opposition, 39(2), 211-233. http://doi.org/10.1111/j.1477-7053.2004.00121.x

Scott, J. C. (1998). Seeing like a state: How certain schemes to improve the human condition have failed. New Haven, CT: Yale University Press.

Sen, A. (2009). The idea of justice. Cambridge, MA: Harvard University Press.

Shapin, S., \& Schaffer, S. (1985). Leviathan and the air-pump: Hobbes, Boyle, and the experimental life. Princeton, NJ: Princeton University Press.

Sievanen, L., Gruby, R. L., \& Campbell, L. M. (2013). Fixing marine governance in Fiji? The new scalar narrative of ecosystem-based management. Global Environmental Change, 23(1), 206-216. http://doi.org/10.1016/j.gloenvcha.2012.10.004

Slatter, C. (2015). The New Framework for Pacific Regionalism: Old kava in a new tanoa? In G. Fry \& S. Tarte (Eds.), The New Pacific Diplomacy (pp. 4964). Canberra: Australian National University Press. 
Sprague, J. (2011). Empire, global capitalism, and theory: Reconsidering Hardt and Negri. Current Perspectives in Social Theory (Vol. 29). Emerald Group Publishing Ltd. http://doi.org/10.1108/S0278-1204(2011)0000029014

Stewart, A. (2016). Fiji's evolving foreign policy and Pacific multilateral order: Pre- and post-election. In S. Ratuva \& S. Lawson (Eds.), The People Have Spoken: The 2014 Elections in Fiji (pp. 229-247). ANU Press. Retrieved from http://www.jstor.org/stable/j.ctt1bw1hc6.14

Stone, D. (2008). Global public policy, transnational policy communities, and their networks. Policy Studies Journal, 36(1), 19-38.

Storey, W. K. (1997). Science and power in colonial Mauritius. University of Rochester Press.

Turnhout, E., Dewulf, A., \& Hulme, M. (2016). What does policy-relevant global environmental knowledge do? The cases of climate and biodiversity. Current Opinion in Environmental Sustainability, 18, 65-72. http://doi.org/10.1016/j.cosust.2015.09.004

United Nations Framework Convention on Climate Change. (2017). New UN Platform for indigenous and local community climate action. Retrieved March 1, 2018, from http://newsroom.unfccc.int/paris-agreement/new-un-platformto-boost-indigenous-peoples-and-local-communities-climate-action/ Vaubel, R. (2006). Principal-agent problems in international organizations. Review of International Organizations, 1(2), 125-138. http://doi.org/10.1007/s11558-006-8340-z 
Waltz, K. (1979). Theory of international politics. Long Grove, IL: Waveland Press.

Wapner, P. (1995). Politics beyond the state: Environmental activism and world civic politics. World Politics, 47(3), 311-340.

http://doi.org/10.1017/S0022381600053962

Wasserman, S., \& Faust, K. (1994). Social network analysis: Methods and applications. Cambridge, MA: Cambridge University Press.

Webber, S. R. (2015). Adaptation ecologies: Circuits of climate change finance, policy, and science in the Pacific islands. The University of British Columbia. Weiss, L. (2005). The state-augmenting effects of globalisation. New Political Economy, 10(3), 345-353. http://doi.org/10.1080/13563460500204233

Wesley-Smith. (2013). Changing patterns of power. In M. Rapaport (Ed.), The Pacific Islands: Environment and society (pp. 147-156). Honolulu, HI: University of Hawai'i Press.

Wesselink, A., Buchanan, K. S., Georgiadou, Y., \& Turnhout, E. (2013).

Technical knowledge, discursive spaces and politics at the science-policy interface. Environmental Science and Policy, 30, 1-9.

http://doi.org/10.1016/j.envsci.2012.12.008

West, P. (2006). Conservation is our government now: The politics of ecology in Papua New Guinea. Duke University Press.

Ziegler, A. D., Phelps, J., Yuen, J. Q., Webb, E. L., Lawrence, D., Fox, J. M., ... Dressler, W. (2012). Carbon outcomes of major land-cover transitions in SE 
Asia: Great uncertainties and REDD+ policy implications. Global Change Biology, 18(10), 3087-3099.

Zizek, S. (Ed.). (1994). Mapping ideology. London: Verso.

Five Pacific islands lost to rising seas as climate change hits. (2016, May 10). Reuters. 


\section{Appendix A: Interview Guide for Chapter 3}

Introduction of the interviewer.

Sample:

Hello, and thank you for agreeing to an interview. Again, my name is Ashlie Denton, and I am a doctorate student at Portland State University, in the United States. As you may remember from my phone call/email, participation in this interview is voluntary. This means you may choose now not to participate, refuse to answer any question, or end the interview at any time. If you decide after the interview that you do not wish your interview to be included in the study, you can contact me and have your interview deleted. I will leave my contact information for you. Additionally, this interview will be recorded, per your approval. Recording the interview will help me ensure that I capture your answers more fully, but if you wish to not be recorded, that will in no way effect your participation in the interview process. Here is the consent form that goes into greater detail on the information that I have just provided to you. Please check the boxes accordingly and sign.

Thank you! Now I am going to ask a few questions that will help me better understand the environmental governance work that is occurring in the Pacific Islands. Please feel free to expand on any questions you find interesting. Any information you can provide is valuable to my research.

\begin{tabular}{|c|c|c|}
\hline Main Questions & Additional Questions & $\begin{array}{l}\text { Clarifying } \\
\text { Questions }\end{array}$ \\
\hline $\begin{array}{l}\text { - What work do you do in } \\
\text { environmental governance? }\end{array}$ & $\begin{array}{l}\text { - What is your job position? } \\
\text { - What (other) environmental } \\
\text { organizations are you associated } \\
\text { with (if any)? }\end{array}$ & - Can you \\
\hline $\begin{array}{l}\text { What other organizations, } \\
\text { individuals, or government } \\
\text { agencies do you work with } \\
\text { regularly? }\end{array}$ & $\begin{array}{l}\text { - How frequently would you say that } \\
\text { you are in contact? }\end{array}$ & $\begin{array}{l}\text { - Can you tell } \\
\text { me anything } \\
\text { else? }\end{array}$ \\
\hline $\begin{array}{l}\text { - Tell me about a time in } \\
\text { which a project or series of } \\
\text { projects were particularly } \\
\text { successful. }\end{array}$ & $\begin{array}{l}\text { Why do you think these were } \\
\text { successes? } \\
\text { - Which other organizations worked } \\
\text { on these projects? }\end{array}$ & $\begin{array}{l}\text { - Can you } \\
\text { give me } \\
\text { some } \\
\text { examples? }\end{array}$ \\
\hline $\begin{array}{l}\text { - Tell me about a time in } \\
\text { which a project or series of }\end{array}$ & $\begin{array}{l}\text { - Why do you think these projects } \\
\text { were less successful? }\end{array}$ & \\
\hline
\end{tabular}




\begin{tabular}{|l|l|}
\hline $\begin{array}{l}\text { projects did not turn out as } \\
\text { planned. }\end{array}$ & $\begin{array}{c}\text { - Which other organizations worked } \\
\text { on these projects? }\end{array}$ \\
\hline $\begin{array}{l}\text { - What sources of } \\
\text { information do you use to } \\
\text { make decisions on } \\
\text { mitigation/advocacy/policy? }\end{array}$ & $\begin{array}{l}\text { - Do these sources of information } \\
\text { come from local, regional, or } \\
\text { international sources? }\end{array}$ \\
\hline $\begin{array}{l}\text { Is there any organization, } \\
\text { individual, or agency that } \\
\text { your or your organization } \\
\text { has chosen not to work with } \\
\text { for any reason? }\end{array}$ & $\begin{array}{l}\text { - Who made the decision to no longer } \\
\text { work with them? (If applicable) }\end{array}$ \\
\hline $\begin{array}{l}\text { - What changes in recent } \\
\text { years do you see around } \\
\text { the issue of climate change, } \\
\text { locally, domestically, and/or } \\
\text { internationally? }\end{array}$ & $\begin{array}{l}\text { - What do you attribute these } \\
\text { changes to? }\end{array}$ \\
\hline
\end{tabular}

What do you think would help facilitate working together as a group?

Is there anything you would like to add to what we have spoken of thus far?

This concludes your interview. Thank you again for allowing me to interview you. As stated in the letter, if you would like to receive results of these interviews, please email me. Also, please let me know if you decide at any point that you wish for your interview to not be included in the final reports. Also, it is possible that I will contact you in the next few months to clarify answers or confirm findings. If you wish to not be contacted, you are welcome to say so now or email me.

Finally, I am contacting participants for my surveys through recommendations of other participants. (Name of previous participant) referred you for this interview (if applicable). I was wondering if there were other individuals with whom you think I should speak. Would you be willing to provide me with their name and email/phone number?

Thank you again for your time. Here is my card, please contact me with any questions or comments. 


\section{Appendix B: Social Network Analysis for Chapter 4}

For the social network analysis, I used an 'actors-as-networks approach' (Kahler, 2009), where the unit of analysis was not the whole network, but rather the organizations in the network. The boundaries of the network were formed using a positional approach, where characteristics or formal membership criteria are used to determine whether actors are a part of the network (Wasserman \& Faust, 1995). The boundary was drawn at organizations-government agencies, environmental NGOs (Pacific Islands focused and global; advocacy and scientific), local user groups, and financers - that identify one of their primary activities as governance of climate change within the Pacific Islands. The data was organized into an adjacency matrix, one-mode (e.g. actor $\mathrm{x}$ actor; where rows and columns refer to a single set of entities), and using a weighted, directional approach (Wasserman \& Faust, 1995). This research focused on organizations as nodes. Analysis focused specifically on organizations that identify as:

- having an office in the Pacific Islands,

- engaging in transnational projects, and

- working on climate change adaptation and mitigation governance.

The ties in the network were defined as the resource exchange evident in websites, grey papers (technical reports, programmatic information, etc.), newspapers, blogs, environmental reports, and financial statements. This data was restricted to that information which is provided in the archival data itself. This has its limitations, as it only captured those relationships that are formalized 
through reporting, but it missed informal discussions and collaborations. This is why feedback from local practitioners was vitally important to understanding whether the data gathered through archival data captures the nature of transnational relationships in climate governance in the Pacific Islands.

In addition to the data on collaborations and relationships, attributes of the organizations networked together in climate governance in the Pacific Islands were also gathered. This included:

- Type-consultancy, financial organization, intergovernmental organization, nongovernmental organization, private company, scientific advisory organization, government, or university

- Level of work-local, regional (within the whole Pacific Islands), or international

- Location - this applied to both the location of their primary offices and any office within the Pacific for those organizations working internationally

- Focus-carbon trading, climate change, communications, conservation, development, education, financial, food systems, government, health, human rights, marine resources, modeling and scientific advice, power, private business, religion, and general consultants.

Finally, the type of interaction was recorded for analysis:

- Archival type -this was used to indicate whether the demonstration of resource exchange happened in the context of:

- Project or Program

- Scientific Report

- Policy or Plan of Action

- Event

- Level of interaction-categorization and the weight of interaction was determined through the level of participation ascribed through the introduction, acknowledgements, participant lists, or other key indicators, including the presence of logos.

- Coleadership was demonstrated in the archives when the two organizations were discussed as both being central to the functioning of the project/plan/event or key to the production of the document itself. This category was given mutual directionality and given a score of 5 . 
- Financial Support was demonstrated in the archives when the organization was discussed as providing "support," "funding," or was thanked in the document without clear reference to their role in participation. This category was used as an "input" to the leadership, and was given a weight of 3 .

- Participation was demonstrated in the archives when the organization was mentioned in a participant list ${ }^{21}$ or acknowledged or thanked without showing leadership. This category was the recipient of the "output" of resources through the leadership, and given a weight of 1 .

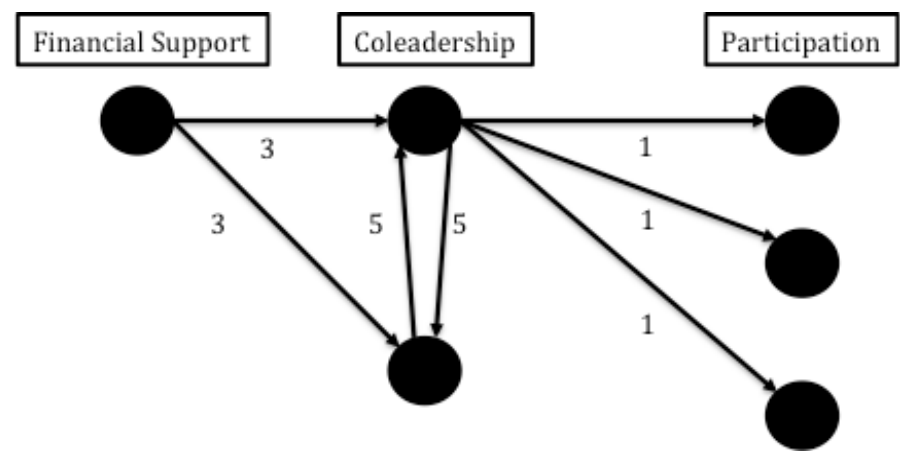

Organizations were combined for clarity into the largest organization that could

be distinguished from all other organizations listed. For instance, if multiple government agencies from the Cook Islands were listed, they were collapsed under one "Cook Islands" governmental node. A few other combinations are of note:

- The European Commission was combined with the European Union

- SOPAC, as it is now under the Secretariat of the Pacific Community, was combined with the Secretariat of the Pacific Community.

- When the participant in the document is listed as a program, the organization at the head of the program is given credit for the interaction. This does include secretariats of agreements and programmatic organizations, though. In other words, the European Union's GCCA program would be listed under the European Union, but Intergovernmental Panel on Climate Change would remain.

- If an organization is a branch of a larger org, then they were combined under the name of the larger organization.

${ }^{21}$ Note: For larger conferences that do not list participants, conference agendas were used. 
In order to ensure that Wasserman's and Faust (1995) patterns of interaction and longevity of structure are exhibited in the network, any interactions that scored less than 5 were removed from analysis.

\section{Data Limitations}

While the PCCP database provided access to many of the documents produced in climate change governance in the Pacific, it is still limited to those resource exchanges that were evident in the documents. This limits the data to those relationships that were formalized, and may miss the exchanges occurring through conversations, undocumented projects, or organizations that have not uploaded their documents to the database. It also may miss small NGOs that engaged regularly, but may not have held leadership positions. As PCCP is administrated by the Secretariat of the Pacific Regional Environmental Programme [SPREP], this could account for some of the strength of ties seen with this program and others with whom SPREP partners, such as the Secretariat of the Pacific Community, University of the South Pacific, and the European Union. This is why conversations with local practitioners are vital to understanding more about the network.

\section{Data Analysis}

For the SNA, I focused on exploring the relative power positions of various organizations in the network. In order to do so, I used a combination of network analysis software options-R, Graph Commons, Gephi, and UCINET. R was 
used to transform the data from an affiliation matrix to an adjacency matrix.

Graph Commons was used primarily for visualization of the network. Gephi and UCINET provided the analysis measures.

There are a few measures that provide key insight into the power of particular organizations, all of which rely on a graph-theoretic analysis of the network (Wasserman \& Faust, 1995). The measurements used in this dissertation are as follows:

- Centrality-Centrality is a measure of where an organization is in the network, as a whole. There are a number of measures of centrality that was explored here:

- Degree centrality-Degree centrality is a simple measure of to how many other nodes (organizations) a particular node is tied. Indegree centrality refers to the number of directed ties going into the node, out-degree refers to the number going out of the node. Below the first grey node has an in-degree centrality score of 4 , the second has an out-degree centrality of 4 :
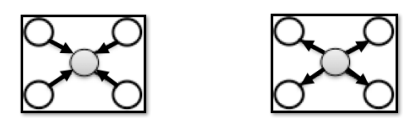

- Betweenness centrality-Betweenness centrality was used to show how central the organization is to the entire network. Betweenness centrality measures the number of times a node is located on the shortest path between two other nodes. In the example below, the grey node would have the highest betweenness centrality, because many of the shortest paths between two nodes must past through the grey node.

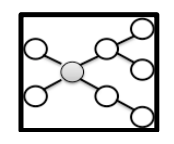

These measures were used for the visualization below. 


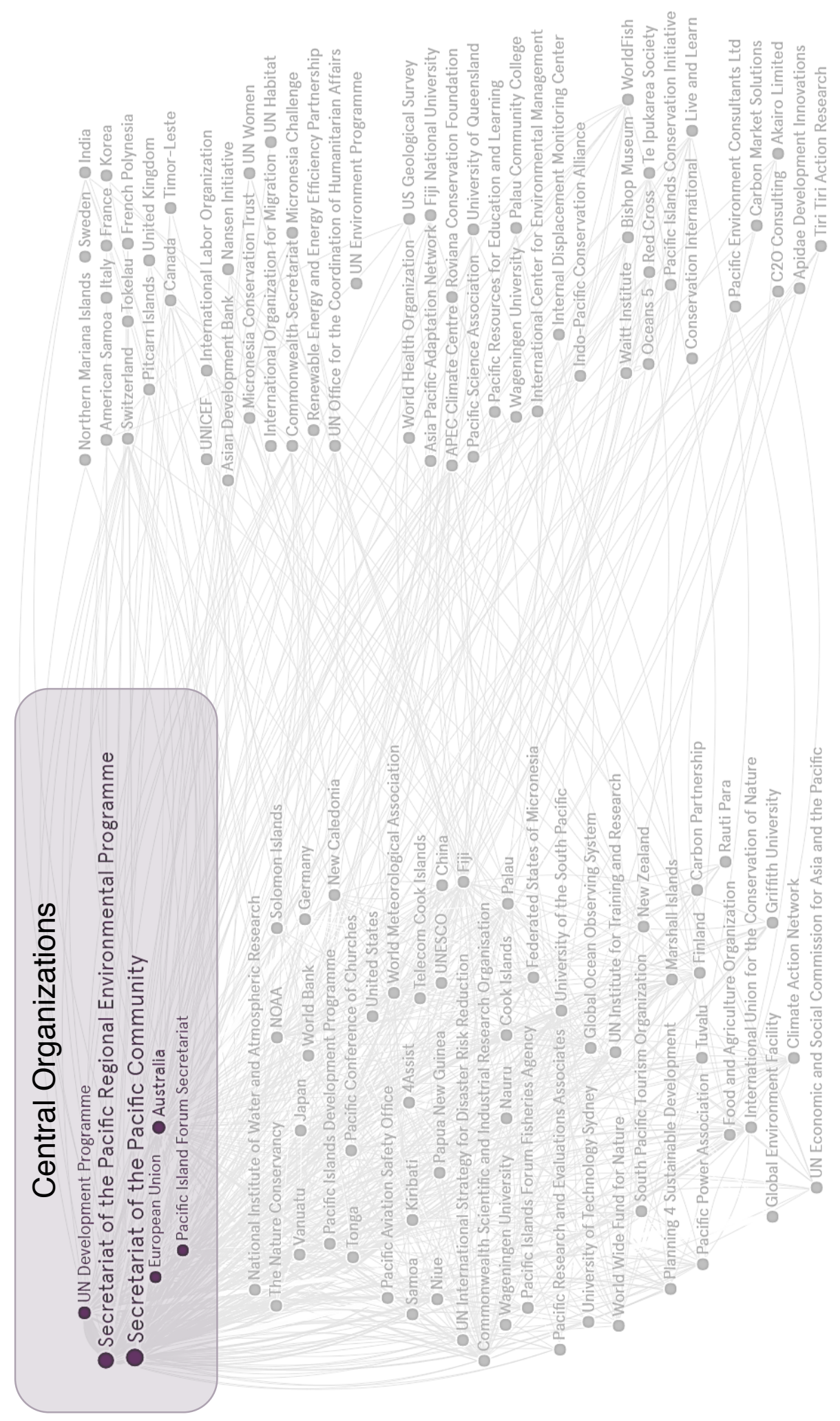




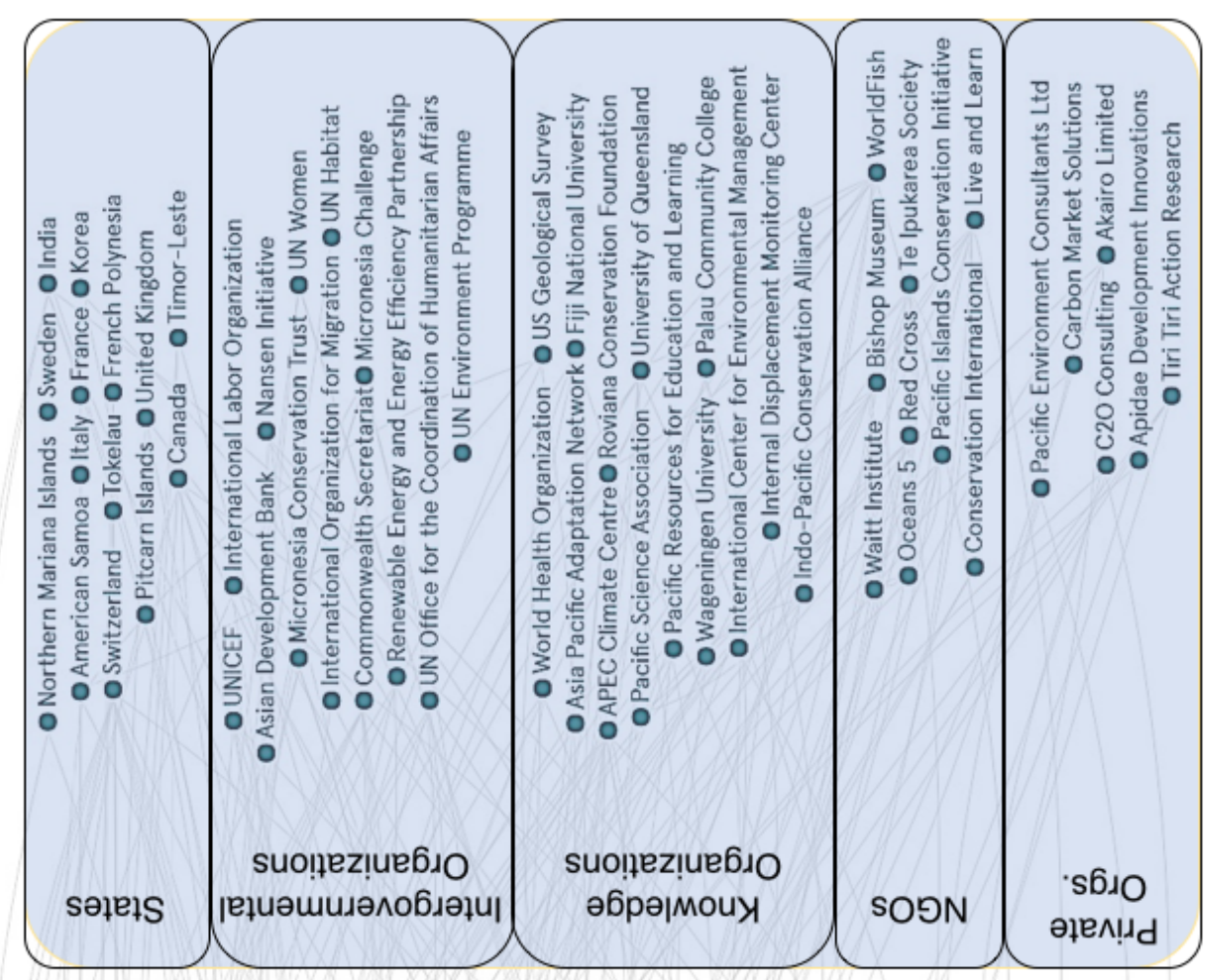




\section{Appendix C: Interview Guide for Chapter 4}

Introduction of the interviewer.

Sample:

Hello, and thank you for agreeing to an interview. Again, my name is Ashlie Denton, and I am a doctoral student at Portland State University, in the United States. I am talking with individuals throughout the Pacific Islands in order to better understand how climate change issues are understood and governed. As you may remember from my [phone call/email], participation in this interview is voluntary. This means you may choose not to answer any question, or end the interview at any time. If you decide after the interview that you do not wish your interview to be included in the study, you can contact me and have your interview deleted. I will leave my contact information for you. I would like to record this interview to help ensure that I capture your answers more fully. However, if you do not wish to be recorded, that will in no way effect your ability to participate in the interview process. Here is the consent form that goes into greater detail on the information that I have just provided to you. Please sign, and please keep a copy for your records.

Thank you! Now I am going to ask a few questions that will help me better understand the climate change work that is occurring in the Pacific Islands, including the relationships between organizations, the knowledge they share, and challenges they face. Please feel free to expand on any questions you find interesting. Any information you can provide is valuable to my research. 


\begin{tabular}{|c|c|c|}
\hline Main Questions & Additional Questions & $\begin{array}{l}\text { Clarifying } \\
\text { Questions }\end{array}$ \\
\hline $\begin{array}{l}\text { - First, l'd like to ask you a few } \\
\text { questions about your organization } \\
\text { and your work. In your own words, } \\
\text { tell me the mission or purpose of } \\
\text { your organization. }\end{array}$ & $\begin{array}{l}\text { - How does [name of organization] } \\
\text { engage with climate change } \\
\text { issues? } \\
\text { - And what is your role in } \\
\text { [organization]? Please tell me a } \\
\text { little bit about the nature of your } \\
\text { job, specifically. }\end{array}$ & \multirow{2}{*}{$\begin{array}{l}\text { Can you } \\
\text { expand a } \\
\text { little on this? } \\
\text { Can you tell } \\
\text { me anything } \\
\text { else? } \\
\text { Can you give } \\
\text { me some } \\
\text { examples? }\end{array}$} \\
\hline $\begin{array}{l}\text { - Of course, a lot of organizations } \\
\text { are working on climate change } \\
\text { issues in the Pacific. What is your } \\
\text { experience and understanding of } \\
\text { how organizations work on these } \\
\text { issues? Do you see organizations } \\
\text { working together, or more } \\
\text { independently? }\end{array}$ & $\begin{array}{l}\text { - How do you think about your } \\
\text { work in terms of a larger } \\
\text { network? How do you understand } \\
\text { your place in regards to the larger } \\
\text { picture? }\end{array}$ & \\
\hline
\end{tabular}

For this research, I looked at the documents shared on the Pacific Climate Change Portal. Through these documents, it seems that there are a number of ways that organizations work together or share resources. They participate in events together, work together on research reports, co-produce plans or policies for governments, or engage in projects or programs together. In terms of these sorts of activities which organizations jump out to you as being central to climate change activities, and what kinds of activities do they perform?

Give participant a copy of the social network map that highlights the highly central participants and explain:

This is a visualization that I made from information from the Pacific Climate Change Portal that represents the documented interactions between different organizations engaged in climate change issues in this region. The organizations highlighted in this map are those that are most central to the network as a whole. We're going to discuss the "map" of relationships for the rest of our interview, so take a moment to look over it.

\section{Pause briefly.}

Ok, now we're going to discuss what these highlighted organizations bring to the network. [Provide the list of resources that organizations can bring to the network.] Here is a list of things that I think these organizations can bring to the network as a whole. For instance, an organization can provide practical resources to the network, including knowledge of the local situation and a history 
of past successful projects. They may also bring informational resources to the network, such as scientific knowledge about climate change adaptation, or they may be in a position to set rules or standards, such as limiting the amount of greenhouse gas emissions that others can produce. Finally, they may bring what I refer to as governmental resources, meaning that they have access to government funding or their decisions are determined by a government body. Are these clear to you?

Pause for a response and take the time to answer any questions/respond to any comments.

Ok. Now we are going to talk through what these highlighted organizations bring to the network. Feel free to discuss any contributions of the network outside of what I have listed here. The point of our conversation is for me to get a better picture of how climate change issues are understood and governed.

- Looking at X organization, specifically, can you please tell me which of these resources $X$ organization brings to the network.

\begin{tabular}{|c|c|c|}
\hline $\begin{array}{l}\text { - If the interviewee denotes that the } \\
\text { organization brings practical } \\
\text { resources: What practical } \\
\text { resources do they bring? }\end{array}$ & $\begin{array}{l}\text { How do these practical } \\
\text { resources facilitate the work of } \\
\text { the network, either positively or } \\
\text { negatively? }\end{array}$ & \\
\hline $\begin{array}{l}\text { - If the interviewee denotes that the } \\
\text { organization brings knowledge or } \\
\text { information: What types of } \\
\text { knowledge or information do they } \\
\text { bring? }\end{array}$ & $\begin{array}{l}\text { Is this knowledge useful for } \\
\text { decision-making in the region? If } \\
\text { yes, in what ways? }\end{array}$ & $\begin{array}{c}\text { Can you } \\
\text { expand a little } \\
\text { on this? }\end{array}$ \\
\hline $\begin{array}{l}\text { - If the interviewee denotes that the } \\
\text { organization sets rules or } \\
\text { standards: What types of } \\
\text { rules/standards do they set in the } \\
\text { network? }\end{array}$ & $\begin{array}{l}\text { How does their ability to affect } \\
\text { processes and procedures } \\
\text { impact the work of the network? }\end{array}$ & $\begin{array}{l}\text { Can you tell } \\
\text { me anything } \\
\text { else? } \\
\text { Can you give } \\
\text { me some } \\
\text { examples? }\end{array}$ \\
\hline $\begin{array}{l}\text { - If the interviewee denotes that the } \\
\text { organization brings government } \\
\text { resources: What types of } \\
\text { government resources do they } \\
\text { bring to the network? }\end{array}$ & $\begin{array}{l}\text { - How would you characterize } \\
\text { their level of involvement in the } \\
\text { network? Would you like to see } \\
\text { more, less, or the same level of } \\
\text { involvement? }\end{array}$ & \\
\hline
\end{tabular}


Give participant a copy of the social network map that highlights the peripheral participants and explain:

These organizations appear to not be as involved in the network as other participants. I'm now going to ask you to circle the 5 organizations that you engage with most frequently or that impact your organization's work most directly. These could be organizations that enjoy working with, or organizations that present challenges to your work. I just want to make sure that you are familiar enough with the organizations that you choose so that we can have a conversation about them. Please take a few moments to select the 5 most relevant organizations to your work.

Pause and allow for the participant to complete this activity.

Thank you. Now, we're going to go through a similar exercise with the 5 organizations that you listed.

- Looking at X organization, specifically, can you please tell me which of these resources $\mathrm{X}$ organization brings to the network.

- If the interviewee denotes that the organization brings practical resources: What practical resources do they bring?
- How do these practical resources facilitate the work of the network, either positively or negatively?

- Is this knowledge useful for decision-making in the region? If yes, in what ways? knowledge or information do they bring?

- If the interviewee denotes that the organization sets rules or standards: What types of rules/standards do they set in the network?

- If the interviewee denotes that the organization brings government resources: What types of government resources do they bring?
- How does their ability to affect processes and procedures impact the work of the network?

- How would you characterize their level of involvement in the network? Would you like to see more, less, or the same level of involvement?
Can you expand a little on this?

Can you tell me anything else?

Can you give me some examples? 
In your opinion, why are they not more central to the work of the network?

Repeat for 5 peripheral organizations.

Is there anything we haven't discussed that you feel is important for me to know about your organization's work in climate change efforts and your understanding of how others are involved in those efforts?

This concludes your interview. Thank you again for allowing me to interview you. As stated in the letter, if you would like to receive results of these interviews, please email me. Also, it is possible that I will contact you in the next few months to clarify answers or confirm findings. If you wish to not be contacted, you are welcome to say so now or email me.

Finally, I am contacting participants for my interviews by my own identification, as well as through recommendations of other participants. Another participant referred you for this interview (if applicable). I was wondering if there were other individuals with whom you think I should speak. Would you be willing to provide me with their name and email/phone number?

Thank you again for your time. Here is my card, please contact me with any questions or comments. 


\section{Appendix D: Interview Participants and Times for Chapter 4}

List of organizations interviewed during the second trip to the Pacific Islands and their approximate recorded interview times (many interviews lasted much longer than their recorded sessions, however). These do not include numerous informal conversations, such as those with individuals from the University of the South Pacific, local organizations, and independently interested parties.

\begin{tabular}{|l|l|}
\hline \multicolumn{1}{|c|}{ Organization } & \multicolumn{1}{c|}{ Interview Time } \\
\hline Apidae Development Innovations & 50 minutes \\
\hline $\begin{array}{l}\text { Australian Bureau of Meteorology } \\
\text { (BOM) }\end{array}$ & 49 minutes \\
\hline $\begin{array}{l}\text { Commonwealth Scientific and } \\
\text { Industrial Research Organisation } \\
\text { (CSIRO) }\end{array}$ & 1 hour, 14 minutes \\
\hline The Fiji Red Cross Society & 1 hour, 43 minutes \\
\hline $\begin{array}{l}\text { International Union for the } \\
\text { Conservation of Nature (IUCN) }\end{array}$ & 46 minutes \\
\hline Live and Learn & 1 hour, 11 minutes \\
\hline $\begin{array}{l}\text { National Oceanic and Atmospheric } \\
\text { Administration (NOAA) }\end{array}$ & 53 minutes \\
\hline $\begin{array}{l}\text { Pacific Centre for Environment and } \\
\text { Sustainable Development (PaCE-SD) }\end{array}$ & 24 minutes \\
\hline $\begin{array}{l}\text { Pacific Islands Forum Secretariat } \\
\text { (PIFs) }\end{array}$ & 33 minutes \\
\hline $\begin{array}{l}\text { Secretariat of the Pacific Community } \\
\text { (SPC) }\end{array}$ & 1 hour, 15 minutes \\
\hline $\begin{array}{l}\text { Secretariat of the Pacific Regional } \\
\text { Environment Programme (SPREP) } 1\end{array}$ & 1 hour, 23 minutes \\
\hline SPREP 2 & 1 hour, 53 minutes \\
\hline SPREP 3 & 1 hour, 26 minutes \\
\hline British High Commission Suva & 53 minutes \\
\hline $\begin{array}{l}\text { United Nations Development } \\
\text { Programme (UNDP) }\end{array}$ & 41 minutes \\
\hline World Wildlife Fund (WWF) & 50 minutes \\
\hline
\end{tabular}

Unrecorded interviews:

Cook Islands MET

Samoa MET

Samoa Ministry of Natural Resources and Environment (MNRE)

Te Ipukarea Society 